\title{
Age-related cytoskeletal pathologies
}

\author{
Citation for published version (APA):
}

Wijesinghe (nee Kentheeswaran), P. (2020). Age-related cytoskeletal pathologies: A study on elderly brains to investigate the extent of neuropathological and cerebrovascular changes at death ad their risk factors. [Doctoral Thesis, Maastricht University]. Maastricht University. https://doi.org/10.26481/dis.20202508pk

Document status and date:

Published: 01/01/2020

DOI:

10.26481/dis.20202508pk

Document Version:

Publisher's PDF, also known as Version of record

\section{Please check the document version of this publication:}

- A submitted manuscript is the version of the article upon submission and before peer-review. There can be important differences between the submitted version and the official published version of record.

People interested in the research are advised to contact the author for the final version of the publication, or visit the DOI to the publisher's website.

- The final author version and the galley proof are versions of the publication after peer review.

- The final published version features the final layout of the paper including the volume, issue and page numbers.

Link to publication

\footnotetext{
General rights rights.

- You may freely distribute the URL identifying the publication in the public portal. please follow below link for the End User Agreement:

www.umlib.nl/taverne-license

Take down policy

If you believe that this document breaches copyright please contact us at:

repository@maastrichtuniversity.nl

providing details and we will investigate your claim.
}

Copyright and moral rights for the publications made accessible in the public portal are retained by the authors and/or other copyright owners and it is a condition of accessing publications that users recognise and abide by the legal requirements associated with these

- Users may download and print one copy of any publication from the public portal for the purpose of private study or research.

- You may not further distribute the material or use it for any profit-making activity or commercial gain

If the publication is distributed under the terms of Article $25 \mathrm{fa}$ of the Dutch Copyright Act, indicated by the "Taverne" license above, 


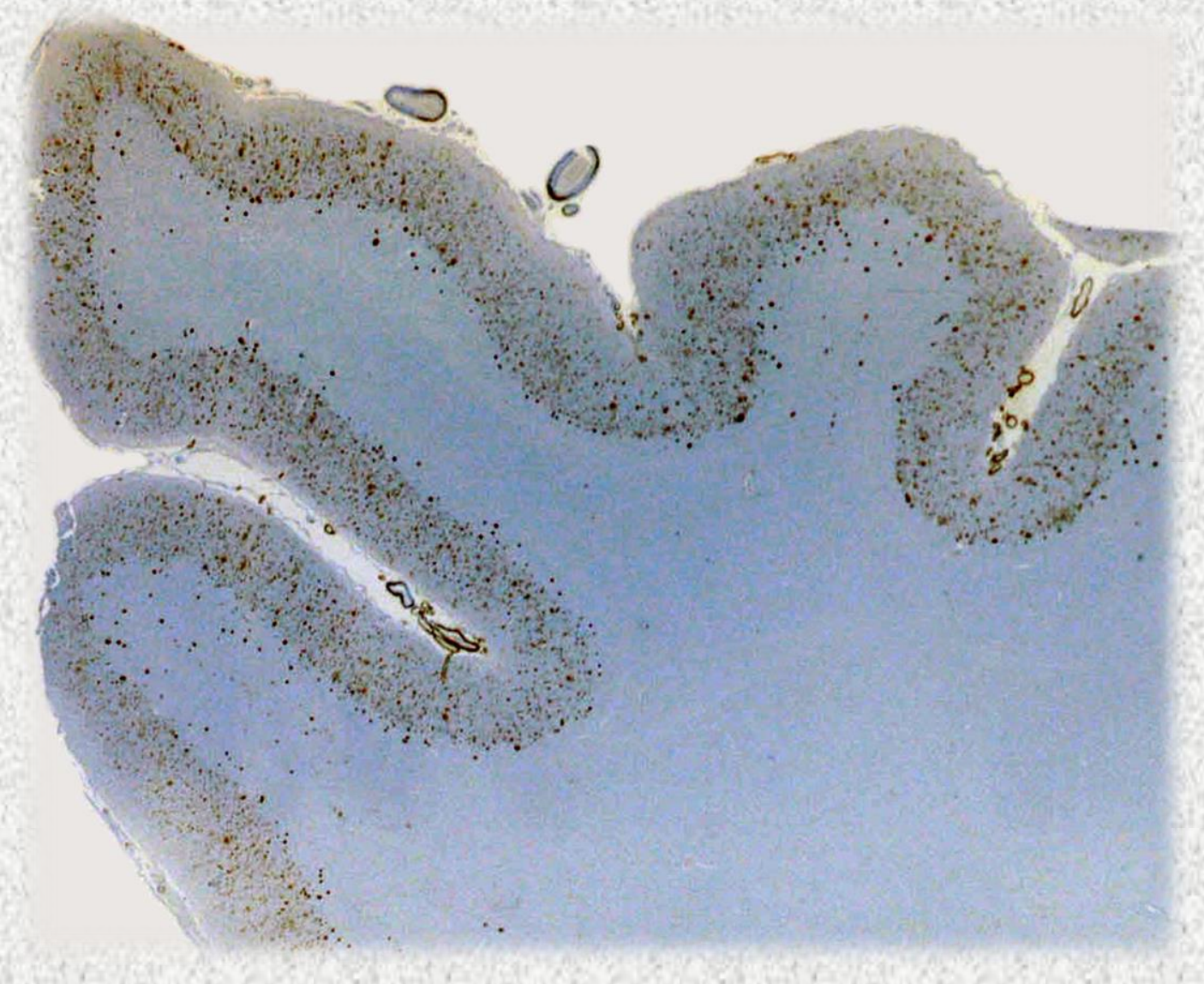

Printha Wijesinghe (nee Kentheeswaran)

\section{Age-related aytoskeletal pathologies:}

\section{A study on elderly brains to} investigate the extent of neuropathological and cerebrovascular changes at death and their risk factors 2020 
Age-related cytoskeletal pathologies

A study on elderly brains to investigate the extent of neuropathological and cerebrovascular changes at death and their risk factors

Printha Wijesinghe (nee Kentheeswaran) 


\title{
Statements
}

Belonging to the $\mathrm{PhD}$ thesis: Age-related cytoskeletal pathologies

\author{
Printha Wijesinghe
}

1. While there is voluminous literature in the West, there is glaring paucity of data on age associated pathomorphological changes in the brains of South Asians that still need to be addressed. (This thesis)

2. Age-based risk of neurofibrillary tangles (NFTs), apolipoprotein $E$ (ApoE) $\varepsilon 4$ allele-based risk of $\beta$-amyloid (A $\beta$ ) plaques, and the survival probabilities of $A p o E \varepsilon 4$ allele carriers could possibly be one of the reasons for the discordance between NFT and A $\beta$ plaque stages in AD neuropathological diagnosis. (This thesis)

3. Cerebral small vessel diseases such as white matter hyperintensities and cerebral amyloid angiopathy are predominant comorbid cerebrovascular changes that associate with sporadic Alzheimer's disease (AD) compared with large vessel disease atherosclerosis of the circle of Willis (CW). (This thesis)

4. ApoE $\varepsilon 4$ and $\varepsilon 2$ allelic frequencies and their carrier's survival probabilities could possibly be the main reasons for the differences observed in posterior versus anterior circulation atherosclerosis in population-based studies. (This thesis)

5. Hypoplastic CW component arteries (diameter $<0.1 \mathrm{~mm}$ ), the most probably communicating arteries, could possibly contribute to white matter lesions. (This thesis)

6. "Anyone who has never made a mistake has never tried anything new." (Albert Einstein)

7. "Difficulties in your life do not come to destroy you, but to help you realize your hidden potential and power, let difficulties know that you too are difficult." (Dr. A.P.J. Abdul Kalam)

8. "Everyone can rise above their circumstances and achieve success if they are dedicated to and passionate about what they do." (Nelson Mandela)

9. "You must always think and aim high, though sometimes things did not happen in your favor, you must never lose your positive attitude and continue to aim high." (Thirrukkual)

10. "What you think, you become. What you feel, you attract. What you imagine, you create." (Gautama Buddha) 
(C) Printha Wijesinghe (nee Kentheeswaran) 2020

Age-related cytoskeletal pathologies: A study on elderly brains to investigate the extent of neuropathological and cerebrovascular changes at death and their risk factors

All rights are reserved. No part of this book may be reproduced or transmitted in any form or by any means, without permission in writing from the copyright holder.

Cover design: Printha Wijesinghe 
Age-related cytoskeletal pathologies

A study on elderly brains to investigate the extent of neuropathological and cerebrovascular changes at death and their risk factors

\section{DISSERTATION}

To obtain the Degree of Doctor at the Maastricht University, on the authority of the Rector Magnificus Prof.dr. Rianne M. Letschert in accordance with the decision of the Board of Deans, to be defended in public on Tuesday 25 August 2020, at 16:00 hours

\section{Printha Wijesinghe}




\section{Promoters}

Prof. Dr. Harry W.M. Steinbusch

Prof. Dr. Ranil de Silva, University of Sri Jayewardenepura, Nugegoda

Emeritus Prof. Dr. S.K. Shankar, NIMHANS, Bangalore

\section{Assessment committee}

Prof. David Linden (Chairman)

Prof. Boris Kramer

Dr. Heidi Jacobs

Prof. Joachim Weis, Klinikum, Aachen, Germany

Dr. Wilma D.J. van de Berg, VUmc, Amsterdam, The Netherlands 
To all my well-wishers 


\section{TABLE OF CONTENTS}

Chapter 1

General Introduction

Chapter 2

9

Cytoskeletal Pathologies of Age-Related Diseases between Elderly Sri Lankan

(Colombo) and Indian (Bangalore) Brain Samples

Current Alzheimer Research, 2016;13(3): 268-280

Chapter 3

Vascular contributions in Alzheimer's disease related neuropathological change:

First autopsy evidence from a South Asian ageing population

Journal of Alzheimer's Disease, 2016;54(4):1607-161

Chapter 4

Early stages of Alzheimer's disease are alarming signs in injury deaths caused by traffic accidents in elderly people ( $\geq \mathbf{6 0}$ years of age): A neuropathological study

Indian Journal of Psychiatry, 2017;59(4):471-477

Chapter 5

Circle of Willis abnormalities and their clinical importance in ageing brains: $A$ cadaveric anatomical and pathological study

Journal of Chemical Neuroanatomy, 2020;106;101772

Chapter 6

General Discussion

Societal Impact

Chapter 7

103

Acknowledgements

Appendices

Supplementary files 


\section{CHAPTER 1}




\subsection{General Introduction}

The global population of people aged 60 years and over was 962 million in 2017 equating to $13 \%$ of the total population and this number is projected to 2.1 billion in 2050 and 3.1 billion in 2100 (World Population Prospects, 2017). For this age range, 65\% of the global increase between 2017 and 2050 will occur in Asia, 14\% in Africa, 11\% in Latin America and the Caribbean, and the remaining $10 \%$ in other areas. South Asia represented $24.7 \%$ of the world total population in 2015 and the people aged over 60 years was 154 million. South Asia is considered as one of the global burdens of dementia regions and about 5.13 million people affected by dementia in 2015 (World Alzheimer Report, 2015). Within South Asian countries, Sri Lanka is continuously experiencing fastest ageing due to its rapid demographic transition caused by low fertility and higher life expectancy. The proportion of Sri Lankan population aged over 60 years was $14 \%$ in 2015 whereas it was $\leq 9 \%$ in India and other South Asian countries (World Population Prospects, 2017). Ageing population is often accompanied by increase in occurrence of diseases, of which dementia is the most prominent, which provide major challenges to family members, society and to the healthcare systems.

Clinical prevalence of dementia is often underestimated in developing countries (De Silva et al., 2009; Umayal et al., 2010). It faces several obstacles such as poor education, stigma attached to relative diagnosis of dementia, prevailing notion that memory problems and cognitive loss are natural features of normal ageing, social acculturation of low expectation and demand for elder participation in daily functional roles and activities, over representation of coexisting physical morbidities than functional disability associated with cognitive decline, variations in the survival probabilities / life expectancies after the development of dementia and the variations in screening tools and diagnostic thresholds for case ascertainment; all could possibly account for lower prevalence in developing regions (Purohit et al., 2011; Venketasubramanian et al., 2010). Clinical studies have estimated that dementia prevalence in elderly Sri Lankans is 3.98\% (De Silva et al., 2003), in elderly Indians is $2.7 \%$ (Kalaria et al., 2008) and in elderly Bangladeshians is 3.6\% (Palmer et al., 2014). Besides the above studies, prevalence of dementia has not been extensively studied in other South Asian countries. Infact, documentation of substantial heterogeneity in dementia prevalence among different countries / ethnics need to be investigated based on genetic, environmental, cultural factors, and preventive approaches in reducing the burden of dementia (Venketasubramanian et al., 2010).

Alzheimer's disease (AD) is the most common form of dementia and possibly contributes 60$70 \%$ (World Health Organization, 2012). Other major forms include vascular dementia, dementia with Lewy bodies (abnormal aggregates of protein that develop inside nerve cells), and a group of diseases that contribute to frontotemporal dementia (degeneration of the frontal lobe of the brain). The boundaries between different forms of dementia are indistinct and mixed forms which often co-exist. Accurate diagnosis of most diseases that cause dementia depends on post-mortem neuropathological examination (Love, 2005). Autopsy-based neuropathological diagnoses are central to $\mathrm{AD}$ research. A basic assumption is that $\mathrm{AD}$ is defined by 2 pathological hallmarks: beta amyloid $(\mathrm{A} \beta)$ plaques and tau neurofibrillary tangles (NFTs) (Montine et al., 2012). The reason for the discrepancy between clinical and pathologybased AD diagnoses is related to the prevalence of non-AD brain diseases, including alpha $(\alpha)$ -synucleinopathies, non-AD tauopathies, hippocampal sclerosis and many types of cerebrovascular disease, all of which can mimic AD clinically (Neloson et al., 2012; Brenowitz et al., 2014; Kovacs et al., 2016; Dickson, 2009).

Vascular-derived insults might initiate and / or contribute to neuronal degenerations (Zlokovic, 2011). Of note, midlife hypertension, diabetes mellitus, apolipoprotein E $\varepsilon 4$ isoforms, hypercholesterolemia, homocysteinemia, smoking, obesity, and, of course, age are vascular 
risk factors that predispose individuals to AD (O'Brien and Markus, 2014; Reitz et al., 2011; de Bruijn and Ikram, 2014; Gorelick et al., 2011). However, interaction between vascular factors and amyloidosis or tauopathy still remains unresolved (Reitz et al., 2011; Attems and Jellinger, 2014). Neuropathological examinations reveal that most cases of AD have mixed vascular pathology and small vessel disease (Attems and Jellinger, 2014; Kalaria and Ballard, 1999). In addition, brain hypoperfusion / hypoxia, silent infarcts, the presence of one or more infarcts, stroke episodes, and transient ischemic or hypoxic attacks all increase the risk of AD (Ruitenberg et al., 2005; Vermeer et al., 2003; Snowdon et al, 1997); however underlying mechanism remains unclear. Intracranial atherosclerosis of the circle of Willis (CW) is associated with $\mathrm{AD}$ via mechanical obstruction and reduction in cerebral arterial inflow; caused by atherosclerotic lesions (Roher et al., 2011; Roher et al., 2003; Beach et al., 2007; Yachoan et al., 2012). However, other studies (Luoto et al., 2009; Dolan et al., 2010; Bangen et al., 2015) indicate that $\mathrm{CW}$ atherosclerosis is not in direct association with $\mathrm{A} \beta$ load or NFTs numbers. And the severity of the cognitive impairment in AD patients with and without cerebrovascular changes is not varied. Recent hypoperfusion studies that developed via post-mortem biochemical methods indicate that the main cause for $\mathrm{AD}$ is probably via non-structural vascular dysfunctions influenced strongly by amyloid $\beta(A \beta)$ rather than structural pathology (Love and Miners, 2015; Barker et al., 2014).

Moreover, cognitive decline or impairment at ageing has received much attention as a possible risk factor for fatal traffic accidents in elderly populations. As dementia becomes a risk factor in traffic accidents, it is reasonable to expect increased dementia related neuropathologies in the brains of accident victims. Whereas, the contribution of dementia related pathologies as the cause of suicide in a geriatric population remains unresolved. There is a small number of studies from Western countries which investigated the extent of dementia related pathologies in the brains of elderly victims of suicide (Rohde et al., 1995; Lesco, 1989; Rubio et al., 2001; Peisah et al., 2007) and fatal traffic accident (Viitanen et al., 1998; Gorrie, 2006; 2007). Autopsy findings, however, were inconclusive.

Besides, the CW located at the base of the brain forms an important collateral network to maintain adequate cerebral perfusion, especially in clinical situations requiring compensatory changes in blood flow. It has been reported that in more than $50 \%$ of the healthy brains (Alpers et al., 1959; Lippert and Pabst, 1985; Macchi et al., 2005) and in more than $80 \%$ of the dysfunctional brains (Riggs and Rubb, 1963), the CW contains at least one artery that is absent or underdeveloped. Anatomical variations which are probably genetically determined, develop in early embryonic stage and persist in post natal life. These topological variations may affect the ability to maintain cerebral perfusion, which may increase the risk of stroke and transient ischemic attack in patients with atherosclerosis (Henderson et al., 2000). Typically, older patients who have a limited ability to compensate to acute changes in blood flow are at greater risk for developing an acute ischemia (stroke) or chronic hypoperfusion. The significance of these problems cannot be underestimated since stroke ranks second among the leading causes of death and third among the leading causes of disability in elderly population (Feigin et al., 2017). 


\section{Thesis aim and outline}

The general aim of this thesis was to investigate the age-related cytoskeletal changes in elderly brains representing two South Asian sample populations, and to explore AD-related neuropathological changes with respect to vascular and genetic risk factors, and comorbid cerebrovascular pathologies. To address this aim, elderly brain samples were collected at postmortem and the extent of neuropathological and cerebrovascular changes were assessed using histopathological / immunohistochemical staining.

This general aim is addressed by several objectives:

1) To compare the extent of age-related cytoskeletal pathologies between two closely related South Asian elderly sample populations: Colombo vs. Bangalore. To carry out this objective, we have collected 76 elderly brains at postmortem which formed one and only human brain bank in Sri Lanka. 50 elderly brains from Sri Lanka and 42 elderly brains from human brain bank, National Institute of Mental Health and Neurosciences, Bangalore, India were used to determine the extent of age-related cytoskeletal pathologies such as AD, Lewy body diseases, cerebrovascular diseases and non-AD tauopathies. (Chapter 2)

2) To investigate the potential vascular risk factors and the coexisting cerebrovascular pathologies that might contribute to AD-related neuropathological changes in the elderly Sri Lankan brains. Two main pathological hallmarks of AD: A $\beta$ plaques and tau NFTs observed in the elderly Sri Lankan brains were comprehensively assessed for risk factors including age, gender, education level, candidate genes for vascular diseases: apolipoprotein $E$ (ApoE) $\varepsilon 4$ allele, angiotensin converting enzyme (ACE) and methylenetetrahydrofolate reductase (MTHFR C677T), medical history: hypertension, diabetes, high cholesterol and ischemic heart disease, and health habits: smoking and alcohol consumption; and coexisting cerebrovascular pathologies such as cerebral amyloid angiopathy (CAA), white matter hyperintensities (WMHs), atherosclerosis of the $\mathrm{CW}$ and microscopic infarcts. (Chapter 3)

3) To compare the extent of neurodegenerative and cerebrovascular pathologies in the brains of elders who succumbed to injury deaths compared to elders who died due to natural causes. For this work, neuropathological findings of elderly Sri Lankans who had died due to fatal traffic accidents (4 victims) and suicide (5 victims) were separately compared with age and gender matched cases of natural deaths. (Chapter 4)

4) To investigate CW abnormalities and the clinical importance of these anatomical factors in the ageing brains' neuropathologies. Component arteries of $73 \mathrm{CW}$ samples collected from elderly Sri Lankan brains were rigorously examined for degree of stenosis, anatomical variations, aneurysms, hypoplasia and $\mathrm{CW}$ atherosclerosis. (Chapter 5) 


\subsection{References}

Alpers B, Berry J, Paddison R (1959) Anatomical studies of the circle of Willis in normal brain. AMA Arch Neurol Psychiatry 81, 409-418.

Attems J, Jellinger KA (2014) The overlap between vascular disease and Alzheimer's disease - lessons from pathology. BMC Med 12, 206.

Bangen KJ, Nation DA, Delano-Wood L, Weissberger GH, Hansen LA, Galasko DR, et al (2015) Aggregate effects of vascular risk factors on cerebrovascular changes in autopsyconfirmed Alzheimer's disease. Alzheimers Dement 11, 394-403.

Barker R, Ashby EL, Wellington D, Barrow VM, Palmer JC, Kehoe PG, et al (2014) Pathophysiology of white matter perfusion in Alzheimer's disease and vascular dementia. Brain 137, 1524-1532.

Beach TG, Wilson JR, Sue LI, Newell A, Poston M, Cisneros R, et al (2007) Circle of Willis atherosclerosis: association with Alzheimer's disease, neuritic plaques and neurofibrillary tangles. Acta Neuropathol 113, 13-21.

Brenowitz WD, Monsell SE, Schmitt FA, Kukull WA, Nelson PT (2014) Hippocampal sclerosis of aging is a key Alzheimer's disease mimic: clinical-pathologic correlations and comparisons with both alzheimer's disease and non-tauopathic frontotemporal lobar degeneration. J Alzheimers Dis 39, 691-702.

de Bruijn RF, Ikram MA (2014) Cardiovascular risk factors and future Alzheimer's disease risk. BMC Med 12, 130.

De Silva HA, Gunathilake SB, Smith AD (2003) Prevalence of dementia in a semi-urban population in Sri Lanka: report from a regional survey. Int J Geriatr Psychiatry 18, 711-715.

De Silva KR, Silva R, Gunasekera WS, Jayesekera RW (2009) Prevalence of typical circle of Willis and the variation in the anterior communicating artery: A study of a Sri Lankan population. Ann Indian Acad Neurol 12, 157-161.

Dickson DW (2009) Neuropathology of non-Alzheimer degenerative disorders. Int J Clin Exp Pathol 3, 1-23.

Dolan D, Troncoso J, Resnick SM, Crain BJ, Zonderman AB, O’Brien RJ (2010) Age, Alzheimer's disease and dementia in the Baltimore Longitudinal Study of Ageing. Brain 133, $2225-2231$

Feigin VL, Norrving B, Mensah GA (2017) Global burden of stroke. Circ Res 120, 439-448.

Gorelick PB, Scuteri A, Black SE, Decarli C, Greenberg SM, Iadecola C, et al (2011) Vascular contributions to cognitive impairment and dementia: A statement for healthcare professionals from the American Heart Association/American Stroke Association. Stroke 42, 2672-2713. 
Gorrie CA, Rodriguez M, Sachdev P, Duflou J, Waite PM (2006) Increased neurofibrillary tangles in the brains of older pedestrians killed in traffic accidents. Dement Geriatr Cogn Disord 22, 20-26.

Gorrie CA, Rodriguez M, Sachdev P, Duflou J, Waite PM (2007) Mild neuritic changes are increased in the brains of fatally injured older motor vehicle drivers. Accid Anal Prev 39, 1114-1120.

Henderson K, Eliasziw M, Fox Aj, Rothwell PM, Barnett JM (2000) Collateral ability of the circle of Willis in patients with unilateral carotid artery occlusion. Border zone infarcts and clinical symptoms. Storke 31, 128-132.

Kalaria RN, Ballard C (1999) Overlap between pathology of Alzheimer disease and vascular dementia. Alzheimer Dis Assoc Disord 13, S115-S123.

Kalaria NR, Maestre GE, Arizaga R, Friedland RP, Galasko D, Hall K, et al (2008)

Alzheimer's disease and vascular dementia in developing countries: prevalence, management, and risk factors. Lancet Neurol 7, 812-826.

Kovacs GG, Ferrer I, Grinberg LT, Alafuzoff I, Attems J, Budka H et al (2016) Aging-related tau astrogliopathy (ARTAG): harmonized evaluation strategy. Acta Neuropathol 131, 87-102.

Lesco PA (1989) Murder-suicide in Alzheimer's disease. J Am Geriatr Soc 37, 167-168.

Lippert H, Pabst R. Arterial variations in man: classification and frequency. Bergmann JF, editor. Verlag; Munich; 1985.

Love S (2005) Neuropathological investigation of dementia: a guide for neurologists. $J$ Neurol Neurosurg Psychiatry 76, v8-v14.

Love S, Miners JS (2015) White matter hypoperfusion and damage in dementia: post-mortem assessment. Brain Pathol 25, 99-107.

Luoto TM, Haikonen S, Haapasalo H, Goebeler S, Huhtala H, Erkinjuntti T, et al (2009) Large vessel cerebral atherosclerosis is not in direct association with neuropathological lesions of Alzheimer's disease. Eur Neurol 62, 93-98.

Macchi C, Pratesi C, Conti AA, Gensini GF (2005) The circle of Willis in healthy older persons. J Cardiovasc Surg (Toronto) 43, 887-890.

Montine TJ, Phelps CH, Beach TG, Bigio EH, Cairns NJ, Dickson DW, et al (2012) National Institute on Aging-Alzheimer's Association guidelines for the neuropathologic assessment of Alzheimer's disease: a practical approach. Acta Neuropathol 123, 1-11.

Nelson PT, Alafuzoff I, Bigio EH, Bouras C, Braak H, Cairns NJ (2012) Correlation of Alzheimer disease neuropathologic changes with cognitive status: a review of the literature. $J$ Neuropathol Exp Neurol 71, 362-81. 
O'Brien JT, Markus HS (2014) Vascular risk factors and Alzheimer's disease. BMC Med 12, 218.

Palmer K, Kabir ZN, Ahmed T, Hamadani JD, Cornelius C, Kivipelto M, et al (2014)

Prevalence of dementia and factors associated with dementia in rural Bangladesh: data from a cross-sectional, population-based study. Int Psychogeriatr 26, 1905-1915.

Peisah C, Snowdon J, Gorrie C, Kril J, Rodriguez M (2007) Investigation of Alzheimer's disease-related pathology in community dwelling older subjects who committed suicide. $J$ Affect Disord 99, 127-132.

Purohit DP, Batheia NO, Sano M, Jashnani KD, Kalaria RN, Karunamurthy A, et al (2011) Profile of Alzheimer's disease-related pathology in an aging urban population sample in India. J Alzheimers Dis 24, 187-196.

Reitz C, Brayne C, Mayeux R (2011) Epidemiology of Alzheimer disease. Nat Rev Neurol 7 , 137-152.

Riggs H, Rubb C (1963) Variaions in form of circle of Willis. The relation of the variations to collateral circulation: Antomic analysis. Arch Neurol 8, 24-30.

Rohde K, Peskind ER, Raskind MA (1995) Suicide in two patients with Alzheimer's disease. J Am Geriatr Soc 43, 187-189.

Roher AE, Esh C, Kokjohn TA, Kalback W, Luehrs DC, Seward JD, et al (2003) Circle of Willis atherosclerosis is a risk factor for sporadic Alzheimer's disease. Arterioscler Thromb Vasc Biol 23, 2055-2062.

Roher AE, Tyas SL, Maarouf CL, Daugs ID, Kokjohn TA, Emmerling MR, et al (2011) Intracranial atherosclerosis as a contributing factor to Alzheimer's disease dementia. Alzheimers Dement 7, 436-444.

Rubio A, Vestner AL, Stewart JM, Forbes NT, Conwell Y, Cox C, et al (2001) Suicide and Alzheimer's pathology in the elderly: A case-control study. Biol Psychiatry 49, 137-145.

Ruitenberg A, den Heijer T, Bakker SL, van Swieten JC, Koudstaal PJ, Hofman A, et al (2005) Cerebral hypoperfusion and clinical onset of dementia: the Rotterdam Study. Ann Neurol 57, 789-794.

Snowdon DA, Greiner LH, Mortimer JA, Riley KP, Greiner PA, Markesbery WR (1997) Brain infarction and the clinical expression of Alzheimer's disease. The Nun Study. JAMA 277, 813-817.

Umayal S, Kulathunga M, Somaratne S, SriKanth S, Kathirarachchi S, De Silva R (2010) Validation of a functioal screening instrument for dementia in an elderly Sri Lankan population: comparison of modified bristol and blessed activities of daily living sclaes. BMC Rec Notes 3, 268. 
Venketasubramanian N, Sahadevan S, Kua EH, Chen CP, Ng TP (2010) Interethnic differences in dementia epidemiology: Global and Asia-Pacific perspectives. Dement Geriatr Cogn Disord 30, 492-498.

Vermeer SE, Prins ND, den Heijer T, Hofman A, Koudstaal PJ, Breteler MM (2003) Silent brain infarcts and the risk of dementia and cognitive decline. N Engl J Med 348, 1215-1222.

Viitanen M, Johansson K, Bogdanovic N, Berkowicz A, Druid H, Eriksson A, et al (1998) Alzheimer changes are common in aged drivers killed in single car crashes and at intersections. Forensic Sci Int 96, 115-127.

World Population Prospects: The 2017 Revision. Department of Economic and Social Affairs. United Nations.

World Alzheimer Report 2015: The global impact of dementia. Alzheimer's Disease International.

World Health Organization. Dementia: A public health priority. Geneva: World Health Organization, 2012.

Yarchoan M, Xie SX, Kling MA, Toledo JB, Wolk DA, Lee EB, et al (2012)

Cerebrovascular atherosclerosis correlates with Alzheimer pathology in neurodegenerative dementias. Brain 135, 3749-3756.

Zlokovic BV (2011) Neurovascular pathways to neurodegeneration in Alzheimer's disease and other disorders. Nat Rev Neurosci 12, 723-738. 


\section{CHAPTER 2}

\section{Cytoskeletal Pathologies of Age-Related Diseases between Elderly Sri}

\section{Lankan (Colombo) and Indian (Bangalore) Brain Samples}

Printha Wijesinghe, S.K. Shankar, Yasha T. Chickabasaviah, Catherine Gorrie, Dhammika Amaratunga, Sanjayah Hulathduwa, K. Sunil Kumara, Kamani Samarasinghe, Yoo Hun Suh, H.W. Steinbusch and K. Ranil D. De Silva

Current Alzheimer Research, 2016;13(3): 268-280 Doi: $10.2174 / 156720501303160217121210$ 


\begin{abstract}
Within South Asia, Sri Lanka represents fastest aging with $13 \%$ of the population was aged over 60's in 2011, whereas in India it was 8\%. Majority of the Sri Lankan population based genetic studies have confirmed their origin on Indian mainland. As there were inadequate data on aging cytoskeletal pathologies of these two nations with their close genetic affiliations, we performed a comparison on their elderly. Autopsy brain samples of 50 individuals from Colombo, Sri Lanka (mean age 72.1 years \pm 7.8 , mean \pm S.D.) and 42 individuals from Bangalore, India (mean age 65.9 years \pm 9.3 ) were screened for neurodegenerative pathologies using immunohistochemical techniques. A total of 79 cases with incomplete clinical history (Colombo- 47 and Bangalore- 32) were subjected to statistical analysis and 13 cases, clinically diagnosed with dementia and/or Parkinsonism disorders were excluded. As per National Institute on Aging- Alzheimer's Association guidelines, between Colombo and Bangalore samples, Alzheimer's disease neuropathologic change for intermediate / high level was $4.25 \%$ vs. $3.12 \%$ and low level was $19.15 \%$ vs. $15.62 \%$ respectively. Pathologies associated with Parkinsonism including brainstem predominant Lewy bodies- $6.4 \%$ and probable progressive supra nuclear palsy- $2.13 \%$ were found solely in Colombo samples. Alzheimer related pathologies were not different among elders, however, in Colombo males, neurofibrillary tangle grade was significantly higher in the region of hippocampus (odds ratio $=1.46,95 \%$ confidence interval $=0.07$ $0.7)$ and at risk in midbrain substantia nigra $(\mathrm{p}=0.075)$. Other age-related pathologies including spongiform changes $(\mathrm{p}<0.05)$ and hippocampus cell loss in dentate gyrus region $(\mathrm{p}<0.05)$ were also identified prominently in Colombo samples. Taken together, aging cytoskeletal pathologies are comparatively higher in elderly Sri Lankans and this might be due to their genetic, dietary and/or environmental variations.
\end{abstract}

\title{
2.1 Introduction
}

Dementia is a growing public health challenge. Population aging is having a profound impact on dementia epidemic. Alzheimer's disease (AD) is the most common form of dementia and possibly contributes 60-70\% of the cases [World Health Organization (WHO), 2012]. Other major contributors include vascular dementia (VaD), Lewy body diseases (LBDs) and a group of diseases that contribute to frontotemporal dementia (FTD). The boundaries between subtypes are indistinct, thus pure forms are quite rare. South Asia (23.2\% of the world total population) is considered as one of the global burdens of disease regions and about 4.5 million people lived with dementia in the year of 2010 (Prince et al., 2013; World Population Prospects, 2013). Among South Asian countries, Sri Lanka is continuously experiencing fastest ageing due to its rapid demographic transition (low fertility and higher life expectancy) and the proportion of Sri Lankan population aged over 60 years was 13\% in 2011, whereas it was 8\% in India, $7 \%$ in Bhutan, Bangladesh and Maldives, 6\% in Nepal and Pakistan and 4\% in Afghanistan (World Health Statistics, WHO, 2013). Among them, low income countries are Afghanistan, Bangladesh and Nepal and lower middle-income countries are India, Sri Lanka, Pakistan and Bhutan and upper middle-income country is Maldives (World Health Statistics, WHO, 2013). About 58\% of the people affected with dementia lived in low- and middleincome countries (LMICs) in 2010 (WHO, 2012) and this proportion is anticipated to rise to $63 \%$ in 2030 and $71 \%$ in 2050 (Alzheimer Disease International, 2010).

Within South Asia, India is the largest populous country with over 1.2 billion people in the year of 2011, where elderly population aged over 60 years contributes around 99.3 million. Whereas, Sri Lanka remains around 21.0 million people in 2011, where elderly 
portion aged over 60 years is around 2.7 million (World Health Statistics, WHO, 2013 ). Indian economy is one of the fastest growing economies of the world. Even though, due to its population explosions, demographic and socioeconomic parameters are still behind that of Sri Lanka and the statistics are as follows: Sri Lanka vs. India: life expectancy rate at birth and at 60 years - 75 years vs. 65 years and 20 years vs. 17 years in 2011; total fertility rate per woman -2.3 vs. 2.6 in 2011 ; literacy rate among adults aged $\geq 15$ years $-91 \%$ vs. $63 \%$ for a period of 2005 to 2011; living in urban areas - $15 \%$ vs. $31 \%$ in 2011; gross national income per capita (purchasing power parity int. \$) - $5520 \mathrm{vs} .3590$ in 2011 and per capita government expenditure on health at average exchange rate (US\$) - 16 to 37 vs. 5 to 14 for a period of 2000 to 2011 (World Health Statistics, WHO, 2013 ). Historically and culturally the se two nations have been considerably close (Kirk, 1976) and majority of the Sri Lankan population genetic studies have confirmed their origin on Indian mainland. However, such genetic studies looking at the immediate origin of Sinhalese (Sinhalese constitute $74.9 \%$ of the total Sri Lankan population) have been contradictory (Kshatriya, 1995; Saha, 1988; Papiha et al., 1996; Malavige et al., 2007). The most recent human genetic study (Ranaweera et al., 2014) on Sri Lankan ethnic population based on mitochondrial DNA hyper variable segments for the genotyping, suggests that all island populations except some subgroups of the Vedda (indigenous people) form close genetic affiliations among themselves and with majority of the group from Indian subcontinent suggesting the origin on Indian motherland. However, no definite association of the Sinhalese with any specific ethnic or linguistic groups of Indians was identified; thus, their exact immediate origin on the motherland remains yet to be investigated.

Prevalence of dementia in Sri Lanka, reported from a semi urban elderly Sinhala speaking population (3.98\%), is higher by comparing community based clinical studies from North India (2.7\%) (De Silva et al., 2003; Kalaria et al., 2008). The prevalence of neuropathologically defined AD is higher than that reported in most previous studies based on clinical diagnosis alone. Epidemiological / clinical studies investigating dementia prevalence face several barriers including lower literacy levels, lack of awareness on cognitive loss and memory problems and the dependent lifestyle, where the activity of daily livings is highly limited to elderly people. Due to these reasons, results of clinical studies may not provide accurate estimates of prevalence and incidence of dementia. The discrepancy between the neuropathologic and clinical diagnoses of AD in elderly subjects, may affect the results of population-based studies (Polvikoski et al., 2001), and thus, there is no alternative to neuropathology as the gold standard in dementia diagnostics. So far, neuropathologic changes related to $\mathrm{AD}$ and other dementia types have not been reported in the elderly Sri Lankans and there have b e e n n o direct comparative clinical and/or autopsy studies between Sri Lankan and Indian elderly samples reported these pathologies. As there were inadequate data on aging cytoskeletal pathologies of these two nations with their close cultural and genetic affiliations, we performed a direct comparison between their elderly samples.

\subsection{Materials and Methods}

Human brain samples were obtained at autopsy from 50 elderly Sri Lankans between May 2009 to March 2010 (age range 55-89 years; mean age \pm S.D. $=72.1$ years \pm 7.8 , male : female $=29: 21$, Sinhalese $:$ Tamil $=45: 5$ ), at the Department of Judicial Medical Office, Colombo South Teaching Hospital following approval by the Institutional Scientific Ethics Committee to carry out the study, and with informed consent from the relatives. 
Representative brain samples were obtained from a semi urban population (Colombo South) with majority of Sinhalese people $(90 \%)$. Specific neuroanatomical regions were sampled for paraffin embedding and sectioning from both hemispheres: hippocampus along with parahippocampal gyrus, superior frontal gyrus, middle temporal gyrus, superior parietal lobule and midbrain at the superior colliculus level. For the comparison, autopsy brain samples from 42 elderly Indians from a semi urban Bangalore population (age range 5089 years; mean age \pm S.D. $=65.9$ years \pm 9.3 , male: female $=30: 12)$ were obtained at the Human Brain Tissue Repository-National Institute of Mental Health and Neurosciences [HBTR-NIMHANS], Bangalore, India. In the total of 92 cases, there were 13 cases clinically diagnosed as dementia and/or Parkinsonism (3 samples from Colombo with Parkinson's disease (PD) and 10 samples from Bangalore: Parkinsonism- 7, AD- 2 and FTD- 1) and the remaining (47 Colombo samples and 32 Bangalore samples) had incomplete clinical history. Neuropathological screening for all the recruited samples was carried out in the host laboratory NIMHANS, thus both Colombo and Bangalore samples were subjected to same methodological procedures and diagnostic criteria.

Following routine histological evaluation (with Haematoxylin and Eosin staining), the formalin fixed paraffin embedded brain sections were immunostained by standard immunoperoxidase technique follow ing antigen retrieval by heat and $\mathrm{DAB} / \mathrm{H}_{2} \mathrm{O}_{2}$ as the chromogen to visualize the immunolabelling (DAKO Envision Detection System). For this purpose, following three antibodies were used.

(a) $\beta$ amyloid- Monoclonal antibody (1:200 dilution) from Novacastra ${ }^{\mathrm{TM}}$

(b) Ubiquitin- Monoclonal antibody (1:150 dilution) from Novacastra ${ }^{\mathrm{TM}}$

(c) Phosphorylated tau PHF-1 Monoclonal antibody (1:50 dilution) from USA (A gift)

The presence and extent of neurodegenerative pathologies were assessed in these stained sections blinded to the case histories under the direct supervision of two neuropathologists SKS and YTC. Final decisions were made jointly. The diagnostic criteria for "AD neuropathologic change" were based on National Institute on Aging-Alzheimer's Association guidelines for the neuropathological assessment of AD (NIA-AA) (Montine et al., 2012) a practical approach which included:

- Consortium to Establish a Registry for AD (CERAD) protocol for neuritic plaque (NP) scoring (Mirra et al., 1991),

- Braak and Braak staging scheme for neurofibrillary degeneration (Braak and Braak, 1991; Braak et al., 2006) which was adapted to four stages that improves inter-rater reliability (stage 0, stage I or II, stage III or IV and stage V or VI) (Nagy et al., 1998) and - A modified version of Thal phases of $\beta$ amyloid (A $\beta$ ) plaque accumulation (Thal et al., 2002) which was adapted to four-point scale (phase 0 , phase 1 or 2 , phase 3 and phase 4 or 5).

AD neuropathologic change was ranked by three parameters: $A \beta$ plaque score (Thal et al., 2002), Braak and Braak neurofibrillary tangle (NFT) stage (Braak et al., 2006a), and CEARD NP (neuritic plaque) score (Mirra et al., 1991) to obtain ABC scores and then transformed into 4 levels: not, low, intermediate or high. Cerebral amyloid angiopathy (CAA) grades were not included in the $\mathrm{ABC}$ scores although amyloid buildup on the walls of the arteries was frequently observed along with cortical A $\beta$ plaques. Neuropathological criteria for LBDs including PD and dementia with Lewy bodies (DLB) were based on NIA-AA modifications to existing criteria which included Consortium on Dementia with Lewy Bodies 2005 (CDLB05) (McKeith et al., 2005) and Braak's PD staging (Braak et al., 2003), and based on the 
reconsidered staging procedure for the inclusion body pathology associated with sporadic PD (Braak et al., 2006b).

Semi quantitative grading (Lace et al., 2009) of phosphorylated tau positive and A $\beta$ positive pathologies were performed in the regions of hippocampus along with parahippocampal gyrus, midbrain and in the neocortex as given below.

1) Semi-quantitative 0-3 scale (0- none, +- low, ++- moderate, +++- high) for tau positive neuropil threads, neurons (neurons demonstrating tangle and pre-tangle pathology), NPs and white matter neuropil threads.

2) Semi-quantitative 0-3 scale (0- none, + - sparse, ++ - moderate, +++ - frequent) for $\mathrm{A} \beta$ positive senile plaques (SPs) (dystrophic neurites and an amyloid core) and diffuse plaques (DPs).

Actual burden of AD neuropathological hallmarks- tau positive NFTs, NPs and A $\beta$ positive SPs were counted in specific brain regions such as hippocampus, entorhinal cortex, superior frontal gyrus and midbrain based on Purohit et al (2011) study. For this purpose, a medium high power (20X) objective lens producing a visual field $0.785 \mathrm{~mm} 2$ (field diameter $=2.0 \mathrm{~mm})$ was used. Lesions were counted in medium high (200X magnification, Olympus U-CTR30-2 Trinocular objective tubes and 10X eye piece) power fields and then converted into average per $200 \mathrm{X}$ as follows: for superior frontal gyrus, areas with high NPs/SPs/NFTs were selected and visual counts were carried out in five non-over lapping fields. For hippocampus, entorhinal cortex and midbrain, the areas with high NPs/SPs/NFTs were identified in each sub fields and then visual counts were carried out in the non-over lapping fields (wherever possible five non-over lapping fields were selected). CAA in leptomeningeal and cortical arteries was graded into 5 levels (grade 0,1,2, 3 and 4) based on Greenberg and Vonsattel (1997) specifications and the average grade was reported for each case. The presence of other cerebrovascular changes including dilated perivascular spaces, spongiform changes of neuropil, and white matter lesion leukoaraiosis in frontal and temporal cortex regions and the hippocampus cell loss in Cornu Ammonis area 1 (CA1) and dentate gyrus (DG) regions were assessed using H \& E stained sections. Luxol fast blue and Eosin stained sections were used for the assessment of leukoaraiosis. Other than CAA, comorbidity of the above pathologies was reported as present or absent (none or rare). Due to the high variability of morphological findings and multifactorial pathogenesis of $\mathrm{VaD}$, no generally accepted morphologic scheme for quantitating vascular brain injury and no validated neuropathological criteria for $\mathrm{VaD}$ have been established to date (Jellinger, 2013; Gorelick et al., 2011; Alafuzoff, 2012). On the whole, the basis of VaD diagnosis is simply the presence of brain lesions related to vascular pathology and highly depends on neuropathologist's judgment.

\subsubsection{Statistical Analysis}

To compare elderly samples, a total of 79 cases (Colombo 47 and Bangalore- 32) with incomplete clinical history were subjected to statistical analysis and excluded 13 clinically diagnosed cases with dementia and/or Parkinsonism disorders. Analysis was performed with statistical software SPSS version 16.0. Hierarchical multiple regression adjusted for age and sex was used to determine the odds ratio (OR) with a 95\% confidence interval (CI) for Colombo and Bangalore samples for different $\mathrm{AD}$ related neuropathological scores in different brain regions. Binary logistic regression adjusted for age and sex, was used to determine the OR with a $95 \%$ CI for the presence of comorbid pathologies between elderly samples. Degree of association among these age-related pathologies was determined using Fisher's exact test ( $2 \mathrm{X} 2$ contingency table) and Kendall's tau b correlation coefficient as the 
sample size is small and the variables are categorical.

\subsection{Results}

Our study included 92 brains of deceased persons aged 50 to 89 years (Colombo- 50 and Bangalore- 42) and their mean age at death is almost equivalent to their standard population life expectancy. Among the cases with incomplete clinical history (79 cases), about $87 \%$ (41/47) of the Colombo and 62.5\% (20/32) of the Bangalore sample brains showed some degree of Alzheimer related pathology at death $(\mathrm{p}=0.230, \mathrm{OR}=2.15,95 \% \mathrm{CI}=0.6-7.5$, reference category: Bangalore samples). Moderate to severe neurofibrillary degenerations i.e. extended to limbic and neocortical regions (Braak stage III to stage VI) were observed in $34 \%$ of the Colombo and $18.75 \%$ of the Bangalore samples. Thal A $\beta$ phases for SPs in neocortical and allocortical regions (phase 1-2) were observed in $21.3 \%$ of the Colombo and $15.6 \%$ of the Bangalore sample. Thal $\mathrm{A} \beta$ phase extended to midbrain nuclei was found in single cases in both samples. Tau positive NPs in neocortical regions were comparatively lower than $A \beta$ positive SPs in both groups and it was $10.63 \%$ in Colombo sample and $6.25 \%$ in Bangalore sample. Between Colombo and Bangalore samples, AD neuropathologic change for "intermediate / high" level was $4.25 \%$ and $3.12 \%$ respectively. For individuals with incomplete clinical history, AD neurolopathologic change for higher levels is considered as greater likelihood for cognitive impairment (Montine et al., 2012) and found in one Bangalore sample. AD neuropathologic change for low levels, although they are considered as inadequate explanation for cognitive impairment or dementia (Montine et al., 2012) were $19.15 \%$ in Colombo samples and $15.62 \%$ in Bangalore samples. Sample summary consist of AD, CAA and LBD neuropathological changes are given in (Table 1).

\begin{tabular}{|c|c|c|c|c|c|c|}
\hline Sample Size & Braak NFT stage & $\begin{array}{l}\text { CERAD NP } \\
\text { score }\end{array}$ & $\begin{array}{c}\text { Thal } \\
\text { A } \beta \text { phase }\end{array}$ & NIA-AA (criteria) & $\begin{array}{l}\text { CAA } \\
\text { grade }\end{array}$ & LBD stage \\
\hline \multirow{5}{*}{$\begin{array}{l}\text { Sri Lanka } \\
(47 \text { cases })\end{array}$} & none $17.02 \%$ & none $89.4 \%$ & none $76.6 \%$ & $\operatorname{not} 76.6 \%$ & none $80.85 \%$ & none $93.6 \%$ \\
\hline & stage I-II $48.94 \%$ & stage A $2.13 \%$ & phase1-2 21.28\% & \multirow[t]{2}{*}{$\begin{array}{c}\text { Intermediate / } \\
\text { high } 4.25 \%\end{array}$} & grade $117.02 \%$ & $\begin{array}{c}\text { brainstem predominant } \\
6.4 \%\end{array}$ \\
\hline & stage III-IV $31.91 \%$ & stage B & phase $32.13 \%$ & & grade $22.13 \%$ & limbic (transitional) 0\% \\
\hline & \multirow[t]{2}{*}{ stage V-VI $2.13 \%$} & \multirow[t]{2}{*}{$\begin{array}{l}\text { stage C } \\
4.25 \%\end{array}$} & \multirow[t]{2}{*}{ phase $4-50 \%$} & \multirow[t]{2}{*}{ low $19.15 \%$} & grade $30 \%$ & neocortical (diffuse) $0 \%$ \\
\hline & & & & & grade $40 \%$ & $\begin{array}{c}\text { amygdala predominant } \\
\text { N/A }\end{array}$ \\
\hline \multirow{5}{*}{$\begin{array}{c}\text { India } \\
(32 \text { cases })\end{array}$} & none $37.5 \%$ & none $93.7 \%$ & none $81.25 \%$ & $\operatorname{not} 81.25 \%$ & none $90.62 \%$ & none $100 \%$ \\
\hline & stage I-II $43.8 \%$ & stage A $3.12 \%$ & phase 1-2 15.65\% & \multirow[t]{2}{*}{$\begin{array}{c}\text { Intermediate / } \\
\text { high } 3.12 \%\end{array}$} & grade $13.12 \%$ & brainstem predominant $0 \%$ \\
\hline & stage III-IV $15.62 \%$ & stage B $0 \%$ & phase $30 \%$ & & grade $20 \%$ & limbic (transitional) $0 \%$ \\
\hline & stage V-VI $3.12 \%$ & stage C $3.12 \%$ & phase $4-53.12 \%$ & \multirow[t]{2}{*}{ low $15.62 \%$} & grade $36.25 \%$ & neocortical (diffuse) $0 \%$ \\
\hline & & & & & grade $40 \%$ & amygdala predominant N/A \\
\hline
\end{tabular}

Table 1. Sample summary on AD, CAA and LBD neuropathological changes.

NFT: neurofibrillary tangle, CERAD NP score: Consortium to Establish a Registry for AD (CERAD) protocol for neuritic plaque score, A $\beta$ : $\beta$ amyloid, NIA-AA: National Institute on Aging- Alzheimer's Association, AD: Alzheimer's disease, CAA: cerebral amyloid 
angiopathy, LBD: Lewy body disease, N/A: not available.

Neuropathological findings on 13 clinically diagnosed cases are given in (Table 2) and the majority showed clinicopathological correlations. A variety of neurodegenerative pathologies including AD, PD, progressive supra nuclear palsy (PSP), diffuse Lewy body disease (DLBD), frontotemporal lobar degeneration tauopathy and CAA were observed in these brains and are illustrated in (Figure 1).

\begin{tabular}{|c|c|c|c|c|}
\hline Sample & Age at death & Gender & Clinical Diagnosis & Neuropathological diagnosis \\
\hline \multirow[t]{3}{*}{$\begin{array}{l}\text { Sri Lanka } \\
(3 \text { cases })\end{array}$} & (1) 74 & Male & PD & $\begin{array}{l}\text { Mixed dementia (definite PSP, AD neuropathologic change- } \\
\text { intermediate and brainstem predominant Lewy bodies) }\end{array}$ \\
\hline & (2) 73 & Female & $\mathrm{PD}$ & $\begin{array}{l}\text { Brainstem predominant Lewy bodies } \\
\text { Idiopathic PD, stage III }\end{array}$ \\
\hline & (3) 73 & Male & PD & $\begin{array}{c}\text { No Lewy bodies } \\
\text { Vascular Parkinsonism due to ischemic stroke }\end{array}$ \\
\hline \multirow{10}{*}{$\begin{array}{c}\text { India } \\
(10 \text { cases })\end{array}$} & (4) 89 & Male & Parkinsonism & No lesions \\
\hline & (5) 86 & Male & $\mathrm{AD}$ & $\begin{array}{c}\text { AD neuropathologic change- intermediate } \\
\text { Severe CAA }\end{array}$ \\
\hline & (6) 76 & Male & Parkinsonism & $\begin{array}{l}\text { Brainstem predominant Lewy bodies } \\
\text { Idiopathic PD, stage III }\end{array}$ \\
\hline & $(7) 75$ & Male & Parkinsonism & $\begin{array}{l}\text { Mixed dementia (neocortical Lewy bodies- diffuse Lewy body } \\
\text { disease and AD neuropathologic change- intermediate) }\end{array}$ \\
\hline & (8) 72 & Male & $\mathrm{AD}$ & AD neuropathologic change: high \\
\hline & (9) 62 & Female & Parkinsonism & Brainstem predominant Lewy bodies and multiple system atrophy \\
\hline & (10) 61 & Male & Parkinsonism & $\begin{array}{l}\text { Brainstem predominant Lewy bodies } \\
\text { Idiopathic PD, stage III }\end{array}$ \\
\hline & (11) 60 & Male & Parkinsonism & $\begin{array}{c}\text { Brainstem predominant Lewy bodies and Creutzfeldt-Jakob } \\
\text { disease }\end{array}$ \\
\hline & (12) 52 & Male & Parkinsonism & $\begin{array}{c}\text { Brainstem predominant Lewy bodies } \\
\text { Idiopathic PD, stage III }\end{array}$ \\
\hline & (13) 50 & Male & FTD & Frontotemporal lobar degeneration - tauopathy \\
\hline
\end{tabular}

Table 2. Neuropathological findings of 13 clinically diagnosed cases with dementia and/or Parkinsonism disorders.

PD: Parkinson's disease, AD: Alzheimer's disease, PSP: progressive supra nuclear palsy, FTD: Frontotemporal dementia

Moreover, we have summarized the AD related neuropathological scores of our study and the scores obtained for elderly Mumbai and New York samples from Purohit et al autopsy study (2011) in (Table 3). This table facilitates the comparison on AD related neuropathologic scores among LMICs and between LMICs and high-income country (HIC). 


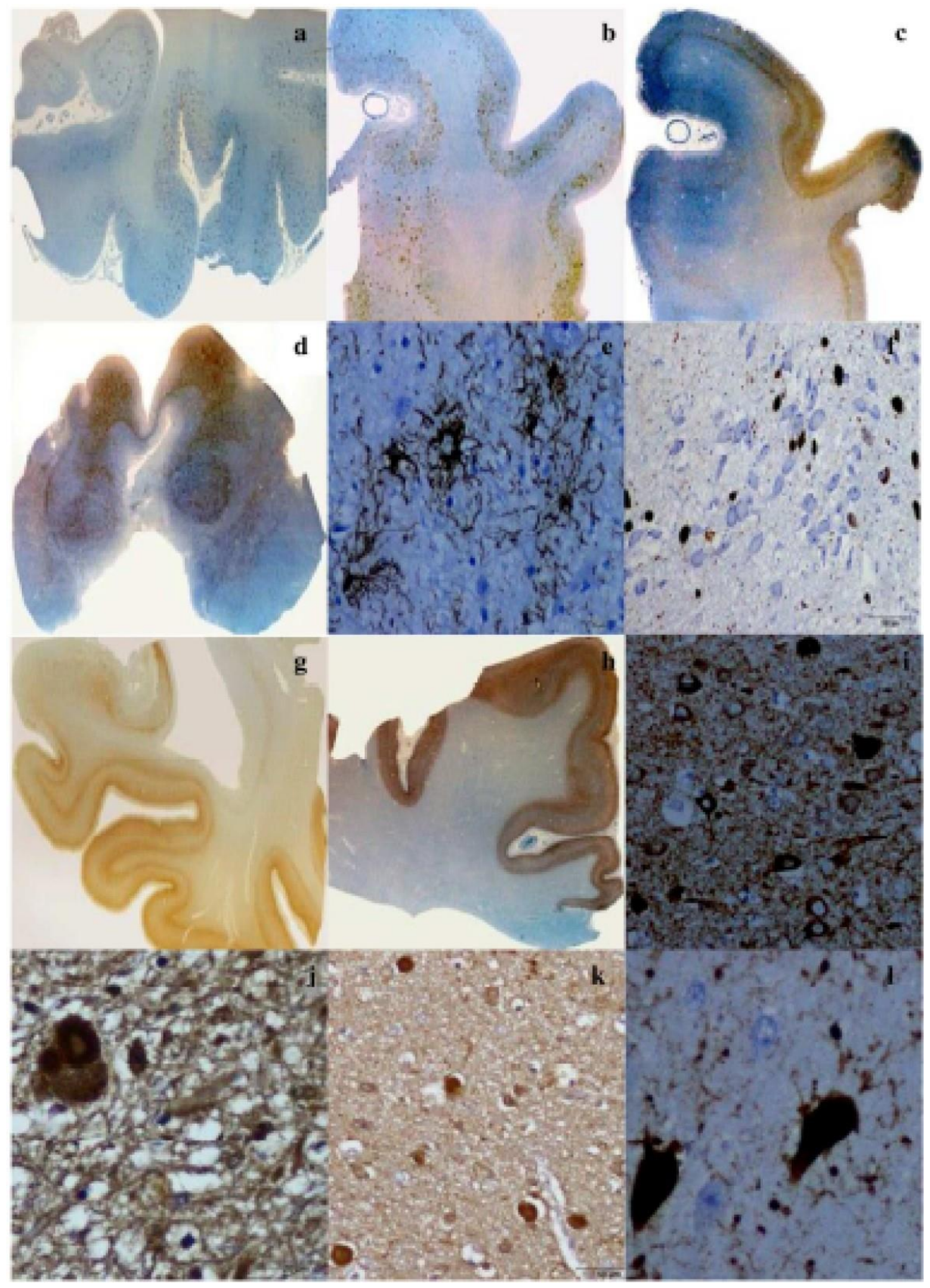

Figure 1. Neurodegenerative pathologies: a,b\&c- Alzheimer's disease (a) NPs in hippocampus whole mount, (b) Bamyloid (+) ve SPs in frontal cortex, (c) tau (+) ve neurofibrillary pathology in the frontal cortex; d,e\&f- Progressive supra nuclear palsy (d) $\operatorname{tau}(+)$ ve lesions in midbrain whole mount, (e) tufted astrocytes at $400 \mathrm{X}$ (scale bar- $20 \mu \mathrm{m}$ ), (f) globes tangles at $100 \mathrm{X}$ (scale bar- $100 \mu \mathrm{m})$; g,h\&i- Fronto temporal dementia- 
frontotemporal lobar degeneration tauopathy $(\mathrm{g}) \operatorname{tau}(+)$ ve inclusion bodies in the hippocampus whole mount, (h) frontal cortex whole mount (i) at 200X (scale bar- $50 \mu \mathrm{m}$ ) in hippocampal CAl region; j-Brainstem predominant Lewy bodies in substantia nigra of a Parkinson disease case at 400X (scale bar- $20 \mu \mathrm{m}$ ), k- Neocortical Lewy bodies in the frontal

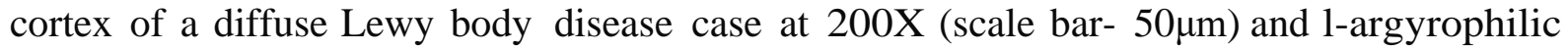
grains at $400 \mathrm{X}$ (scale bar- $20 \mu \mathrm{m}$ ) in hippocampal CAl region.

\begin{tabular}{|c|c|c|c|c|}
\hline & $\begin{array}{c}\text { Colombo } \\
\text { Sri Lanka (SE) }\end{array}$ & \multicolumn{2}{|c|}{$\begin{array}{c}\text { Bangalore } \\
\text { India (SE) }\end{array}$} & \multicolumn{2}{|c|}{$\begin{array}{c}\text { Mumbai } \\
\text { India (SE) }\end{array}$} & New York USA (SE) \\
\cline { 3 - 5 } & & & \multicolumn{2}{|c|}{ Reference (Purohit et al... 2011) } \\
\hline Mean age \pm S.D. in years & $72.1 \pm 7.8$ & $65.9 \pm 9.3$ & $71.1 \pm 8.3$ & $71.1 \pm 9.3$ \\
\hline NFT in Hippocampus (grade) & $0.91(0.11)$ & $0.75(0.08)$ & $1.24(0.18)$ & $1.16(0.18)$ \\
\hline NFT in Hippocampus (count/mm $\left.{ }^{2}\right)$ & $4.36(1.16)$ & $1.30(0.42)$ & $4.41(0.87)$ & $3.78(0.78)$ \\
\hline NFT in EC (grade) & $1.20(0.14)$ & $1.11(0.11)$ & $1.39(0.20)$ & $1.32(0.16)$ \\
\hline NFT in EC (count/mm $\left.{ }^{2}\right)$ & $4.58(0.82)$ & $3.27(0.80)$ & $4.06(0.71)$ & $3.81(0.63)$ \\
\hline SP in neocortex (count/mm $\left.{ }^{2}\right)$ & $0.44(0.17)$ & $0.95(0.60)$ & $1.15(0.31)$ & $0.59(0.18)$ \\
\hline Braak stage for NFT & $1.91(0.2)$ & $1.19(0.2)$ & $1.01(0.14)$ & $1.11(0.12)$ \\
\hline SP, age adjusted CERAD score & $0.45(0.13)$ & $0.41(0.16)$ & $0.80(0.17)$ & $0.39(0.11)$ \\
\hline
\end{tabular}

Table 3. Comparison of AD related neuropathological scores between LMICs, and between LMICs and HIC.

LMICs: low- and middle-income countries, HIC: high income country, USA: United States of America, S.E.: standard error, S.D.: standard deviation, NFT: neurofibrillary tangle, EC: entorhinal cortex, SP: senile plaque.

Mean counts of both, NFTs and SPs (count/mm2) among different age groups were plotted against specific neuroanatomical regions: entorhinal cortex, hippocampus, superior frontal gyrus and midbrain in (Figure 2) and (Figure 3) to show their involvement during aging. Overall pattern of their involvement follows the Braak and Braak staging scheme for NFTs and Thal $\mathrm{A} \beta$ phases for SPs accumulation. 

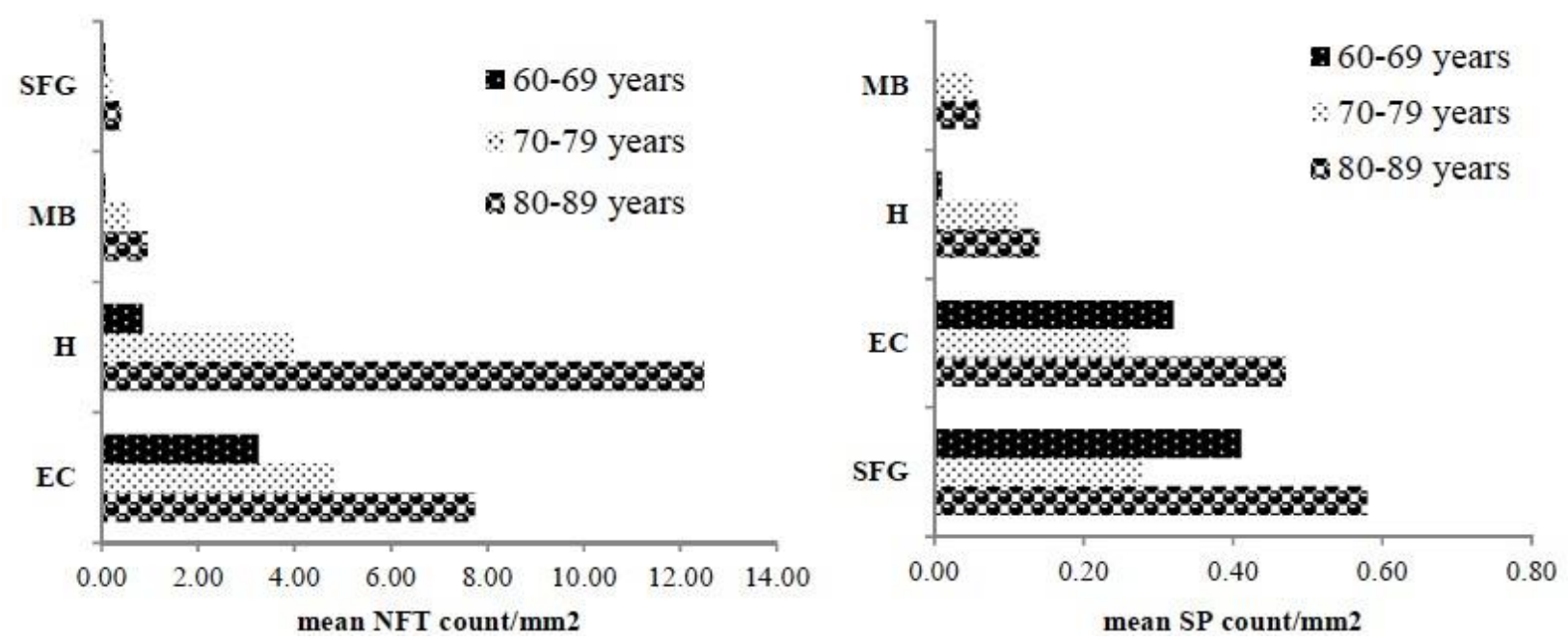

Figure 2. Colombo samples: Mean NFT and SP counts were plotted against different neuroanatomical regions (EC- entorhinal cortex, H- hippocampus, MB- midbrain, SFGsuperior frontal gyrus, NFT- neurofibrillary tangle, SP- senile plaque. Excluded clinically diagnosed cases and aged $<60$ years).
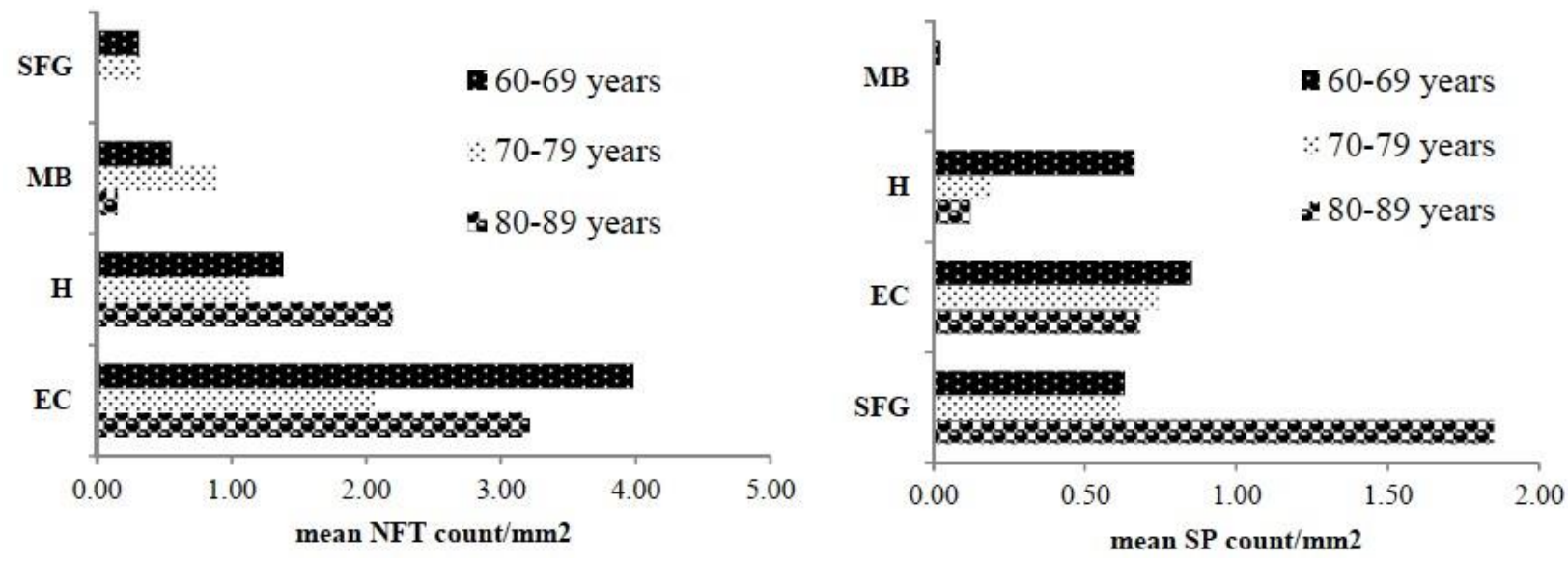

Figure 3. Bangalore samples: Mean NFT and SP counts were plotted against different neuroanatomical regions

EC- entorhinal cortex, H- hippocampus, MB - midbrain, SFG- superior frontal gyrus, NFTneurofibrillary tangle, SP- senile plaque. Excluded clinically diagnosed cases and aged $<60$ years.

Between the males of both populations, mean NFT grade was significantly different (mean 1.05 , standard error of mean $(\mathrm{SEM})=0.13$ vs. 0.34 , $\mathrm{SEM}=0.07, \mathrm{p}=0.019^{*}$, odds ratio $(\mathrm{OR})=1.46,95 \% \mathrm{CI}=0.07-0.7$ ) in hippocampus and at risk (mean 0.81, $\mathrm{SEM}=0.09 \mathrm{vs}$. $0.25, \mathrm{SEM}=0.13, \mathrm{p}=0.075, \mathrm{OR}=1.39,95 \% \mathrm{CI}=-0.03-0.7)$ in midbrain nigral neurons with hierarchical multiple regression adjusted for age, and it was prominent in Colombo samples. Apart from above findings, AD related neuropathological scores (grades and counts) between elderly samples, between sex and between the females of both populations were not different in any brain region. (Figure 4) shows the mean grades of AD related pathologies between Colombo and Bangalore samples and it was not significantly different among them. Tau positive pathologies were comparatively higher in Colombo samples, whereas $\mathrm{A} \beta$ positive pathologies were prominent in Bangalore samples. 


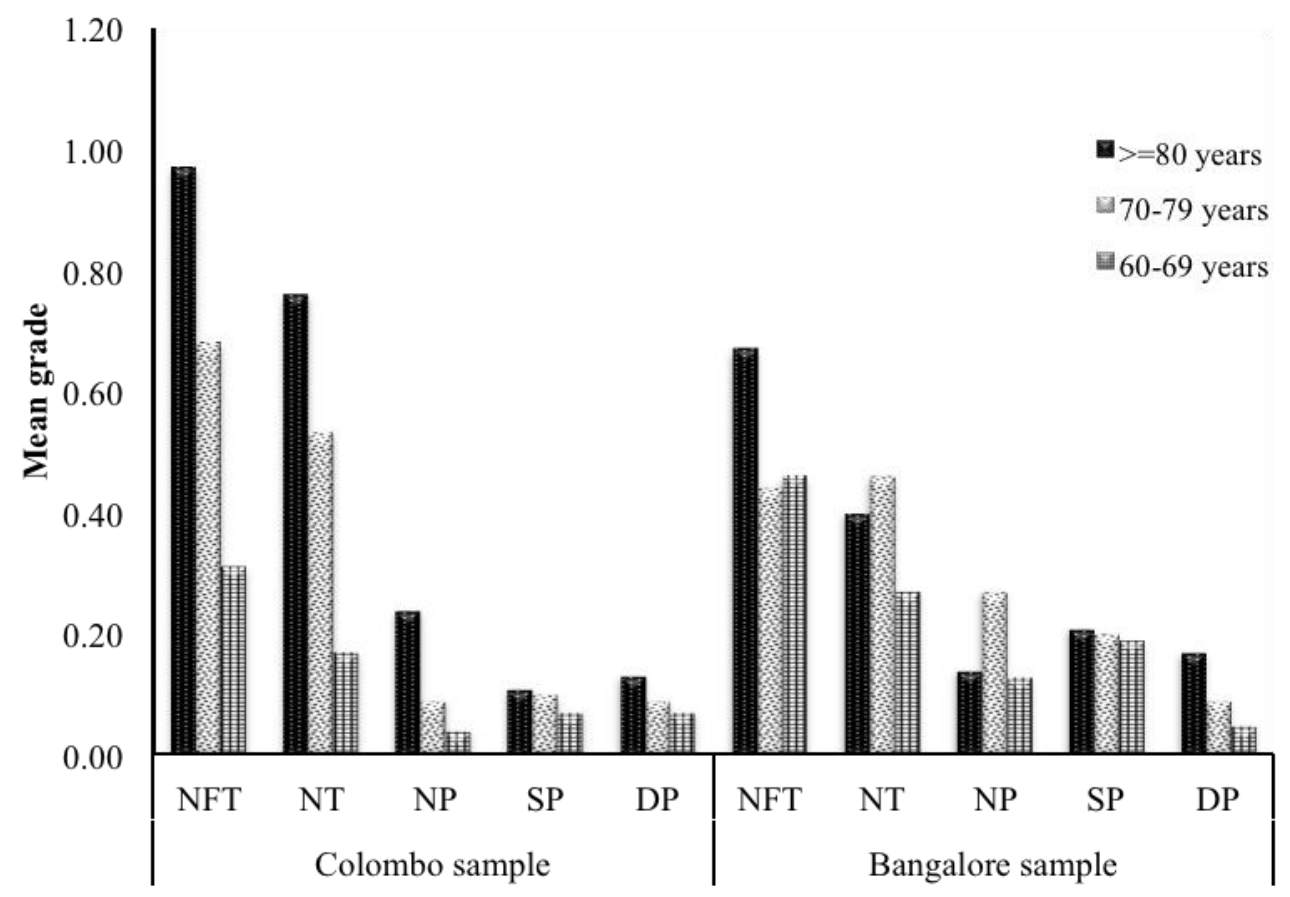

Figure 4. Mean grades of both tau and $\beta$ amyloid positive pathologies were plotted against elderly Colombo and Bangalore samples

NFT- neurofibrillary tangle, NT- neuropil thread, NP- neuritic plaque, SP- senile plaque and DP- diffuse plaque

Furthermore, A $\beta$ positive CAA pathology in cortical and leptomeningeal arteries was found in $19.15 \%$ of the Colombo and $9.37 \%$ of the Bangalore samples. Brainstem predominant Lewy bodies were observed in $6.4 \%$ of the Colombo samples and possibly at stage 3 (Braak et al., 2006b). Meanwhile, none of the Bangalore samples showed Lewy body pathology at death. Pathology associated with PSP (tufted astrocytes and globose tangles in the midbrain) was observed in one Colombo sample $(2.13 \%)$ and due to its incomplete clinical history; it was diagnosed as probable PSP. Other age-related pathologies and their extent between elderly samples are given in percentage in the following (Table 4) with $\mathrm{p}$ values. Among them, spongiform changes $(\mathrm{p}=0.000, \mathrm{OR}=8.75,95 \% \mathrm{CI}=2.8-27.6)$ and granular cell loss in $\mathrm{DG}$ region $(\mathrm{p}=0.009, \mathrm{OR}=5.65,95 \% \mathrm{CI}=1.5-20.6)$ were found prominently in Colombo samples.

\begin{tabular}{|c|c|c|c|c|}
\hline \multirow{2}{*}{ Pathology } & \multicolumn{2}{|c|}{ Presence in \% } & $\begin{array}{c}\text { P value } \\
\text { (age, sex adjusted) }\end{array}$ & $\begin{array}{c}\text { Odds ratio } \\
\text { (95\% CI) }\end{array}$ \\
\cline { 2 - 3 } & Colombo samples & Bangalore samples & & \\
\hline Cerebral amyloid angiopathy & $19.1 \%$ & $9.4 \%$ & - & $1.30(0.3-5.9)$ \\
\hline Lewy bodies & $6.4 \%$ & $0.0 \%$ & $0.000^{* *}$ & $8.75(2.8-27.6)$ \\
\hline Spongiform changes & $80.9 \%$ & $29.0 \%$ & 0.0737 & $3.19(0.9-11.3)$ \\
\hline Dilated perivascular spaces & $87.2 \%$ & $68.8 \%$ & 0.706 & $0.80(0.3-2.5)$ \\
\hline Leukoaraiosis & $32.6 \%$ & $31.0 \%$ & 0.162 & $2.55(0.7-9.5)$ \\
\hline Cell loss in CA1region & $53.2 \%$ & $17.2 \%$ & $0.009^{* *}$ & $5.65(1.5-20.6)$ \\
\hline Cell loss in DG region & $51.1 \%$ & $13.8 \%$ & & \\
\hline
\end{tabular}

Table 4. Co-morbid age-related pathologies between Colombo and Bangalore samples. Dichotomized variables (present or absent) with binary logistic regression adjusted for age and 
sex (reference category- Bangalore samples, ${ }^{* *} \mathrm{p}$ value significant at $<0.01$ and $¥$ at risk at $<0.1$ ) $\mathrm{C} 1$ : confidence interval, Coronu Ammonis area 1: CA1, DG: dentate gyrus

Degree of associations among these age-related pathologies are given in (Table 5) and the majority showed a significant relationship with positive correlations.

\begin{tabular}{|c|c|c|c|c|}
\hline \multicolumn{2}{|c|}{$\begin{array}{c}\text { Pathology } \\
\text { (Dichotomized variables) }\end{array}$} & $\begin{array}{c}\text { P value } \\
\text { (Fisher's exact test) }\end{array}$ & $\begin{array}{c}\text { Kendall's tau b } \\
\text { correlation }\end{array}$ & Strength \\
\hline AD intermediate/ high & CAA grade 2/3 & 0.003 & 0.654 & strong \\
\hline Thal A $\beta$ phase 1-5 & CAA 1-4 & 0.000 & 0.465 & very strong \\
\hline Thal A $\beta$ phase $\geq 2$ & CERAD NP score A-C & 0.000 & 0.808 & moderate \\
\hline Braak NFT stage IV-VI & CERAD NP score A-C & 0.000 & 0.448 & weak \\
\hline Braak NFT stage IV-VI & Thal A $\beta$ phase $\geq 2$ & 0.028 & 0.298 & weak \\
\hline Braak NFT stage IV-VI & Leukoaraiosis & 0.006 & 0.317 & weak \\
\hline CERAD NP score A-C & Leukoaraiosis & 0.005 & 0.325 & weak \\
\hline CAA 1-4 & Leukoaraiosis & 0.014 & 0.324 & weak \\
\hline Lewy bodies & Leukoaraiosis & 0.030 & 0.298 & weak \\
\hline Braak NFT stage III-VI & cell loss in CA1 & 0.036 & 0.270 & \\
\hline Spongiform changes & cell loss in CA1 & 0.005 & & \\
\hline & dilated perivascular space & 0.015 & & \\
\hline
\end{tabular}

Table 5. Degree of association among the age-related pathologies: $2 \mathrm{X} 2$ contingency table. $P$ value is calculated using Fisher's exact test and presented only the significant $p$ values at $<0.05$

Correlation strength: very weak $0.00-0.19$, weak $0.20-0.39$, moderate $0.40-0.59$, strong 0.60 0.79 and very strong $0.80-1.00$.

\subsection{Discussion}

While there is voluminous literature in the West, there is glaring paucity of data on age associated pathomorphological changes in the brain in Sri Lankan population. This is the first autopsy study in Sri Lanka (Colombo) and the first direct comparative study between Sri Lankan and Indian (Ban- galore) elderly samples that investigated the extent of agerelated cytoskeletal pathologies. In overall, $87 \%$ (41/47) of the Colombo sample and $62.5 \%$ (20/32) of the Bangalore sample show some degree of cytoskeletal pathology at death but it was not significantly different $(\mathrm{p}=0.23)$. Neuropathological diagnosis indicated that AD related pathologies obtained from a semi urban Colombo samples are remarkably similar to that in the brains obtained from a semi urban Bangalore sample. Meanwhile, presence of spongiform changes and granular cell loss in the DG region are higher $(p<0.05)$ in Colombo 
samples after controlling age and sex. Moreover, pathologies associated with Parkinsonism including PD- 6.4\% (3/47) and probable PSP- 2.13\% (1/47) were found only in Colombo samples.

To date, there is only one study reported the dementia prevalence from Sri Lanka [12]. This study was performed in a semi urban Sinhala speaking elderly population ( $>65 \mathrm{yrs}$ ) based on clinical diagnosis (Diagnostic and Statistical Manual of Mental Disorders IV: DSM-IV). All kinds of dementia were 3.98\% (95\% CI $=2.6-5.7)$ including AD 2.85\%, $\mathrm{VaD} 0.6 \%$ and the remaining due to other causes of dementia. Dementia prevalence in India (>65 years) based on clinical diagnosis (DSM-III, DSM-IV criteria) are as follows: all dementia $2.7 \%$ $(95 \% \mathrm{CI}=1.4-4.0)$, AD $1.3 \%$, vascular dementia $1.1 \%$ and the remaining due to other causes (Kalaria et al., 2008). Dementia prevalence in Bangladesh was reported very recently and it is 3.6\% based on clinical diagnosis (>60 years) (Palmer et al., 2014). Besides the reports from Sri Lanka, India, and Bangladesh, prevalence of dementia has not been extensively studied in other South Asian countries. Dementia prevalence in some other Asian human races is as follows: Chinese 3.1\% (>65 years) (Dong et al., 2007), Koreans 6.3\% (>65 years) (Jhoo et al., 2008), Thai people 3.4\% (>60 years) (Jitapunkul et al., 2001), Singaporeans $6.5 \%$ ( $\geq 65$ years) (Kua and Ko., 1995) and Israelis 26.4\% (>65 years) (Bowirrat et al., 2002). Dementia prevalence in Japan based on recent systemic review has been increased from $2.9 \%$ to $12.5 \%$ (Okamura et al., 2013). According to Prince et al. (2013) systematic review on global burden of disease regions, in the year 2010, prevalence of dementia aged $>60$ years was as follows: Asia 3.9\% (Central Asia 4.6\%, East Asia 3.2\%, South Asia 3.6\% and Southeast Asia 4.8\%), Australia 6.4\%, Europe 6.2\%, The Americas 6.5\% and Africa 2.6\%. These estimates are entirely based on clinical criteria and the prevalence rates seem to be high in developed regions.

In our study, we found that the $\mathrm{AD}$ neuropathologic change for intermediate / high level is 4.25\% (2/47) in Colombo sample and 3.12\% (1/32) in Bangalore sample and it is not different between elders ( $\mathrm{p}=0.798$, after age and sex adjustment). Our study was not a prospective clinicopathological correlative study. However, it appears that in both populations, percentage of $\mathrm{AD}$ neuropathologic change for higher levels is greater than that reported in literatures based on clinical diagnosis alone $(4.25 \%$ vs. $2.85 \%$ in Sri Lanka and $3.12 \%$ vs. $1.3 \%$ in India). Therefore, such prospective clinicopathological study in Sri Lanka could provide better indications of the true extent of dementia burden, help plan for future health care needs and offer neurobiological perspectives that underlie lifestyle and environmental risk / protective factors for AD affecting these cultures (Purohit et al., 2011). It is suggested in the NIA-AA guidelines, that for individual with cognitive impairment at the time of tissue was obtained, intermediate or high level of AD neuropathologic change should be considered as adequate explanation of cognitive impairment or dementia and should be reported with a final diagnosis of AD. Unfortunately, clinical diagnosis of dementia or $\mathrm{AD}$ in these cases had failed in obtaining ante-mortem detection. This may be due to identification of dementia as a clinical entity is not common in the population from which subjects were obtained or the prevailing notion among the people that the memory problems and cognitive loss are natural phenomena during aging and are not due to a disease which might require an intervention (Purohit et al., 2011).

An older autopsy study conducted by our co-authors Yasha and colleagues (1997) on AD related pathology of the 53 Bangalore samples collected over 10 years indicated that the incidence of both SPs and NFTs together were found to increase with age from $21 \%$ in seventh 
decade to $33 \%$ in eighth decade and $54 \%$ in ninth decade and the increasing incidence of NFTs being statistically significant. Above study was entirely based on silver stains for the assessments of neuropathological scores. In our study, recently collected samples from same Bangalore population show that incidence of both SPs and NFTs together were found to increase with age from $20.8 \%$ in sixth decade to $37.5 \%$ in seventh decade and $60 \%$ in eighth decade and the higher percentage of this report may be a reflection of more sensitive pick up using immunohistochemistry and may also represent the vulnerability of current population to such pathologies which start at their early periods as indicated. Yasha and her colleagues (1997) also suggested from their findings that AD related lesions were similar to that reported in the high-income countries (HICs), although they didn't conduct a direct comparison. Meanwhile, a recent autopsy report (Purohit et al., 2011) from India, which compared the profile of AD related pathology in an ageing semi urban Mumbai population with similar samples from New York, USA indicated that the burden of AD related pathology was approximately equivalent in Mumbai and New York samples, which is at variance with expected lower AD-related lesion burden based on the clinical / epidemiological studies suggesting lower prevalence of AD in India. To compare LMICs and HIC, we have summarized the findings of our study with AD related neuropathological scores of Mumbai and New York samples obtained from Purohit et al (2011) study in (Table 3). Overall summary of these neuropathological scores shows that AD related neuropathological changes in all four elderly populations are almost similar to each other and suggests that income status, in other words, living standard didn't cause any vital difference in $\mathrm{AD}$ occurrence.

Various clinical and epidemiological studies have highlighted the functional consequences of the phenotype-genotype relationship of gene apolipoprotein $E(A p o E)$ and its affiliation with diverse pathological conditions and cognitive traits (Corder et al., 1993; Schachter et al., 1994; Mahley,1988). ApoE $\varepsilon 4$ allele is the strongest genetic risk factor for $\mathrm{AD}$ and $\mathrm{VaD}$ and its frequency in Colombo elderly samples is 0.146. In addition to ApoE, methylenetetrahydrofolate reductase (MTHFR) $T$ allele has also been discussed in AD (Seshadri et al., 2002), PD (Yasui et al., 2000) and other dementias (Frosst et al., 1995) and its frequency in elderly Colombo samples is 0.062 , whereas in previous Sri Lankan populationbased study, it was 0.049 (Scheinder et al., 1998). Although we didn't carry out a simultaneous genotyping in elderly Bangalore samples, according to the community / population-based findings from India, frequency of $A p o E \varepsilon 4$ allele is 0.101 (Mastana et al., 1998), 0.073 (Thelma et al., 2001) and $0.068 \pm 0.030$ (Singh et al., 2006), and frequency of MTHFR T allele is 0.18 (Mukherjee et al., 2002); 0.10 (Devi et al., 2004) and 0.03 (Saraswathy et al., 2008). Overall allelic frequencies in Sri Lankan and Indian community / population based genetic studies are comparable to each other; however, frequency of $A p o E \varepsilon 4$ allele seems to be high in Colombo samples [0.146 vs. $0.068 \pm 0.030$ (Singh et al., 2006)].

On the other hand, observational studies suggest that lower risk of dementia in some developing countries can be attributed to the type of diet (Luchsinger et al., 2007). Accumulating evidence is highlighting that oxidative stress via generating free radicals plays a pivotal role in neurodegenerative diseases and that can be reduced by diets that are rich in antioxidants such as fruits, vegetables and tea (Martin et al., 2002; Mandel and Youdim, 2004; Rezai-Zadeh et al., 2008; Okello et al., 2004). Tea is the major beverage in Sri Lanka and the total content of antioxidants in both green tea $(190.0 \mathrm{mg} / \mathrm{g})$ and black tea $(186.6 \mathrm{mg} / \mathrm{g})$ are highest in Sri Lankan products compared to other manufacturers of the different countries (Yashin et al., 2011). India and Sri Lanka are the 
two largest black tea exporters in the world and their annual per capita tea consumption is 0.64-0.66Kg and 0.9-1.29Kg (Pandy and Chadha, 1993; Hall, 2000), respectively. In our study, tau positive pathologies are more frequently detected in the brains of elders [74.68\% (59/79)], considering that amyloid plaques are comparatively low [26.58\% (21/79)]. However, between elderly samples, Bangalore brains show more amyloid plaques than the brains obtained from Colombo (Figure 4). In summary, these findings open a biologic means to investigate in-depth scientific and large-scale observational studies in relation to neuroprotective role of tea in future.

Age is by far the largest factor for these diseases, how- ever, besides age, regional variations including genes, environment, infectious agent, chemicals, neurotoxins, diet, vascular disease and its risk factors, and the gene-environment interactions are all suggested to be the risk factors in dementia occurrence (WHO, 2012; Ferri et al., 2005). Therefore, differences observed in Colombo samples including pathologies associated with Parkinsonism and cerebrovascular changes need to be investigated in detail with respect to regional variations. Apart from those differences, AD neuropathologic changes are almost equal in both Colombo and Bangalore elderly samples and surprisingly, the neuropathological scores among LMICs and HIC are remarkably similar based on Purohit et al findings (2011).

Neuropathology of the AD extends beyond amyloid plaques and NFTs and the review of various consortia data shows more than $30 \%$ of the AD cases exhibit cerebrovascular pathology (Kalaria and Ballard, 1999). Certain vascular pathologies such as CAA, microvascular degeneration, and periventricular white matter lesions are evident in almost all the cases of $\mathrm{AD}$ and whether these vascular lesions are coincidental or causal in the pathogenetic processes of AD need further studies (Kalaria and Ballard, 1999). Recent NIAAA guidelines (Montine et al., 2011) emphasize a structured approach for the diagnosis of co-morbid pathologies in addition to AD neuropathologic change. However, in our study, we reported the co-morbid pathologies as present or absent (Table 5) with their strength of association. The presence of white matter lesion- leukoaraiosis is significantly associated with $\mathrm{AD}$ and other neurodegenerative pathologies and shown in the (Table 5). Similar findings have been discussed in previous studies, where more than half of the AD cases exhibit diffuse / non-focal white matter lesions, with the loss of myelin-stained fibres not proportional to the expected level due to cortical neuronal degeneration ( Brun and Englund, 1986; England, 1998). In addition to leukoaraiosis, CAA is also associated with $\mathrm{AD}$ and the progression of $\mathrm{AD}$ pathology is positively correlated with CAA severity (Chalmers et al., 2003; Love et al., 2003). In our study, samples with AD neuropathologic change for intermediate and high level presented CAA grades 2 and 3 respectively ( $\mathrm{p}=0.003$, Kendall's tau b correlation coefficient $(\tau)=0.654)$. The presence of CAA also showed a significant association with leukoaraiosis $(\tau=0.324)$. Leukoaraiosis is increasingly recognized as a feature of sporadic CAA (Hancu et al., 2009). Amyloid deposits are found in more proximal portions of the small penetrating arteries and the contribution of amyloid deposits alone without downstream arteriosclerosis are not clear in the pathogenesis of leukoaraiosis. However, leukoaraiosis found in some of the genetic amyloid angiopathies suggest that amyloid angiopathy alone is sufficient to cause this feature (Greenberg and Vonsattel, 1997; Hancu et al., 2009). Besides the associations with AD and CAA, the presence of leukoaraiosis also showed a significant association with Lewy body pathology and this is opposing to Zijlmans et al (2004) findings where, in the absence of Lewy bodies, involvement of microscopic small vessel diseases was significantly demonstrated for the aetiology of vascular Parkinsonism. Another co-morbid pathology 
noted in these elderly brains is hippo- campus cell loss in DG and CA1 regions and are considerably higher in Colombo samples (51\% and 53\% vs. $14 \%$ and $17 \%$ ). The CA1 region of the hippocampus is vulnerable to both $\mathrm{AD}$ type neurofibrillary degeneration and anoxia-ischemia and is more consistent in $\mathrm{AD}$ than in ischemic vascular dementia (Zarow et al., 2005). In our study, a higher degree of association between CA1 cell loss and Braak NFT stages III-VI $(p=0.036)$ and between CA1 cell loss and spongiform changes of neuropil $(\mathrm{p}=0.005)$ were observed with positive correlations (Table 5). Later one is opposed to the study of Masullo and Macchi (1997) where they demonstrated the resistance of hippocampus, particularly, pyramidal cell layer of CA1 in Creutzfeldt-Jakob disease, group of subacute spongiform encephalopathies of animals and man. On the other hand, cell loss in DG region (almost similar percentage to CA1 cell loss) was neither related AD related pathologies nor cerebrovascular pathologies. But it was significantly related to increasing age $(\mathrm{OR}=1.07,95 \% \mathrm{CI}=1.0-1.1)$. These observations are further strengthened by Small et al. (2011) review on pathophysiological framework of hippocampal dysfunction in ageing and disease. The hippocampal formation has been implicated in a growing number of disorders, from AD and cognitive aging to Schizophrenia and depression. They pinpointed that these disorders differentially target distinct sub regions of the hippocampal circuit. AD, vascular disease and ageing all contribute to hippocampal alterations in late life and their direct comparison suggests that entorhinal cortex is differentially associated with AD and the CA1 with vascular disease, whereas ageing process per se seems to differentially target the DG. On the whole, our observations further support the possible pathological pathways for hippocampal dysfunction during aging.

There are some limitations in our study. Sample size is small and represents an elderly community. Therefore, our study did not report the prevalence of AD neuropathologic changes in Sri Lankan and Indian general populations. Incomplete clinical history of the recruited samples lacking objective psychometry and dementia scores, ubiquitin immunohistochemistry for labelling Lewy bodies instead of $\alpha$-synuclein and non-availability of some brain regions as specified under minimum tissue requirements by NIA-AA guidelines are also considered as important limitation factors of this study. As this was a retrospective study, case history was obtained through informants who were familiar with intellectual and functional status of the subjects before death. However, uncertainty in cognitive status of the subjects at the time of tissue removal affects the final diagnosis of AD based on NIA-AA guidelines. For the LBDs, although $\mathrm{H}$ and $\mathrm{E}$ staining may be used to detect Lewy bodies, greater sensitivity can be achieved with $\alpha$-synuclein immunohistochemistry and is recommended as preferred method in the NIA-AA guidelines. In our study, however, in addition to $H \& E$ staining, ubiquitin instead of $\alpha$-synuclein immunohistochemistry was used in labelling Lewy bodies which was recommended in CDLB 1996 guidelines (McKeith et al., 1996). Further, the assessment of some cerebrovascular changes (leukoaraiosis, spongiform changes \& dilated perivascular spaces) and hippocampus cell loss in DG and CA1 regions were based on their presence in fronto temporal cortex regions and in the hippocampus and did not apply any staging or grading system. In fact, due to the high variability of cerebrovascular changes associated with cognitive impairment, no validated neuropathological criteria are currently available for $\mathrm{VaD}$ or mixed dementia (Jellinger, 2013). Finally, in our study, specific brain sections from deceased victims were collected between May 2009 and March 2010. As a result, some of the brain sections, as specified in the NIA-AA guidelines (2012), were not available in this study but will be included in future concerns. 


\subsection{Conclusion}

Between these two elderly Colombo and Bangalore samples, AD neuropathologic changes did not show any significant variations. However, pathologies associated with Parkinsonism (PD and PSP), cerebrovascular changes (spongiform changes and dilated perivascular spaces) and granular cell loss in DG region were more frequently found in elderly Colombo samples. Taken together, in comparison with elderly Indians, elderly Sri Lankans are more vulnerable to aging cytoskeletal pathologies and this might be due to their genetic, dietary, and/or environmental variations.

\subsection{References}

Alafuzoff I, Gelpi E, Al-Sarraj S, Arzberger T, Attems J, Bodi I, et al. The need to unify neuropathological assessments of vascular alterations in the ageing brain: multicenter survey by the BrainNet Europe consortium. Exp Gerontol 47(11): 825-833 (2012).

Alzheimer Disease International. World Alzheimer report 2010: the global economic impact of dementia. London: Alzheimer Disease International (2010).

Bowirrat A, Friedland RP, Korczyn AD. Vascular dememtia among elderly Arabs in Wadi Ara. J Neurol Sci 203-204: 73-76 (2002).

Braak H, Alafuzoff I, Arzberger T, Kretzschmar H, Del Tredici K. Staging of Alzheimer disease -associated neurofibrillary pathology using paraffin sections and immunocytochemistry. Acta Neuropathol 112(4): 389-404 (2006).

Braak H, Bohl JR, Muller CM, Rub U, de Vos RA, Del Tredici K. Stanley Fahn Lecture 2005: The staging procedure for the inclusion body pathology associated with sporadic Parkinson's disease re- considered. Mov Disord 21(12): 2042-2051 (2006).

Braak H, Braak E. Neuropathological stageing of Alzheimer- related changes. Acta Neuropathol 82(4): 239-259 (1991).

Braak H, Del Tredici K, Rub U, de Vos RA, Jansen Steur EN, Braak E. Staging of brain pathology related to sporadic Parkinson's disease. Neurobiol Aging 24(2): 197-211 (2003).

Brun A, Englund E. A white matter disorder in dementia of the Alzheimer type: a pathoanatomical study. Ann Neurol 19(3): 253-262 (1986).

Chalmers K, Wilcock GK, Love S. APOE epsilon 4 influences the pathological phenotype of Alzheimer's disease by favouring cere- brovascular over parenchymal accumulation of Abeta protein. Neuropathol Appl Neurobiol 29(3): 231-238 (2003).

Corder EH, Saunders AM, Strittmatter WJ. Gene dose of apolipoprotein E4 type alleles and the risk of Alzheimer's disease in the late onset families. Science 261(5123): 921-923 (1993).

De Silva HA, Gunathilake SB, Smith AD. Prevalence of dementia in a semi-urban population in Sri Lanka: report from a regional survey. Int J Geriatr Psychiatry18(8): 711-715 (2003).

Devi ARR, Govindaiah V, Ramakrishna G, Naushad SM. Prevalence of methylene 
tetrahydrofolate reductase polymorphism in South Indian population. Current Science 86(3): 440-443 (2004).

Dong MJ, Peng B, Lin XT, Zhao J, Zhou YR, Wang RH. The prevalence of dementia in the People's Republic of China: a systemic analysis of 1980-2004. Age Ageing 36(6): 619-624 (2007).

Englund E. Neuropathology of white matter changes in Alzheimer's disease and vascular dementia. Dement Geriatr Cogn Disord 9(Suppl 1): 6-12 (1998).

Ferri CP, Prince M, Brayne C, Brodaty H, Fratiglioni L, Ganguli M, et al. Alzheimer's Disease International. Global prevalence of dementia: a Delphi consensus study. Lancet 366(9503): 2112-2117 (2005).

Frosst P, Blom HJ, Milos R, Goyette P, Sheppard CA, Matthews RG, et al. A candidate genetic risk factor for vascular disease: a common mutation in methylenetetrahydrofolate reductase. Nat Genet 10(1): 111-113 (1995).

Gorelick PB, Scuteri A, Black SE, Decarli C, Greenberg SM, Ia- decola C et al. Vascular contributions to cognitive impairment and dementia: A statement for healthcare professionals from the American Heart Association/American Stroke Association. Stroke 42(9): 2672-2713 (2011).

Greenberg SM, Vonsattel JP. Diagnosis of cerebral amyloid angiopathy: Sensitivity and specificity of cortical biopsy. Stroke 28(7): 1418-1422 (1997).

Hall N. The tea industry. Cambridge: Woodhead Publishing Ltd. Pp 31, 40 (2000).

Hancu A, Rasanu I, Butoi G. White matter changes in cerebrovas- cular disease: Leukoaraiosis. In: Chaudhary V, Ed. Advances in Brain Imaging. Europe: InTech pp. 249250 (2009).

Jellinger KA. Challenges in the neuropathological diagnosis of dementias. Int J Neuropathol 1: 8-52 (2013).

Jellinger KA. Pathology and pathogenesis of vascular cognitive impairment- a critical update. Front Aging Neurosci 5: 17 (2013).

Jhoo JH, Kim KW, Huh Y, Lee SB, Park JH, Lee JJ et al. Preva- lence of dementia and its subtypes in an elderly urban Korean population: results from the Korean longitudinal study on health and aging (KLoSHA). Dement Geriatr Cogn Disord 26(3): 270-276 (2008).

Jitapunkul S, Kunanusont C, Phoolcharoen W, Suriyawongpaisal P. Prevalence estimation of dementia among Thai elderly: a national survey. J Med Assoc Thai 84(4): 461-467 (2001).

Kalaria RN, Ballard C. Overlap between pathology of Alzheimer disease and vascular dementia. Alzheimer Dis Assoc Disord 13(Suppl 3): S115-123 (1999).

Kalaria RN, Maestre GE, Arizaga R, Friedland RP, Galasko D, Hall K, et al. World 
Federation of Neurology Dementia Research Group. Alzheimer's disease and vascular dementia in developing countries: prevalence, management, and risk factors. Lancet Neurol 7(9): 812-826 (2008).

Kirk RL. "The legend of Prince Vijaya-a study of Sinhalese origins". Am J Phys Anthropol 45: 91 (1976).

Kshatriya GK. Genetic affinities of Sri Lankan populations. Hum Biol 67(6): 843-866 (1995).

Kua EH, Ko SM. Prevalence of dementia among elderly Chinese and Malay residents of Singapore. Int Psychogeriatr 7(3): 439-446 (1995).

Lace G, Savva GM, Forster G, de Silva R, Bravne C, Matthews FE, et al. Hippocampal tau pathology is related to neuroanatomical connections: an ageing population-based study. Brain 132(Pt 5):1324-1334 (2009).

Love S, Nicoll JA, Hughes A, Wilcock GK. APOE and cerebral amyloid angiopathy in the elderly. Neuroreport 14(11): 1535-1536 (2003).

Luchsinger JA, Noble JM, Scarmeas N. Diet and Alzheimer's disease. Curr Neurol Neurosci Rep 7(5): 366-372 (2007).

Mahley RW. Apolipoprotein E: Cholesterol transport protein with expanding role in cell biology. Science 240(4852): 622-630 (1988).

Malavige GN, Rostron T, Seneviratne SL, Fernando S, Sivayogan S, Wijewickrama A, et al. "HLA analysis of Sri Lankan Sinhalese predicts North Indian origin". Int J Immunogenet 34(5): 313-315 (2007).

Mandel S, Youdim MB. Catechin polyphenols: neurodegeneration and neuroprotection in neurodegenerative diseases. Free Radic Biol Med 37(3): 304-317 (2004).

Martin A, Cherubini A, Andres-Lacueva C, Paniagua M, Joseph J. Effects of fruits and vegetables on levels of vitamins $\mathrm{E}$ and $\mathrm{C}$ in the brain and their association with cognitive performance. J Nutr Health Aging 6(6): 392-404 (2002).

Mastana SS, Calderon R, Pena J, Reddy PH, Papiha SS. Apoplipoprotein E (Apo E) gene: low frequency of apo E4 allele in Basques and tribal (Baiga) populations of India. Ann Hum Biol 25(2): 137-143 (1998).

Masullo C and Macchi G. Resistance of the hippocampus in Creutzfeldt-Jacob disease. Clin Neuropathol 16(1): 37-44 (1997).

McKeith IG, Dickson DW, Lowe J, Emre M, O'Brien JT, Feldman H, et al. Diagnosis and management of dementia with Lewy bod- ies: third report of the DLB Consortium. Neurology 65(12): 1863-1872 (2005).

McKeith IG, Galasko D, Kosaka K, Perry EK, Dickson DW, Han- sen LA et al. Consensus guidelines for the clinical and pathologic diagnosis of dementia with Lewy bodies (DLB): 
report of the consortium on DLB international workshop. Neurology 47(5): 1113-1124 (1996).

Mirra SS, Heyman A, McKeel D, Sumi SM, Crain BJ, Brownlee LM, et al. The Consortium to Establish a Registry for Alzheimer's Disease (CERAD). Part II. Standardization of the neuropathologic assessment of Alzheimer's disease. Neurology 41(4): 479-486 (1991).

Montine TJ, Phelps CH, Beach TG, Bigio EH, Cairns NJ, Dickson DW,et al. NationaNational Institute on Aging-Alzheimer's Asso- ciation guidelines for the neuropathological assessment of Alzheimer's disease: practical approach. Acta Neuropathol 123(1): 1-11 (2012).

Mukherjee M, Joshi S, Bagadi S, Dalvi M, Rao A, Shetty KR. A low prevalence of the C677T mutation in the methylenetetrahydrofolate reductase gene in Asian Indians. Clin Genet 61(2): 155-159 (2002).

Nagy Z, Yilmazer-Hanke DM, Braak H, Braak E, Schultz C, Hanke J. Assessment of the pathological stages of Alzheimer's dis- ease in thin paraffin sections: a comparative study. Dement Geriatr Cogn Disord 9(3): 140-144 (1998).

Okamura H, Ishii S, Ishii T, Eboshida A. Prevelence of dementia in Japan: a systematic review. Dement Geriatr Cogn Disrod 36(1-2):111-118 (2013).

Okello EJ, Savelev SU, Perry EK. In vitro anti-beta-secretase and dual anti-cholinesterase activities of Camellia sinensis L. (tea) rele- vant to treatment of dementia. Phytother Res 18(8): 624-627 (2004).

Palmer K, Kabir ZN, Ahmed T, Hamadani JD, Cornelius C, Kivipelto M, et al. Prevalence of dementia and factors associated with dementia in rural Bangladesh: data from a crosssectional, population - based study. Int Psychogeriatr 26(11): 1905-1915 (2014).

Prince M, Bryce R, Albanese E, Wimo A, Ribeiro W, Ferri CP. The global prevalence of dementia: a systematic review and meta analysis. Alzheimer's Dement 9(1): 63-75 (2013).

Pandy SN, Chadha A. A text book of botany: Plant anatomy and economic botany, volume 3. New Delhi: VIKAS Publishing House Pvt Ltd. pp 210-212 (1993).

Papiha SS, Mastana SS, Purandare CA, Jayasekara R, Chakraborty R. Population genetic study of three VNTR loci (D2S44, D7S22, and D12S11) in five ethnically defined populations of the Indian subcontinent. Hum Biol 68(5): 819-835 (1996).

Polvikoski T, Sulkava R, Myllykangas L, Notkola IL, Niinistö L, Verkkoniemi A, et al. Prevalence of Alzheimer's disease in very elderly people: a prospective neuropathological study. Neurology 56(12): 1690-1696 (2001).

Purohit DP, Batheja NO, Sano M, Jashnani KD, Kalaria RN, Karunamurthy A, et al. Profiles of Alzheimer's disease-related pa- thology in an aging urban population sample in India. J Alzheimers Dis 24(1): 187-196 (2011). 
Ranaweera L, Kaewsutthi S, Win Tun A, Boonyarit H, Poolsuwan S, Lertrit P. Mitochodrial DNA history of Sri Lankan ethnic people: their relations within the island and with the Indian sub continental populations. J Hum Genet 59(1): 28-36 (2014).

Rezai-Zadeh K, Arendash GW, Hou H, Fernandez F, Jensen M, Runfeldt M, et al. Green tea epigallocatechin-3-gallate (EGCG) reduces beta-amyloid mediated cognitive impairment and modulates tau pathology in Alzheimer transgenic mice. Brain Res 1214: 177-187 (2008).

Saha N. Blood genetic markers in Sri Lankan populations reappraisal of the legend of Prince Vijaya. Am J Phys Anthropol 76(2): 217-225 (1988).

Saraswathy KN, Mukhopadhyay R, Sinha E, Aggarwal S, Sachdeva MP, Kalla AK. MTHFR C677T polymorphisms among the Ahirs and Jats of Haryana (India). Am J Hum Biol 20(1): 116-117 (2008).

Schachter F, Faure-Delanf L, Guenet F. Genetic association with human longevity at ApoE and ACE loci. Nat Genet 6(1): 29-32 (1994).

Scheinder JA, Rees DC, Liu YT, Clegg JB. World wide distribution of a common methylenetetrahydrofolate reductase mutation. Am J Hum Genet 62(5): 1258-1260 (1998).

Seshadri S, Beiser A, Selhub J, Jacques PF, Rosenberg IH, D'Aqostino RB, et al. Plasma homocysteine as a risk factor for dementia and Alzheimer's disease. N Engl J Med 346(7): 476-483 (2002).

Singh PP, Singh M, Mastana SS. APOE distribution in world popu- lations with new data from India and the UK. Ann Hum Biol 33(3):279-308 (2006).

Small SA, Schobel SA, Buxton RB, Witter MP, Barnes CA. A pathophysiological frame work of hippocampal dysfunction in age- ing and disease. Nat Rev Neurosci 12(10): 585-601 (2011).

Thal DR, Rub U, Orantes M, Braak H. Phase of A beta-deposition in the human brain and its relevance for the development of AD. Neurology 58(12): 1791-1800 (2002).

Thelma BK, Juyal RC, Dodge HH, Pandav R, Chandra V, Ganguli M. APOE polymorphism in a rural older population-based sample in India. Hum Biol 73(1): 135-144 (2001).

World Health Organization. Dementia: A public health priority. Geneva: World Health Organization (2012).

World Health Organization. World Health Statistics 2013. Geneva: World Health Organization Press, (2013).

World Population Prospects: The 2012 Revision, DVD Edition. United Nations, Department of Economic and Social Affairs, Population Division (2013).

Yasha TC, Shankar L, Santosh V, Das S, Shankar SK. Histopathological and immunohistochemical evaluation of ageing changes in normal human brain. Indian J Med Res 
105: 141-150 (1997).

Yashin A, Yashin Y, Nemzer B. Determination of antioxidant activity in tea extracts, and their total antioxidant content. Am J Biomed Sci 3(4): 322-335 (2011).

Yasui K, Kowa H, Nakaso K, Takeshima T, Nakashima K. Plasma homocysteine and MTHFR C677T genotype in levodopa treated patients with PD. Neurology 55(3): 437-440 (2000).

Zarow C, Vinters HV, Ellis WG, Weiner MW, Mungas D, White L, et al. Correlates of hippocampal neuron number in Alzheimer's disease and ischemic vascular dementia. Ann Neurol 57(6): 896-903 (2005).

Zijlmans JC, Daniel SE, Hughes AJ, Revesz T, Lees AJ. Clinicopathological investigation of vascular parkinsonism, including clini- cal criteria for diagnosis. Mov Disord 19(6): 630-640 (2004). 


\section{CHAPTER 3}

Vascular contributions in Alzheimer's disease related neuropathological changes: First autopsy evidence from a South Asian ageing population

Printha Wijesinghe, S.K. Shankar, T.C. Yasha, Catherine Gorrie, Dhammika Amaratunga, Sanjayah Hulathduwa, K. Sunil Kumara, Kamani Samarasinghe, Yoo-Hun Suh, Harry W.M. Steinbusch and K. Ranil D. De Silva

Journal of Alzheimer's Disease, 2016;54(4):1607-1618 doi:10.3233/JAD-160425 


\begin{abstract}
Background: Evidence from various consortia on vascular contributions has been inconsistent in determining the etiology of sporadic Alzheimer's disease (AD).

Objective: To investigate vascular risk factors and cerebrovascular pathologies associated in manifestation of $\mathrm{AD}$ related neuropathological changes of an elderly population.

Methods: Postmortem brain samples from 76 elderly subjects ( $\geq 50$ years) were used to study genetic polymorphisms, intracranial atherosclerosis of the circle of Willis (IASCW), and microscopic infarcts in deep white matters. From this cohort 50 brains ( $\geq 60$ years) were subjected to neuropathological diagnosis using immunohistopathological techniques.

Results: Besides the association with age, the apolipoprotein $E \& 4$ allele was significantly and strongly associated with Thal amyloid- $\beta$ phases $\geq 1$ [odds ratio $(\mathrm{OR})=6 \cdot 76,95 \%$ confidence interval (CI) 1.37 to 33.45 ] and inversely with Braak neurofibrillary tangle (NFT) stages $\geq$ III $(0 \cdot 02,0 \cdot 0$ to $0 \cdot 47)$. Illiterates showed a significant positive association for Braak NFT stages $\geq \mathrm{IV}(14.62,1.21$ to 176.73$)$ and a significant negative association for microscopic infarcts $(0 \cdot 15,0.03$ to 0.71$)$ in deep white matters. With respect to cerebrovascular pathologies, cerebral small vessel lesions (white matter hyperintensities and cerebral amyloid angiopathy) showed a higher degree of associations among them and, with AD related neuropathological changes $(p<0 \cdot 05)$ compared to large vessel pathology (IASCW) which showed a significant association only with Braak NFT stages $\geq \mathrm{I}(p=0 \cdot 050)$.

Conclusion: These findings suggest that besides age, education and genetic factors, other vascular risk factors were not associated with $\mathrm{AD}$ related neuropathological changes and urge prompt actions be taken against cerebral small vessel diseases as evidence for effective prevention is still lacking.
\end{abstract}

Keywords: Alzheimer's disease, Neuropathology, Apolipoprotein E, Atherosclerosis, Cerebral small vessel diseases

\title{
3.1 Introduction
}

Vascular-derived insults might initiate and/or contribute to neuronal degenerations (Zlokovic, 2011). Of note, midlife hypertension, diabetes mellitus, apolipoprotein $\mathrm{E}(A P O E) \varepsilon 4$ isoforms, hypercholesterolemia, homocysteinemia, smoking, obesity, and of course, age are vascular risk factors that predispose individuals to Alzheimer's disease (AD) (O'Brien and Markus, 2014; Reitz et al., 2011; de Bruijn and Ikram, 2014; Gorelick et al., 2011); however, interaction between vascular factors and amyloidosis or tauopathy still remains unresolved (Reitz et al., 2011; Attems and Jellinger, 2014). Neuropathological examinations reveal that most cases of AD have mixed vascular pathology and small-vessel disease (Attems and Jellinger, 2014; Kalaria and Ballard, 1999). In addition, brain hypoperfusion / hypoxia, silent infarcts, the presence of one or more infarcts, stroke episodes and transient ischemic or hypoxic attacks all increase the risk of AD (Ruitenberg et al., 2005; Vermeer et al., 2003; Snowdon et al., 1997); however, underlying mechanism in the pathogenetic processes of $\mathrm{AD}$ remains unclear. Cerebral hypoperfusion theory is one of the major theories in determining the aetiology of sporadic $\mathrm{AD}$ and intracranial atherosclerosis of the circle of Willis (IASCW) has been associated with $\mathrm{AD}$ via mechanical obstruction and reduction in cerebral arterial inflow; caused by atherosclerotic lesions (Roher et al., 2011; Roher et al., 2003; Beach et al., 2007; Yarchoan et al., 2012). However, inconsistencies exist in other investigations (Luoto et al., 2009; Dolan et al., 2010; Bangen et al., 2015) and the recent hypoperfusion studies developed via postmortem biochemical methods indicate that the main cause for $\mathrm{AD}$ is probably via non-structural 
vascular dysfunctions influenced strongly by $\beta$-amyloid $(\mathrm{A} \beta)$ rather than structural pathology (Love and Miners, 2015; Barker et al., 2014).

Asians, represent approximately $60 \%$ of the total world population (World Population Prospects, 2015) are identified as high-risk populations as several modifiable vascular risk factors such as intracranial atherosclerosis (Lee et al., 2006), hypertension (Kearney et al., 2005), diabetes (Chan et al., 2009) and metabolic syndrome (Misra and Khurana, 2009) are being increasingly recognized and may contribute to increased incidence of dementia in addition to their genetic predispositions i.e., risk and protective effect of $A P O E \varepsilon 4$ and $\varepsilon 2$ allelic frequencies respectively (Verghese et al., 2011; Farrer et al., 1997). Within Asia, South Asia represents more than $40 \%$ of the total Asian and one-fourth $(24.8 \%)$ of the total world population (World Population Prospects, 2015). To the best of our knowledge, this is being the first brain autopsy study undertaken in South Asia that was intended to explore the vascular risk factors and cerebrovascular pathologies associated with AD related neuropathological changes as identification of such factors and pathologies may offer new insights into diagnosis and/or early intervention in these populations.

\subsection{Materials and Methods}

\subsubsection{Sample collection}

Consecutive human brain samples were obtained at postmortem examination from 76 older people between May 2009 and March 2010, in the Department of Judicial Medical Office, Colombo South Teaching Hospital. Ethics approval was obtained from the Institutional Scientific Ethics Committee to carry out the study, and informed consent was obtained from the kin to utilize the material for research. The age range was 50-89 years, mean age \pm S.D was $67 \cdot 3 \pm 10$ years, median age was $65 \cdot 5$ years, the male: female ratio was $52: 24$ and the mean postmortem interval \pm S.D was $17 \cdot 3 \pm 14 \cdot 2$ hours. Recruited cases represented a semi urban population and the final autopsy diagnosis of these subjects included cardiovascular diseases (45), coronary obstructive airway disease (2), suicide (6), accident (7), pneumonia (3), asphyxia (1), cancer (2), cirrhosis of the liver (1), septicemia / septic shock (3), protracted complicated illness (2) and unknown causes (4). As the samples were collected at postmortem, detailed psychometric evaluation couldn't be possible, but the pathomorphological features were noted. An ante-mortem questionnaire was given to kin who were familiar with intellectual and motor functional status of the subjects before death. The purpose of this questionnaire was to obtain information on demographic data, past medical history, family history, health habits and consumption pattern of the deceased. This information was held strictly confidential. All the recruited cases had incomplete clinical history except three cases which were clinically diagnosed as Parkinson's disease (PD). Specific neuroanatomical regions were sampled for paraffin embedding and sectioning from both hemispheres: hippocampus along with parahippocampal gyrus, superior frontal gyrus, middle temporal gyrus, superior parietal lobule, midbrain at superior colliculus level and deep white matters from corpus callosum- major interhemispheric white matter tract. Circle of Willis (CW) and cadaver blood / clotted blood were also collected at autopsy for the subsequent atherosclerotic and genetic polymorphism studies, respectively.

\subsubsection{Screening for neurodegenerative pathologies using histopathological / immunohistochemical techniques}

For this purpose, brain samples from 50 out of 76 elderly subjects aged $\geq 60$ years (mean age $72 \cdot 1$ year $\pm 7 \cdot 8$, mean \pm S.D., male: female $=29: 21$ ) were used. In the total of 59 cases at the age of $\geq 60$ years, there were 9 cases with incomplete case histories and unavailability of some 
specific neuroanatomical regions were excluded from this screening. Following routine histological evaluation [Hematoxylin and Eosin (H\&E) staining], brain sections ( $4 \mu \mathrm{m}$ thick) were immunostained by standard immunoperoxidase technique following antigen retrieval by heat and $\mathrm{DAB} / \mathrm{H}_{2} \mathrm{O}_{2}$ as the chromogen to visualize the immunolabelling (DAKO Envision Detection System). For this screening, following three antibodies namely (i) $\beta$ amyloidmonoclonal antibody (1:200 dilution) from Novacastra ${ }^{\mathrm{TM}}$, (ii) ubiquitin- monoclonal antibody (1:150 dilution) from Novacastra ${ }^{\mathrm{TM}}$ and (iii) phosphorylated tau- $\mathrm{PHF}-1$ monoclonal antibody (1:50 dilution, a gift) were used. The diagnostic criteria for AD neuropathologic change and Lewy body diseases (LBDs) were based on National Institute on Aging-Alzheimer's Association guidelines- a practical approach (NIA-AA) (Montine et al., 2012). Phosphorylated tau and $A \beta$ positive pathologies were graded semi quantitatively as given below.

1) Semi-quantitative 0-3 scale (0- none, +- low, ++- moderate, +++- high) for tau positive neurons (neurons demonstrating tangle and pre-tangle pathology), neuritic plaques (NPs) and neuropil threads (NTs).

2) Semi-quantitative 0-3 scale (0- none, + - sparse, ++- moderate, +++- frequent) for $\mathrm{A} \beta$ positive senile plaques (SPs- dystrophic neurites and an amyloid core) and diffuse plaques (DPs).

Actual burden of AD related neuropathological changes [neurofibrillary tangles (NFTs) and SPs] were counted in specific brain regions such as hippocampus and parahippocampus, superior frontal gyrus and midbrain based on the methods described by Purohit and colleagues (Purohit et al., 2011).

Due to the high variability of morphological findings and multifactorial pathogenesis of vascular cognitive impairment (VCI) / vascular dementia (VaD), no generally accepted morphologic scheme for quantitating vascular brain injury and no validated neuropathological criteria for $\mathrm{VaD}$ have been established to date (Jellinger, 2013; Alafuzoff et al., 2012). On the whole, the basis of $\mathrm{VaD}$ diagnosis is simply the presence of brain lesions related to vascular pathology and it highly depends on neuropathologist's judgment. IASCW was assessed macroscopically based on degree of stenosis of each CW component artery (World Health Organ Tech Rep Ser, 1958) and gross visual inspection and it was graded semi quantitatively into four levels: none, mild, moderate and severe. Cerebral amyloid angiopathy (CAA) in leptomeningeal and cortical arteries of the specific neuroanatomical regions was graded semi quantitatively based on Greenberg and Vonsattel (Greenberg and Vonsattel, 1997) specifications and the average CAA grade was reported for each case. To assess the microscopic infarcts, deep white matter sections $(7 \mu \mathrm{m}$ thick) from both hemispheres were stained with Luxol Fast Blue (LFB) and Cresyl violet, and graded semi quantitatively as absent (none or mild) or present (considerable extent at least in one hemisphere). Extent of white matter hyperintensities (WMHs) stained with LFB and Eosin, and dilated perivascular spaces stained with $H \& E$ were identified in the regions of hippocampus and parahippocampus, middle temporal gyrus and superior frontal gyrus and reported semi quantitatively as absent (none / rare) or present (minimum involvement at least in one region). Hippocampal cell loss in cornu ammonis area 1 (CA1) and dentate gyrus (DG) regions were also assessed semi quantitatively as absent (none / rare) or present.

Finally, all elderly subjects were screened for polymorphisms in genes encoding for ApoE, angiotensin converting enzyme (ACE) and methylenetetrahydrofolate reductase (MTHFR C677T) based on standard protocols using polymerized chain reaction-based restriction fragment length polymorphism with cadaver blood DNAs. 


\subsubsection{Statistical Analysis}

For this purpose, statistical software SPSS version 16.0 was used. Due to the small number of samples, each dependent variable was individually tested for each independent variable/ factor, controlling for age and sex. Binary logistic regression was used to find the odds ratio (OR) for each factor with a 95\% confidence interval (CI). For this purpose, dependent variables were dichotomized primarily based on number of cases that have presented it and then by its severity / topographical progression.

I. CERAD (Consortium to Establish a Registry for Alzheimer's disease) NP scores were divided into none vs. CERAD scores $\mathrm{A}$ to $\mathrm{C}$ (presence of tau positive NPs) as few numbers of cases presented it $(6 / 50)$,

II. Thal $\mathrm{A} \beta$ phases were divided into none vs. phases $\geq 1(12 / 50)$, and phases $\leq 1$ vs. phases $\geq 2$ $(8 / 50)$ as few numbers of cases presented it (12/50) and the neocortical $A \beta$ plaques are considered as the best correlate for cognitive impairment in $\mathrm{AD}$,

III. Braak staging was divided into none vs. stages I-VI (42/50, presence of tau positive neurofibrillary pathology), stages 0 -II (32/50, none to low) vs. stages III-VI (18/50, moderate to severe) and stages 0 -III (43/50, none to moderate) vs. stages IV-VI (7/50, moderate to severe) as it was detected more frequently than tau and $A \beta$ positive plaques, and based on its topographical progression.

Factors including, age, sex, vascular genetic risk factors (ApoE, ACE and MTHFR), physiological factors (diabetes, high blood pressure or hypertension, high cholesterol, ischemic heart disease and stroke) and life style factors (level of education, smoking and alcohol consumption) were tested in this analysis. Hierarchical multiple regression adjusted for age and sex was used to find the relationship between continuous dependent variables (mean NFTs counts, total SPs counts, total CAA score and total stenosis score) and dichotomized factors (i.e.: presence of $A p o E \varepsilon 4$ allele vs. ApoE $\varepsilon 3$ and $\varepsilon 2$ alleles, presence of MTHFR CT/TT genotype vs. $C C$ genotype, etc.). Degree of association between AD related neuropathological stages and cerebrovascular pathologies were assessed using Fisher's exact test (2X2 contingency table) and Kendall's tau b correlation coefficient as the sample size is small and the variables are categorical.

\subsection{Results}

Our study consisted of 76 elderly brains aged between 50 and 89 years (mean age $67 \cdot 3$ years \pm 10.0; male: female $=52: 24$ ) and out of that, 50 elderly brains aged $\geq 60$ years were used for neuropathological diagnosis. As per NIA-AA (Montine et al., 2012) guidelines, in the cases with incomplete clinical history (47 cases out of 50), AD neuropathologic change for intermediate level was $4 \cdot 25 \%(2 / 47)$ and low level was $19 \cdot 15 \%(9 / 47)$. Parkinsonism associated pathologies were identified in $8.51 \%(4 / 47)$ of the cases: brainstem predominant Lewy bodies (LBs), hallmarks of PD at 6.38\% (3/47) and probable progressive supra nuclear palsy (PSP) at $2 \cdot 13 \%(1 / 47)$. Since, the lack of high specificity / high correlation among the studied cerebrovascular pathologies and the non-availability of validated criteria for neuropathological diagnosis of $\mathrm{VaD}$, we could not identify any cases confined to $\mathrm{VaD}$. Within the clinically diagnosed cases ( 3 cases out of 50), case one presented mixed dementia pathologies including definite PSP, intermediate AD neuropathologic change and brainstem predominant LBs; case two presented vascular Parkinsonism due to ischemic stroke; and the case three presented idiopathic PD at Braak stage III.

Population demographics including allelic frequency of ApoE, ACE and MTHFR C677T genes, AD related neuropathological changes and comorbid pathologies are summarized in Table 1. 


\begin{tabular}{|c|c|c|}
\hline & & Percentage (\%) \\
\hline \multirow{7}{*}{$\begin{array}{l}\text { Allelic frequency } \\
(\mathrm{n}=72 ; \\
\text { missing cases }-04)\end{array}$} & $A p o E \varepsilon 3$ allele & $79 \cdot 86(115 / 144)$ \\
\hline & ApoE $\& 4$ allele & $14 \cdot 58(21 / 144)$ \\
\hline & ApoE $\varepsilon 2$ allele & $5 \cdot 55(8 / 144)$ \\
\hline & $A C E D$ allele & $52 \cdot 08(75 / 144)$ \\
\hline & $A C E I$ allele & $47 \cdot 91(69 / 144)$ \\
\hline & $M T H F R$ C allele & $93 \cdot 75(135 / 144)$ \\
\hline & $M T H F R T$ allele & $6 \cdot 25(9 / 144)$ \\
\hline \multirow{6}{*}{$\begin{array}{l}\text { AD related neuropathological } \\
\text { changes } \\
(n=50)\end{array}$} & Braak NFT stages I-VI & $84 \cdot 0(42 / 50)$ \\
\hline & Braak NFT stages III-VI & $36 \cdot 0(18 / 50)$ \\
\hline & Braak NFT stages IV-VI & $14 \cdot 0(7 / 50)$ \\
\hline & Thal $A \beta$ phases $\geq 1$ & $24 \cdot 0(12 / 50)$ \\
\hline & Thal $A \beta$ phases $\geq 2$ & $16 \cdot 0(8 / 50)$ \\
\hline & CERAD NP scores A-C & $12 \cdot 0(6 / 50)$ \\
\hline \multirow[t]{2}{*}{ CAA $(n=50)$} & grade 0 & $80 \cdot 0(40 / 50)$ \\
\hline & grades $1-4$ & $20 \cdot 0(10 / 50)$ \\
\hline \multirow[t]{2}{*}{ WMHs $(\mathrm{n}=50)$} & none/rare & $68 \cdot 0(34 / 50)$ \\
\hline & present & $32 \cdot 0(16 / 50)$ \\
\hline \multirow{2}{*}{$\begin{array}{l}\text { Dilated perivascular spaces } \\
(\mathrm{n}=50)\end{array}$} & none/rare & $12 \cdot 0(6 / 50)$ \\
\hline & present & $88 \cdot 0(44 / 50)$ \\
\hline \multirow[t]{2}{*}{ Lewy bodies $(n=50)$} & absent & $90 \cdot 0(45 / 50)$ \\
\hline & present & $10 \cdot 0(5 / 50)$ \\
\hline \multirow{2}{*}{$\begin{array}{l}\text { Hippocampal cell loss in CA1 } \\
\text { region }(n=50)\end{array}$} & none/rare & $48 \cdot 0(24 / 50)$ \\
\hline & present & $52 \cdot 0(26 / 50)$ \\
\hline \multirow{2}{*}{$\begin{array}{l}\text { Hippocampal cell loss in DG } \\
\text { region }(n=50)\end{array}$} & none/rare & $50 \cdot 0(25 / 50)$ \\
\hline & present & $50 \cdot 0(25 / 50)$ \\
\hline \multirow{4}{*}{$\begin{array}{l}\text { IASCW ( } n=73 ; \\
\text { missing cases - 03) }\end{array}$} & no & $9 \cdot 59(7 / 73)$ \\
\hline & mild & $36 \cdot 99(27 / 73)$ \\
\hline & moderate & $36 \cdot 99(27 / 73)$ \\
\hline & severe & $16 \cdot 44(12 / 73)$ \\
\hline \multirow{2}{*}{$\begin{array}{l}\text { Microscopic infarcts } \\
(\mathrm{n}=75 ; \text { missing case }-01)\end{array}$} & none/mild & $32 \cdot 0(24 / 75)$ \\
\hline & present & $68 \cdot 0(51 / 75)$ \\
\hline
\end{tabular}

Table 1. Population demographics on allelic frequency of APOE, ACE and MTHFR C677T genes, Alzheimer's disease related neuropathological changes and comorbid pathologies 
Abbreviations: $\mathrm{n}=$ sample size; $A P O E=$ apolipoprotein $\mathrm{E} ; A C E=$ angiotensin converting enzyme; $M T H F R=$ methylenetetrahydrofolate reductase; $\mathrm{AD}=$ Alzheimer's disease; NFT = neurofibrillary tangles; $A \beta=\beta$-amyloid; CERAD $=$ Consortium to Establish a Registry for Alzheimer's disease; $\mathrm{NP}=$ neuritic plaque; CAA = cerebral amyloid angiopathy; WMHs = white matter hyperintensities; CA1 = cornu ammonis area $1 ; \mathrm{DG}=$ dentate gyrus; IASCW = intracranial atherosclerosis of the circle of Willis.

Factors that have demonstrated considerable associations with AD related neuropathological stages and cerebrovascular pathologies are located in Table 2 (only factors with $p$ values $\leq 0 \cdot 2$ are presented). Age is the strongest risk factor for dementia whether it results from vascular or neurodegenerative origin or both, and in our study, it demonstrated significant associations with Braak NFT stages, CAA, IASCW and hippocampal cell loss in CA1 region. Besides age, illiteracy, ApoE \&4 allele and MTHFR T allele also showed significant associations with tau and/or A $\beta$ positive pathologies. IASCW was significantly and strongly associated with $A P O E$

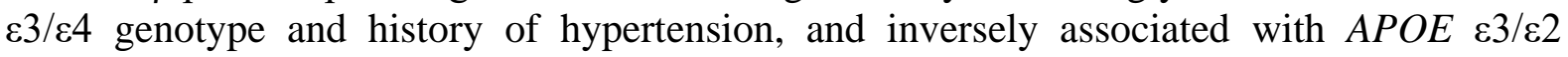
genotype. Increased risk of microscopic infarcts was significantly and strongly associated with history of diabetes and inversely associated with illiteracy. Hierarchical multiple regression analysis did not show any significant associations between factors and mean NFTs counts or total SPs counts in specific neuroanatomical region or in all regions except age and mean NFTs counts $(p<0.000)$. Total stenosis score was significantly and strongly associated with $(p$ $<0.000$ ) history of hypertension, whereas total CAA score was not associated with any factors. 


\begin{tabular}{|c|c|c|c|c|}
\hline Dichotomized variables & Factors & $P$ value & $\begin{array}{l}\text { Odds } \\
\text { Ratio } \\
\end{array}$ & $95 \% \mathrm{CI}$ \\
\hline \multicolumn{5}{|c|}{$A D$ related neuropathological changes $(n=50)$} \\
\hline \multirow[t]{2}{*}{ stage 0 vs. stage I-VI } & age & $0 \cdot 005 *$ & $1 \cdot 30$ & $1 \cdot 08-1 \cdot 57$ \\
\hline & illiteracy & $0 \cdot 184$ & $6 \cdot 45$ & $0 \cdot 41-99 \cdot 93$ \\
\hline \multirow[t]{3}{*}{ stage $0-$ II vs. III-VI } & age & $0 \cdot 001 * *$ & $1 \cdot 22$ & $1 \cdot 08-1 \cdot 37$ \\
\hline & ApoE $\& 4$ allele & $0 \cdot 015^{*}$ & $0 \cdot 02$ & $0 \cdot 00-0 \cdot 47$ \\
\hline & illiteracy & $0 \cdot 166$ & 4.37 & $0 \cdot 54-35 \cdot 14$ \\
\hline \multirow[t]{4}{*}{ stage $0-$ III vs. IV-VI } & age & $0.009 * *$ & $1 \cdot 22$ & $1 \cdot 05-1 \cdot 42$ \\
\hline & illiteracy & $0 \cdot 035^{*}$ & $14 \cdot 62$ & $1 \cdot 21-176 \cdot 73$ \\
\hline & ApoE $\varepsilon 3 / \varepsilon 4$ genotype & $0 \cdot 037^{*}$ & $0 \cdot 05$ & $0 \cdot 00-0 \cdot 83$ \\
\hline & $A C E D D$ genotype & $0 \cdot 160$ & $0 \cdot 14$ & $0 \cdot 01-2 \cdot 15$ \\
\hline \multicolumn{5}{|l|}{ Thal $A \beta$ phases } \\
\hline \multirow[t]{3}{*}{ phase 0 vs. phase $\geq 1$} & ApoE $\& 4$ allele & $0 \cdot 019^{*}$ & $6 \cdot 76$ & $1 \cdot 37-33 \cdot 45$ \\
\hline & sex & 0.063 & 4.90 & $0 \cdot 92-26 \cdot 14$ \\
\hline & hypertension & $0 \cdot 120$ & $0 \cdot 28$ & $0 \cdot 06-1 \cdot 39$ \\
\hline \multirow[t]{2}{*}{ phase 0 vs. phase $\geq 2$} & ApoE $\varepsilon 3 / \varepsilon 4$ genotype & $0 \cdot 038^{*}$ & $7 \cdot 02$ & $1 \cdot 11-44 \cdot 35$ \\
\hline & ApoE $\& 4$ allele & $0 \cdot 034^{*}$ & $6 \cdot 10$ & $1 \cdot 15-32 \cdot 42$ \\
\hline \multicolumn{5}{|l|}{$C A A$ grades $(n=50)$} \\
\hline \multirow[t]{4}{*}{ grade 0 vs. grade $1-4$} & age & $0 \cdot 047 *$ & $1 \cdot 12$ & $1 \cdot 00-1 \cdot 23$ \\
\hline & $M T H F R$ T allele & $0 \cdot 036^{*}$ & $10 \cdot 58$ & $1 \cdot 16-96 \cdot 22$ \\
\hline & $A C E D D$ genotype & $0 \cdot 122$ & $3 \cdot 93$ & $0 \cdot 69-22 \cdot 33$ \\
\hline & hypertension & $0 \cdot 186$ & $0 \cdot 32$ & $0 \cdot 06-1 \cdot 73$ \\
\hline \multicolumn{5}{|l|}{$W M H s(n=50)$} \\
\hline \multirow[t]{2}{*}{ absent vs. present } & age & 0.052 & $1 \cdot 09$ & $1 \cdot 00-1 \cdot 18$ \\
\hline & ApoE $\quad \varepsilon 3 / \varepsilon 4$ genotype & 0.096 & $3 \cdot 87$ & $0 \cdot 79-19 \cdot 03$ \\
\hline \multicolumn{5}{|l|}{$\operatorname{IASCW}(n=76)$} \\
\hline \multirow[t]{2}{*}{ none vs. $\geq$ mild } & age & $0 \cdot 046^{*}$ & $1 \cdot 10$ & $1 \cdot 00-1 \cdot 22$ \\
\hline & ApoE $\varepsilon 3 / \varepsilon 2$ genotype & $0 \cdot 028 *$ & $0 \cdot 03$ & $0 \cdot 00-0.68$ \\
\hline \multirow[t]{5}{*}{$\leq$ mild vs. $\geq$ moderate } & hypertension & $0.000 * *$ & $15 \cdot 06$ & $3 \cdot 27-69 \cdot 31$ \\
\hline & age & $0 \cdot 057$ & $1 \cdot 05$ & $1 \cdot 00-1 \cdot 10$ \\
\hline & diabetes & $0 \cdot 176$ & $2 \cdot 31$ & $0 \cdot 69-7 \cdot 75$ \\
\hline & high cholesterol & $0 \cdot 172$ & $3 \cdot 55$ & $0 \cdot 58-21 \cdot 93$ \\
\hline & Ischemic heart disease & $0 \cdot 190$ & $2 \cdot 25$ & $0 \cdot 70-7 \cdot 58$ \\
\hline \multirow[t]{3}{*}{$\leq$ moderate vs. severe } & ApoE $\varepsilon 3 / \varepsilon 4$ genotype & $0 \cdot 038^{*}$ & $4 \cdot 48$ & $1 \cdot 09-18 \cdot 44$ \\
\hline & hypertension & $0 \cdot 050^{*}$ & $5 \cdot 68$ & $1 \cdot 00-32 \cdot 18$ \\
\hline & $\operatorname{sex}$ & $0 \cdot 143$ & $0 \cdot 39$ & $0 \cdot 11-1 \cdot 38$ \\
\hline \multicolumn{5}{|l|}{ Microscopic infarcts $(n=76)$} \\
\hline \multirow[t]{5}{*}{ none/ mild vs. present } & diabetes & $0 \cdot 028 *$ & $10 \cdot 80$ & $1 \cdot 29-90 \cdot 60$ \\
\hline & illiteracy & $0 \cdot 017 *$ & $0 \cdot 15$ & $0 \cdot 03-0 \cdot 71$ \\
\hline & ischemic heart disease & $0 \cdot 084$ & $3 \cdot 58$ & $0 \cdot 84-15 \cdot 16$ \\
\hline & alcohol consumption & $0 \cdot 109$ & $6 \cdot 24$ & $0 \cdot 66-58 \cdot 65$ \\
\hline & hypertension & $0 \cdot 174$ & $2 \cdot 53$ & $0.66-9 \cdot 62$ \\
\hline
\end{tabular}

Table 2. Factors associated with Alzheimer's disease related neuropathological changes and cerebrovascular pathologies

Factors, which were given the $p$ values $\leq 0 \cdot 2$ are only presented.

Significant levels are at $p^{* *}<0.01$ and $p^{*}<0.05$ controlled for age and sex.

Reference categories: female sex; ApoE $\varepsilon 3 / \varepsilon 3$ genotype; $A p o E \varepsilon 3$ and $\varepsilon 2$ allele; $A C E$ II and ID genotype; MTHFR $C$ allele; history of diabetes- no, history of hypertension- no, history of cholesterol- no, history of ischemic heart disease- no, alcohol consumption- no, educationzprimary.

Abbreviation: $\mathrm{AD}=$ Alzheimer's disease $\mathrm{n}=$ sample size; NFT = neurofibrillary tangle; $\mathrm{A} \beta=$ amyloid- $\beta$; CAA $=$ cerebral amyloid angiopathy; $\mathrm{WMHs}=$ white matter hyperintensities; 
$A P O E=$ apolipoprotein $\mathrm{E} ; M T H F R=$ methylenetetrahydrofolate reductase $; A C E=$ angiotensin converting enzyme; IASCW = intracranial atherosclerosis of the circle of Willis.

Co-morbid cerebrovascular and neurodegenerative pathologies that are commonly detected in the elderly Sri Lankan brains (Figure 1) and the degree of association between AD related neuropathological changes and cerebrovascular pathologies are summarized in Table 3. A higher degree of positive association was observed between AD related neuropathological stages and both the presence of WMHs and CAA. The presence of CAA and WMHs also showed a higher degree of positive association among them. Whereas IASCW was associated only with Braak NFT stages $\geq \mathrm{I}(p=0.050)$. Number of cases that have presented cell loss in DG and CA1 regions of the hippocampus (Table 1) was almost equal but they did not show any significant associations (Fisher's exact test, $p=0 \cdot 77$ ) among them. Hippocampus cell loss in CA1 region was significantly and strongly related to age ( $p=0 \cdot 001$, odds ratio $=1 \cdot 2,95 \%$ confidence interval 1.07 to 1.33 ), whereas cell loss in DG region was not related to any factors. 


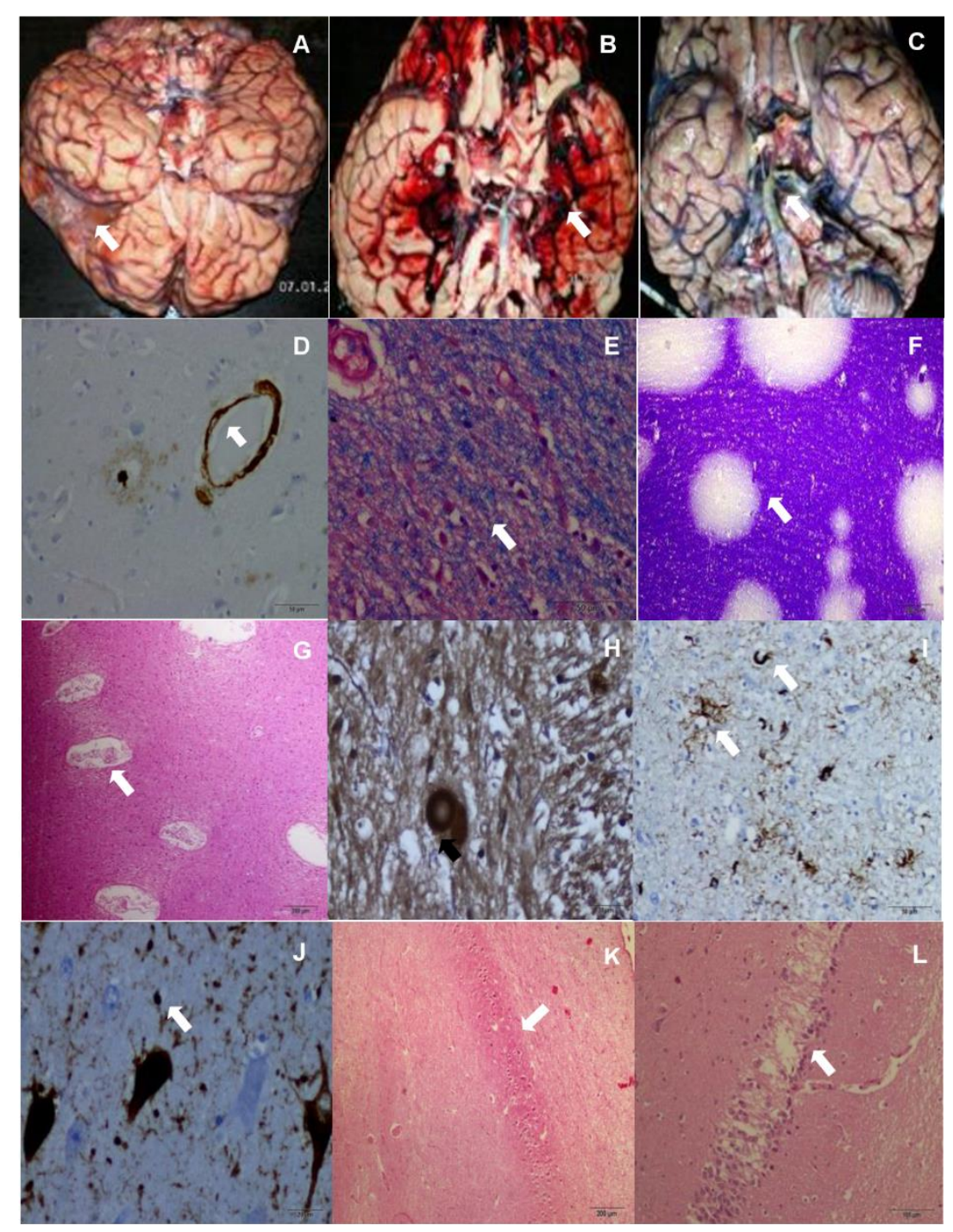

Figure 1. Co-morbid cerebrovascular and neurodegenerative pathologies (indicated by arrows): ischemic stroke attack at the left hemisphere (A), hypertensive intra cerebral haemorrhage (B), severe intracranial atherosclerosis of the circle of Willis (C), amyloid- $\beta$ positive cerebral amyloid angiopathy $(\mathrm{bar}=50 \mu \mathrm{m})(\mathrm{D})$, white matter hyperintensities in superior frontal gyrus with Luzol fast blue (LFB) and Eosin stains (bar $=50 \mu \mathrm{m})$ (E), microscopic infarcts in deep white matters with LFB and Cresyl violet stains $($ bar $=200 \mu \mathrm{m})$ $(F)$, dilated perivascular spaces in superior frontal gyrus $(\mathrm{bar}=200 \mu \mathrm{m})(\mathrm{G})$, ubiquitin positive Lewy bodies in substantia nigra $(\mathrm{bar}=20 \mu \mathrm{m})(\mathrm{H})$, tau positive tufted astrocytes and coiled bodies in midbrain $(\mathrm{bar}=20 \mu \mathrm{m})(\mathrm{I})$, tau positive argyrophilic grains in hipppocampus (bar = $20 \mu \mathrm{m})(\mathrm{J})$ cell loss in hippocampus CA1 region $($ bar $=200 \mu \mathrm{m})(\mathrm{K})$, cell loss in hippocampus dentate gyrus region $(\mathrm{bar}=200 \mu \mathrm{m})(\mathrm{L})(\mathrm{G}, \mathrm{K}$ and $\mathrm{L}$ with $\mathrm{H} \& \mathrm{E}$ staining $)$. 


\begin{tabular}{|c|c|c|c|}
\hline $\begin{array}{c}\text { AD related } \\
\text { neuropathological changes }\end{array}$ & Cerebrovascular pathologies & $\begin{array}{c}P \text { value } \\
\text { (Fisher's exact } \\
\text { test) }\end{array}$ & $\begin{array}{l}\text { Kendall's } \\
\text { tau b } \\
\text { correlation }\end{array}$ \\
\hline Thal $A \beta$ phase $1-5$ & CAA $1-4$ & $0 \cdot 001 * *$ & 0.539 \\
\hline Thal $A \beta$ phase $\geq 2$ &, & $0 \cdot 041^{*}$ & $0 \cdot 327$ \\
\hline CERAD NP score A-C & 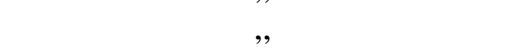 & $0.011 *$ & $0 \cdot 431$ \\
\hline Braak NFT stage IV-VI & 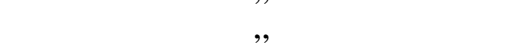 & $0 \cdot 616$ & $0 \cdot 086$ \\
\hline Braak NFT stage III-VI &, & $0 \cdot 138$ & $0 \cdot 250$ \\
\hline Thal $A \beta$ phase $1-5$ & WMHs (present) & $0 \cdot 040 *$ & $0 \cdot 312$ \\
\hline Thal $A \beta$ phase $\geq 2$ &, & $0 \cdot 094$ & $0 \cdot 281$ \\
\hline CERAD NP score $\mathrm{A}-\mathrm{C}$ & 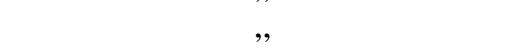 & $0 \cdot 011^{*}$ & $0 \cdot 404$ \\
\hline Braak NFT stage IV-VI & 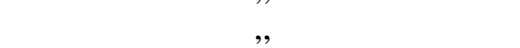 & $0.030 *$ & $0 \cdot 338$ \\
\hline Braak NFT stage III-VI &, & $0 \cdot 009 * *$ & $0 \cdot 407$ \\
\hline Braak NFT stage I-VI &, & $0 \cdot 245$ & $0 \cdot 190$ \\
\hline Thal $A \beta$ phase $\geq 2$ & IASCW $\geq$ mild & $0 \cdot 421$ & $-0 \cdot 118$ \\
\hline Braak NFT stage III-VI &, & $0 \cdot 288$ & $0 \cdot 195$ \\
\hline Braak NFT stage I -VI & , & $0.050 *$ & $0 \cdot 382$ \\
\hline Thal $A \beta$ phase $1-5$ & IASCW $\geq$ moderate & $0 \cdot 316$ & $-0 \cdot 178$ \\
\hline Thal $A \beta$ phase $\geq 2$ &, & $0 \cdot 060$ & $-0 \cdot 287$ \\
\hline CERAD NP score A-C & 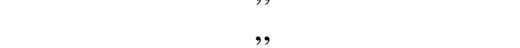 & $0 \cdot 381$ & $-0 \cdot 180$ \\
\hline Braak NFT stage IV-VI & , & 0.683 & $0 \cdot 118$ \\
\hline Braak NFT stage III-VI & 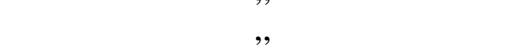 & $0 \cdot 377$ & $0 \cdot 147$ \\
\hline Braak NFT stage I -VI &, & $0 \cdot 443$ & $0 \cdot 118$ \\
\hline Thal $A \beta$ phase $1-5$ & IASCW $\geq$ severe & $0 \cdot 173$ & $-0 \cdot 252$ \\
\hline Thal $A \beta$ phase $\geq 2$ &, & $0 \cdot 322$ & $-0 \cdot 195$ \\
\hline CERAD NP score A-C & 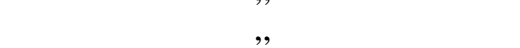 & $0 \cdot 571$ & $-0 \cdot 165$ \\
\hline Braak NFT stage IV-VI & 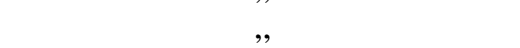 & $0 \cdot 581$ & $-0 \cdot 180$ \\
\hline Braak NFT stage III-VI & 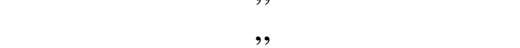 & 0.693 & $-0 \cdot 108$ \\
\hline Braak NFT stage I -VI &, & $0 \cdot 581$ & $0 \cdot 180$ \\
\hline Thal $A \beta$ phase $1-5$ & $\begin{array}{l}\text { microscopic infarcts } \\
\text { (present) }\end{array}$ & $0 \cdot 416$ & $0 \cdot 164$ \\
\hline Braak NFT stage IV-VI &, & 0.616 & $-0 \cdot 086$ \\
\hline Braak NFT stage III-VI & , & $0 \cdot 463$ & $-0 \cdot 146$ \\
\hline Thal $A \beta$ phase $1-5$ & dilated perivascular spaces (present) & $0.024 *$ & $-0 \cdot 369$ \\
\hline Thal $A \beta$ phase $\geq 2$ &, & $0 \cdot 019 *$ & $-0 \cdot 356$ \\
\hline CERAD NP score $\mathrm{A}-\mathrm{C}$ & , & $0 \cdot 146$ & $-0 \cdot 242$ \\
\hline Braak NFT stage I-VI &, & $0 \cdot 242$ & $0 \cdot 175$ \\
\hline CAA $1-4$ & WMHs (present) & $0 \cdot 001 * *$ & $0 \cdot 511$ \\
\hline, & IASCW $\geq$ moderate & $0 \cdot 482$ & $0 \cdot 132$ \\
\hline , & IASCW $\geq$ severe & $0 \cdot 180$ & $-0 \cdot 224$ \\
\hline ", & $\begin{array}{c}\text { microscopic infarcts } \\
\text { (present) }\end{array}$ & $0 \cdot 397$ & $-0 \cdot 125$ \\
\hline , & dilated perivascular spaces (present) & $0 \cdot 327$ & $0 \cdot 185$ \\
\hline
\end{tabular}

Table 3. Degree of association between Alzheimer's disease related neuropathological changes and cerebrovascular pathologies

Significant levels are at $* p \leq 0 \cdot 05$ and at $* * p \leq 0 \cdot 01$. $P$ values equal to 0 and 1.0 are removed from this table.

Correlation strength: very weak $0 \cdot 00-0 \cdot 19$, weak $0 \cdot 20-0 \cdot 39$, moderate $0 \cdot 40-0 \cdot 59$, strong $0 \cdot 60-0 \cdot 79$ and very strong $0 \cdot 80-1 \cdot 00$.

Abbreviations: $\mathrm{AD}=$ Alzheimer's disease; $\mathrm{A} \beta=$ amyloid- $\beta$; CAA $=$ cerebral amyloid angiopathy; CERAD = Consortium to Establish a Registry for Alzheimer's disease; NP = neuritic plaque; NFT = neurofibrillary tangle; $\mathrm{WMHs}=$ white matter hyperintensities; IASCW $=$ intracranial atherosclerosis of the circle of Willis. 


\subsection{Discussion}

This is the first brain autopsy study from a South Asian ageing population that has intended to investigate the vascular risk factors and cerebrovascular pathologies associated with AD related neuropathological changes. It demonstrates that increasing age, APOE $\varepsilon 4$ allele, MTHFR T allele and illiteracy are associated strongly with AD-related tau and/or $\mathrm{A} \beta$ positive pathologies. It also demonstrates that presence of WMHs and CAA could be considered as potential coexistent cerebrovascular lesions underlying cerebral hypoperfusion mechanism in sporadic AD rather than large vessel pathology- IASCW. It is also noted in this study that other vascular risk factors such as hypertension and diabetes are associated with degenerative cerebrovascular pathologies rather than degenerative Alzheimer or Lewy body pathology.

To date, only one clinical study has reported dementia prevalence in elderly Sri Lankans (De Silva et al., 2003), and it was 3.98\% (age $\geq 65$ years) including AD at $2 \cdot 85 \%$, VaD at $0.6 \%$ and the remaining due to other causes. In contrast, our neuropathological findings in elderly Sri Lankans showed a higher prevalence of Parkinsonism associated pathologies $(8 \cdot 51 \%)$ followed by $\mathrm{AD}(4 \cdot 25 \%)$. In low- and middle-income countries (LMICs), dementia prevalence based on clinical diagnosis is often underestimated (Kalaria et al., 2008; Venketasubramanian et al., 2010; De Silva et al., 2009), whereas neuropathological evidences from such populations (Purohit et al., 2011; Wijesinghe et al., 2016) indicate that actual burden of AD- related pathologies are approximately equivalent between LMICs and high-income countries. Therefore, documentation of substantial heterogeneity in dementia prevalence among different counties / ethnicities needs to be investigated on the basis of genetic, environmental and cultural factors, and the preventive approaches in reducing the burden of dementia (Venketasubramanian et al., 2010).

\subsubsection{Contribution of vascular risk factors}

\subsubsection{Genetic factors: $A p o E, A C E$, and MTHFR C677T}

The $\varepsilon 4$ allele of $A p o E$ has been found to be the most consistent risk factor in late-onset AD, notably via $\mathrm{A} \beta$ protein, whereas associations obtained between ApoE $\varepsilon 4$ allele and NFTs are inconsistent (Polvikoski et al., 1995; Warzok et al., 1998; Yip et al., 2005; Morris et al., 2010; Kok et al., 2009). In our study, decedents with 1 or $2 A P O E \varepsilon 4$ allele demonstrated a significant positive association with Thal $A \beta$ phases $\geq 1$ and in contrast, a significant negative association with Braak NFT stages $\geq$ III controlling for age and sex. While former one is in line with worldwide evidence, the later differs from the literature. This finding might be related to ApoE $\varepsilon 4$ allele dispersal among the decedents, which shows an age-associated variation in ApoE $\varepsilon 4$ allele frequency which is presumed to be due to survival effect (Jicha et al., 2008). The majority of the recruited cases died in their 70-s [52\% (26/50)] which reflects the average life expectancy of the Sri Lankans, followed by their 60-s [32\% (16/50)] and 80-s [16\% (8/50)], and therefore a higher number of $A p o E \& 4$ alleles was detected in those aged in their 70-s (6/13), followed by $\geq 60$ year old $(5 / 13)$ and $\geq 80$ year old (2/13). In addition to that, our findings also suggest that there is an age associated increase in risk of NFTs, an ApoE $\varepsilon 4$ allele associated increase in risk of $A \beta$ plaques, and the survival probabilities of $A p o E \varepsilon 4$ allele carriers could possibly be one of the reasons for the discordance between Braak and CERAD scores which have been discussed in population based studies (Geddes et al., 1997; Kazee and Johnson, 1998). Frequency of the ApoE $\varepsilon 4$ allele is an important genetic risk factor for explaining ethnic differences (Verghese et al., 2011) and the $\varepsilon 4$ allele frequency seems to be higher in elderly Sri Lankans compared to the general frequency in Asians (14.6 vs. 9.0\%) (Singh et al., 2006). Therefore, ApoE genotypes and their survival probabilities in different ethnic populations could 
possibly be a one of reasons for the differences observed in $\mathrm{AD}$ prevalence and needs to be confirmed through large scale pathogenetic studies, across a large range of ethnicities.

Elderly subjects with $A p o E \varepsilon 3 / \varepsilon 4$ genotype also demonstrate a strong association with severe IASCW as opposed to $A p o E \varepsilon 3 / \varepsilon 2$ genotype, which showed a protective effect against the presence of IASCW (Anuurad et al., 2006). In addition to ApoE, we also noted a significant association between MTHFR $T$ allele and sporadic CAA. Plasma total homocysteine has considered as a major vascular risk factor (O'Brien et al., 2014) and MTHFR is the central enzyme involved in homocysteine metabolism particularly $T T$ genotype or $T$ allele is associated with high homocysteine levels. Hyperhomocysteinemia is suggested to increase intima-media thickness which in turn damages the micro-vasculature, leading to neuronal damage or death (Gorgone et al., 2009). However, MTHFR polymorphism (C677T) as a risk factor for CAA remains unclear and needs further studies in the future that may offer new therapeutic implications e.g., folic acid supplementation. Effects obtained with ACE polymorphisms were not statistically significant either for AD-related changes or cerebrovascular pathologies.

\subsubsection{Physiological factors: Diabetes and hypertension}

We obtained strong association between history of hypertension and moderate and severe IASCW, and between history of diabetes and microscopic infarcts in deep white matter. However, associations obtained for AD-related neuropathological changes were not statistically significant. Our findings are in line with previous studies (Arvanitakis et al., 2006; Chui et al., 2012) and suggest that metabolic dysfunctions (diabetes and hypertension) could contribute to dementia via vascular degenerations rather than AD-related changes.

\subsubsection{Lifestyle factors: Education, smoking and alcohol consumption}

Accumulating evidence in population-based studies has emphasized the association between education and reduced risk of dementia and the real effect is explained via two hypotheses: "brain reserve" and "brain battering" (Fratiglioni and Wang, 2007; Del Ser et al., 1999). A previous dementia prevalence study in elderly Sri Lankans (De Silva et al., 2003) has also demonstrated that illiteracy is strongly associated with clinical dementia in addition to greater age and female gender. However, there have been no autopsy verification studies representing LMICs that confirm the association between education and reduced risk of dementia pathology. In this study, we found a strong association between illiteracy and both increased risk of neurofibrillary degenerations and reduced risk of microscopic infarcts. Increased risk of neurofibrillary degenerations in illiterates is consistent with the "brain reserve hypothesis", whereas reduced risk of microscopic infarcts may be ascribed to their low level of exposure to cerebrovascular risk factors such as smoking, hypertension, diabetes and obesity (Ferri et al., 2005; LlibreRodriguez et al., 2008). Moreover, effects seen with smoking or alcohol consumption were not found to be statistically important. As far as smoking/alcohol consumption is concerned; it could be that there is a small effect that cannot be detected with statistical significance in a relatively small sample, but it may also be attributable to cultural factors that may attenuate the overall effects given that Sri Lankan women are generally fairly conservative in their smoking/alcohol consumption habits.

\subsubsection{Contribution of cerebrovascular pathologies}

Apart from vascular risk factors, contribution of cerebrovascular pathology to the burden of sporadic $\mathrm{AD}$ has received increasing interest in recent decades. However, autopsy evidence which rely on IASCW, a major cause for cerebral hypoperfusion, are found to be inconsistent (Luoto et al., 2009; Dolan et al., 2010; Bangen et al., 2015) and the recent studies indicate a 
strong relationship between white matter disease (MRI based) and AD type pathology (Braak score, CERAD score and a composite AD pathology score) that would explain in part the relationship between cerebral small vessel disease and cognition (Moghekar et al., 2012; Prins and Scheltens, 2015). There are several studies that have attributed the relationship between white matter disease and cognition to coexisting atherosclerosis (Roher et al., 2011; Roher et al., 2003; Beach et al., 2007); however, it is not the case in all neuropathological studies (Moghekar et al., 2012). Our findings are congruent with those of Moghekar et al., (2012) and to a certain extent with both Roher et al., (2011) and Luoto et al., (2009). Histopathologically assessed WMHs showed a higher degree of association with all AD-related neuropathological changes (Braak NFT, CERAD NP and Thal A $\beta$ scores), whereas CAA is related only with plaques (CERAD NP and Thal A $\beta$ scores) and IASCW is associated only with tangles (Braak NFT score). Our study also demonstrates a strong association between WMHs and CAA, which supports the previous studies that have suggested WMHs as a feature of sporadic CAA (Hancu et al., 2009; Gurol et al., 2013; Gouw et al., 2011). However, IASCW was not associated with any of the cerebrovascular pathologies studied in contrast to studies that have ascribed white matter disease to coexisting atherosclerosis (Roher et al., 2011; Roher et al., 2003; Beach et al., 2007). Further, as per Luoto et al., (2009), it is also arguable that a significant association noted between Braak NFT stage (I-VI) and IASCW ( $\geq$ mild) grades of our cohort may be attributed to the effect of age and not due to a pathologically direct relationship as other grades of Braak NFT score or IASCW didn't show any significant associations.

While- this is the first autopsy verification study of an ageing population from South Asia, we acknowledge there are limitations to this study such as sample size, incomplete clinical history of the recruited samples lacking objective psychometry and dementia scores, reliability of the case histories obtained through kin, ubiquitin immunohistochemistry for labeling LBs instead of $\alpha$-synuclein, histopathological assessments of WMHs instead of radiological examinations, semi-quantitative assessments of certain comorbid pathologies lacking exact quantifications and the non-availability of some brain regions as specified under minimum tissue requirements by NIA-AA guidelines.

Concisely, our findings suggest that besides age, education and genetic factors (ApoE and $M T H F R$, other vascular risk factors were not associated with AD related neuropathological changes. It further confirms the strong contribution of cerebral small vessel diseases in ADrelated changes, contributes to the uncertainty surrounding the true effect of IASCW / large vessel disease on AD-related changes, and urge prompt action be taken against cerebral small vessel diseases possibly via therapeutic agents that contains both anti-amyloidogenic and antiatherosclerotic properties as a preventative strategy for subsequent neurodegenerative disease.

\subsection{References}

Alafuzoff I, Gelpi E, Al-Sarraj S, Arzberger T, Attems J, Bodi I, Bogdanovic N, Budka H, Bugiani O, Englund E, Ferrer I, Gentleman S, Giaccone G, Graeber MB, Hortobagyi T, Hoftberger R, Ironside JW, Jellinger K, Kavantzas N, King A, Korkolopoulou P, Kovacs GG, Meyronet D, Monoranu C, Parchi P, Patsouris E, Roggendorf W, Rozemuller A, Seilhean D, Streichenberger N, Thal DR, Wharton SB, Kretzschmar H (2012) The need to unify neuropathological assessments of vascular alterations in the ageing brain: multicenter survey by the BrainNet Europe consortium. Exp Gerontol 47, 825-833. 
Alzheimer's disease and vascular dementia in developing countries: prevalence, management, and risk factors. Lancet Neurol 7, 812-826.

Anuurad E, Rubin J, Lu G, Pearson TA, Holleran S, Ramakrishnan R, Berglund L (2006) Protective effect of E2 on coronary artery disease in African Americans is mediated through lipoprotein cholesterol. J Lipid Res 47, 2475-2481.

Arvanitakis Z, Schneider JA, Wilson RS, Li Y, Arnold SE, Wang Z, Bennett DA (2006) Diabetes is related to cerebral infarction but not to AD pathology in older persons. Neurology 67, 1960-1965.

Attems J, Jellinger KA (2014) The overlap between vascular disease and Alzheimer's disease - lessons from pathology. BMC Med 12, 206.

Bangen KJ, Nation DA, Delano-Wood L, Weissberger GH, Hansen LA, Galasko DR, Salmon DP, Bondi MW (2015) Aggregate effects of vascular risk factors on cerebrovascular changes in autopsy-confirmed Alzheimer's disease. Alzheimers Dement 11, 394-403.

Barker R, Ashby EL, Wellington D, Barrow VM, Palmer JC, Kehoe PG, Esiri MM, Love S (2014) Pathophysiology of white matter perfusion in Alzheimer's disease and vascular dementia. Brain 137,1524-1532.

Beach TG, Wilson JR, Sue LI, Newell A, Poston M, Cisneros R, Pandya Y, Esh C, Connor DJ, Sabbagh M, Walker DG, Roher AE (2007) Circle of Willis atherosclerosis: association with Alzheimer's disease, neuritic plaques and neurofibrillary tangles. Acta Neuropathol 113, 1321.

Chan JC, Malik V, Jia W, e Kadowaki T, Yajnik CS, Yoon KH, Hu FB (2009) Diabetes in Asia: epidemiology, risk factors and pathophysiology. JAMA 301, 2129-2140.

Chui HC, Zheng L, Reed BR, Vinters HV, Mack WJ (2012) Vascular risk factors and Alzheimer's disease: are these risk factors for plaques and tangles or for concomitant vascular pathology that increases the likelihood of dementia? An evidence-based review. Alzheimers Res Ther 4, 1 .

Classification of Atherosclerotic lesions; a report of a study group (1958) World Health Organ Tech Rep Ser 57, 1-20.

de Bruijn RF, Ikram MA (2014) Cardiovascular risk factors and future Alzheimer's disease risk $B M C$ Med 12, 130.

De Silva HA, Gunathilake SB, Smith AD (2003) Prevalence of dementia in a semi-urban population in Sri Lanka: report from a regional survey. Int J Geriatr Psychiatry 18, 711-715.

De Silva R, Disanayaka S, DeZoysa N, Sanjeewanie N, Somaratne S, Foster J, Srikanth S, Kathriarachchi ST, Martins RM (2009) Norms for the mini-mental state examination from a sample of Sri Lankan older people. Int J Geriatr Psychiatry 24, 666-670. 
Del Ser T, Hachinski V, Merskey H, Munoz DG (1999) An autopsy-verified study of the effect of education on degenerative dementia. Brain 122, 2309-2319.

Dolan D, Troncoso J, Resnick SM, Crain BJ, Zonderman AB, O'Brien RJ (2010) Age, Alzheimer's disease and dementia in the Baltimore Longitudinal Study of Ageing. Brain 133, $2225-2231$.

Farrer LA, Cupples LA, Haines JL Hyman B, Kukull WA, Mayeux R, Myers RH, PericakVance MA, Risch N, van Duijn CM (1997) Effects of age, sex, and ethnicity on the association between apolipoprotein E genotype and Alzheimer's disease. A meta-analysis. APOE and Alzheimer's Disease Meta-Analysis Consortium. JAMA 278, 1349-1356.

Ferri CP, Prince M, Brayne C, Brodaty H, Fratiglioni L, Ganguli M, Hall K, Hasegawa K, Hendrie H, Huang Y, Jorm A, Mathers C, Menezes PR, Rimmer E, Scazufca M; Alzheimer's disease International (2005) Global prevalence of dementia: a Delphi consensus study. Lancet $366,2112-2117$.

Fratiglioni L, Wang HX (2007) Brain reserve hypothesis in dementia. J Alzheimers Dis 12, 1122.

Geddes JW, Tekirian TL, Soultanian NS, Ashford JW, Davis DG, Markesbery WR (1997) Comparison of neuropathologic criteria for the diagnosis of Alzheimer's disease. Neurobiol Ageing 18, S99-S105.

Gorelick PB, Scuteri A, Black SE, Decarli C, Greenberg SM, Iadecola C, Launer LJ, Laurent S, Lopez OL, Nyenhuis D, Petersen RC, Schneider JA, Tzourio C, Arnett DK, Bennett DA, Chui HC, Higashida RT, Lindquist R, Nilsson PM, Roman GC, Sellke FW, Seshadri S; American Heart Association Stroke Council, Council on Epidemiology and Prevention, Council on Cardiovascular Nursing, Council on Cardiovascular Radiology and Intervention, and Council on Cardiovascular Surgery and Anesthesia (2011) Vascular contributions to cognitive impairment and dementia: A statement for healthcare professionals from the American Heart Association/American Stroke Association. Stroke 42, 2672-2713.

Gorgone G, Ursini F, Altamura C, Bressi F, Tombini M, Curcio G, Chiovenda P, Squitti R, Silvestrini M, Ientile R, Pisani F, Rossini PM, Vernieri F (2009) Hyperhomocysteinemia, intima-media thickness and C677T MTHFR gene polymorphism: a correlation study in patients with cognitive impairment. Atherosclerosis 206, 309-313.

Gouw AA, Seewann A, van der Filer WM, Barkhof F, Rozemuller AM, Scheltns P, Geurts JJ (2011) Heterogeneity of small vessel disease: a systematic review of MRI and histopathological correlations. J Neurol Neurosurg Psychiatry 82, 126-135.

Greenberg SM, Vonsattel JP (1997) Diagnosis of cerebral amyloid angiopathy: Sensitivity and specificity of cortical biopsy. Stroke 28, 1418-1422.

Gurol ME, Viswanathan A, Gidicsin C, Hedden T, Martinez-Ramirez S, Dumas A. Vashkevich A, Ayres AM, Auriel E, van Etten E, Becker A, Carmasin J, Schwab K, Rosan J, Johnson KA, Greenberg SM (2013) Cerebral amyloid angiopathy burden associated with leukoaraiosis: a positron emission tomography/ magnetic resonance imaging study. Ann Neurol 73, 529-536. 
Hancu A, Rasanu I, Butoi G (2009) White matter changes in cerebrovascular disease: Leukoaraiosis. In Advances in Brain Imaging, Chaudhary V ed. InTech, Europe, pp 249-250.

Jellinger KA (2013) Pathology and pathogenesis of vascular cognitive impairment - a critical update. Front Aging Neurosci 5, 17.

Jicha GA, Parisi JE, Dickson DW, Cha RH, Johnson KA, Smith GE, Boeve BF, Petersen RC, Knopman DS (2008) Age and ApoE associations with complex pathologic features in Alzheimer's disease. J Neurol Sci 273, 34-39.

Kalaria NR, Maestre GE, Arizaga R, Friedland RP, Galasko D, Hall K, Luchsinger JA, Ogunniyi A, Perry EK, Potocnik F, Prince M, Stewart R, Wimo A, Zhang ZX, Antuono P; World Federation of Neurology Demntia Resrach Group (2008)

Kalaria RN, Ballard C (1999) Overlap between pathology of Alzheimer disease and vascular dementia. Alzheimer Dis Assoc Disord 13, S115-123.

Kazee AM, Johnson EM (1998) Alzheimer's disease pathology in non-demented elderly. $J$ Alzheimers Dis 1, 81-89.

Kearney PM, Whelton M, Reynolds K, Muntner P, Whelton PK, He J (2005) Global burden of hypertension: analysis of worldwide data. Lancet 365, 217-223.

Kok E, Haikonen S, Luoto T, Huhtala H, Goebeler S, Haapasalo H, Karhunen PJ (2009) Apolipoprotein $\mathrm{E}$ dependent accumulation of Alzheimer disease-related lesions begins in middle age. Ann Neurol 65, 650-657.

Lee JH, Han SJ, Yun YH, Choi HC, Jung S, Cho SJ, Yu KH, Lee SM, Hwang SH, Song HK, Kwon KH, Lee BC (2006) Posterior circulation ischemic stroke in Korean population. Eur J Neurol 13, 742-748.

Llibre Rodriguez JJ, Ferri CP, Acosta D, Guerra M, Huang Y, Jacob KS, Krishnamoorthy ES, Salas A, Sosa AL, Acosta I, Dewey ME, Gaona C, Jotheeswaran AT, Li S, Rodriguez D, Rodriquez G, Kumar PS, Valhuerdi A, Prince M; 10/66 Dementia Research Group (2008) Prevalence of dementia in Latin America, India and China: a population based cross-sectional slurvey. Lancet 372, 464-474.

Love S, Miners JS (2015) White matter hypoperfusion and damage in dementia: post-mortem assessment. Brain Pathol 25, 99-107.

Luoto TM, Haikonen S, Haapasalo H, Goebeler S, Huhtala H, Erkinjuntti T, Karhunen PJ (2009) Large vessel cerebral atherosclerosis is not in direct association with neuropathological lesions of Alzheimer's disease. Eur Neurol 62, 93-98.

Misra A, Khurana L (2009) The metabolic syndrome in South Asians: epidemiology, determinants and prevention. Metab Syndr Relat Disord 7, 497-514. 
Moghekar A, Kraut M, Elkins W, Troncoso J, Zonderman AB, Resnick SM, O’Brien RJ (2012) Cerebral white matter disease is associated with Alzheimer pathology. Alzheimers Dement 8, S71-S77.

Montine TJ, Phelps CH, Beach TG, Bigio EH, Cairns NJ, Dickson DW, Duyckaerts C, Frosch MP, Masliah E, Mirra SS, Nelson PT, Schneider JA, Thal DR, Trojanowski JQ, Vinters HV, Hyman BT; National Institute of Aging; Alzheimer's Association. (2012) National Institute on Aging-Alzheimer's Association guidelines for the neuropathological assessment of Alzheimer's disease: practical approach. Acta Neuropathol 123, 1-11.

Morris JC, Roe CM, Xiong C, Fagan AM, Goate AM, Holtzman DM, Mintun MA (2010) APOE predicts amyloid-beta but not tau Alzheimer pathology in cognitively normal ageing. Ann Neurol 67, 122-131.

O'Brien JT, Markus HS (2014) Vascular risk factors and Alzheimer's disease. BMC Med 12, 218.

Polvikoski T, Sulkava R, Haltia M, Kainulainen K, Vuorio A, Verkkoniemi A, Niinisto L, Halonen P, Kontula K (1995) Apolipoprotein E, dementia, and cortical deposition of betaamyloid protein. $N$ Engl J Med 333, 1242-1247.

Population Division of the Department of Economic and Social Affairs of the United Nations (2015) World Population Prospects: The 2015 Revision, DVD Edition, https://esa.un.org/unpd/wpp/Download/Standard/Population/, Assessed on June 5, 2016.

Prins ND, Scheltens P (2015) White matter hyperintensities, cognitive impairment and dementia: an update. Nat Rev Neurol 11, 157-165.

Purohit DP, Batheia NO, Sano M, Jashnani KD, Kalaria RN, Karunamurthy A, Kaur S, Shenoy AS, Van Dvk K, Schmeidler J, Perl DP (2011) Profile of Alzheimer's disease-related pathology in an aging urban population sample in India. J Alzheimers Dis 24, 187-196.

Reitz C, Brayne C, Mayeux R (2011) Epidemiology of Alzheimer disease Nat Rev Neurol 7,137-152.

Roher AE, Esh C, Kokjohn TA, Kalback W, Luehrs DC, Seward JD, Sue LI, Beach TG (2003) Circle of Willis atherosclerosis is a risk factor for sporadic Alzheimer's disease. Arterioscler Thromb Vasc Biol 23, 2055-2062.

Roher AE, Tyas SL, Maarouf CL, Daugs ID, Kokjohn TA, Emmerling MR, Garami Z, Belohlavek M, Sabbagh MN, Sue LI, Beach TG (2011) Intracranial atherosclerosis as a contributing factor to Alzheimer's disease dementia. Alzheimers Dement 7, 436-444.

Ruitenberg A, den Heijer T, Bakker SL, van Swieten JC, Koudstaal PJ, Hofman A, Breteler MM (2005) Cerebral hypoperfusion and clinical onset of dementia: the Rotterdam Study. Ann Neurol 57, 789-794.

Singh PP, Singh M, Mastana SS (2006) APOE distribution in world populations with new data from India and the UK. Ann Hum Biol 33, 279-308. 
Snowdon DA, Greiner LH, Mortimer JA, Riley KP, Greiner PA, Markesbery WR (1997) Brain infarction and the clinical expression of Alzheimer's disease. The Nun Study. JAMA 277, 813817.

Venketasubramanian N, Sahadevan S, Kua EH, Chen CP, Ng TP (2010) Interethnic differences in dementia epidemiology: Global and Asia-Pacific perspectives. Dement Geriatr Cogn Disord 30, 492-498.

Verghese PB, Castellano JM, Holtzman DM (2011) Roles of Apolipoprotein E in Alzheimer's disease and other neurological disorders. Lancet Neurol 10, 241-252.

Vermeer SE, Prins ND, den Heijer T, Hofman A, Koudstaal PJ, Breteler MM (2003) Silent brain infarcts and the risk of dementia and cognitive decline. N Engl J Med 348, 1215-1222.

Warzok RW, Kessler C, Apel G, Schwarz A, Egensperger R, Schreiber D, Herbst EW, Wolf E, Walther R, Walker LC (1998) Apolipoprotein E4 promotes incipient Alzheimer pathology in the elderly. Alzheimer Dis Assoc Disord 12, 33-39.

Wijesinghe P, Shankar SK, Yasha TC, Gorrie CA, Amaratunga D, Hulathduwa SR, Sunil Kumara K, Samarasinghe K, Suh YH, Steinbusch HW and De Silva KRD (2016) Cytoskeletal pathologies of age-related diseases between elderly Sri Lankan and Indian brain samples. Curr Alzheimer Res 13, 268-280.

Yarchoan M, Xie SX, Kling MA, Toledo JB, Wolk DA, Lee EB, Van Deerlin V, Lee VM, Trojanowski JQ, Arnold SE (2012) Cerebrovascular atherosclerosis correlates with Alzheimer pathology in neurodegenerative dementias. Brain 135, 3749-3756.

Yip G, McKee AC, Green RC, Wells J, Young H, Cupples LA, Farrer LA (2005) APOE, vascular pathology, and the AD brain. Neurology 65, 259-265.

Zlokovic BV (2011) Neurovascular pathways to neurodegeneration in Alzheimer's disease and other disorders. Nat Rev Neurosci 12, 723-738. 


\section{CHAPTER 4}

Early stages of Alzheimer's disease are alarming signs in injury deaths caused by traffic accidents in elderly people ( $\geq 60$ years of age): A neuropathological study

Printha Wijesinghe, Catherine Gorrie, S. K. Shankar, Yasha T. Chickabasaviah, Dhammika Amaratunga, Sanjayah Hulathduwa, K. Sunil Kumara, Kamani Samarasinghe, Yoo-Hun Suh, H. W. M. Steinbusch, K. Ranil D. De Silva

Indian Journal of Psychiatry, 2017;59(4):471-477 doi: 10.4103/psychiatry.IndianJPsychiatry_102_16 


\begin{abstract}
Background: There is little information available in the literature concerning the contribution of dementia in injury deaths in elderly people ( $\geq 60$ years).

Aim: This study was intended to investigate the extent of dementia-related pathologies in the brains of elderly people who died in traffic accidents or by suicide and to compare our findings with age- and sex-matched natural deaths in an elderly population.

Materials and Methods: Autopsy-derived human brain samples from nine injury death victims (5 suicide and 4 traffic accidents) and nine age- and sex-matched natural death victims were screened for neurodegenerative and cerebrovascular pathologies using histopathological and immunohistochemical techniques. For the analysis, Statistical Package for the Social Sciences (SPSS) version 16.0 was used.

Results: There was a greater likelihood for Alzheimer's disease (AD)- related changes in the elders who succumbed to traffic accidents (1 out of 4) compared to age- and sex-matched suicides ( 0 out of 5 ) or natural deaths ( 0 out of 9$)$ as assessed by the National Institute on Aging - Alzheimer's Association guidelines. Actual burden of both neurofibrillary tangles (NFTs) and senile plaques was comparatively higher in the brains of traffic accidents, and the mean NFT counts were significantly higher in the region of entorhinal cortex $(P<0.05)$. However, associations obtained for other dementia-related pathologies were not statistically important.

Conclusion: Our findings suggest that early Alzheimer stages may be a contributing factor to injury deaths caused by traffic accidents in elderly people whereas suicidal brain neuropathologies resembled natural deaths.
\end{abstract}

Keywords: Alzheimer-related pathologies, immunohistochemistry, injury deaths, natural diseases

\title{
4.1 Introduction
}

Unnatural causes of death among elderly people on medicolegally examined autopsies have not been studied extensively. Accidents are the main causes of injury deaths among the elderly followed by suicide, whereas homicide is a rare or uncommon cause of injury death among these people (Kumar and Verma, 2014; Eilertsen et al., 2007). To date, there have been no studies compared the extent of dementia-related pathologies in the brains of elderly people who died of injuries and natural diseases. There is a small number of studies from Western countries which investigated the extent of dementia-related pathologies in the brains of elderly victims of suicide (Rohde et al., 1995; Lesco, 1989; Rubio et al., 2001; Peisah et al., 2007) and fatal traffic accident brains (Vitanen et al., 1998; Gorrie et al., 2006; Gorrie et al., 2007). Autopsy findings, however, were inconclusive. Primary objective of this study was to determine whether there is an over-representation of Alzheimer-related pathologies in the brains of elders $(\geq 60$ years) who succumbed to injury deaths caused by traffic accidents and suicide and to compare it with the brains of elders ( $\geq 60$ years) who died of natural diseases.

\subsection{Materials and Methods}

Human brain samples were obtained at autopsy from 18 elderly subjects ( $\geq 60$ years) at the Department of Judicial Medical Office, Colombo South Teaching Hospital, following approval by the Institutional Scientific Ethics Committee to carry out the study and informed consent from kin. Among these samples, nine brains were from injury deaths - five suicide victims and four fatal traffic accident victims (mean age 74.8 years [7.3], mean age [standard deviation]; male: female $=5: 4$ ) - and nine brains from natural deaths (mean age 74.8 years [7.6]; male: 
female $=5: 4$ ). Brains of other injury deaths, including falls, drowning, war, adverse outcome of surgery, and homicide, were not obtained during this period. As this study was a retrospective study, an ante-mortem questionnaire was given to kin who were familiar with intellectual and motor functional status of the subjects before death. The purpose of this questionnaire was to obtain information on demographic data, medical history, family history, and health habits of the deceased. This information was held strictly confidential. All the recruited cases had incomplete clinical history, except one case which was clinically diagnosed as Parkinson's disease (PD). Specific neuroanatomical regions were sampled for paraffin embedding and sectioning from both hemispheres: hippocampus along with parahippocampal gyrus, superior frontal gyrus, middle temporal gyrus, superior parietal lobule, midbrain at superior colliculus level and deep white matters from corpus callosum-major inter-hemispheric white matter tract, and the circle of Willis $(\mathrm{CW})$ for the subsequent atherosclerotic study. Following routine histological evaluation ( $\mathrm{H}$ and $\mathrm{E}$ ), formalin-fixed paraffin-embedded brain sections were immunostained by standard immunoperoxidase technique following antigen retrieval by heat and $\mathrm{DAB} / \mathrm{H}_{2} \mathrm{O}_{2}$ as the chromogen to visualize the immunolabeling (DAKO Envision Detection System). For this screening, three antibodies, namely, (i) $\beta$-amyloid (A $\beta$ ) - monoclonal antibody (1:200 dilution) from Novacastra $^{\mathrm{TM}}$, (ii) ubiquitin - monoclonal antibody (1:150 dilution) from Novacastra ${ }^{\mathrm{TM}}$, and (iii) phosphorylated tau - paired helical filament (PHF) - 1 monoclonal antibody (1:50 dilution, A gift) were used. Phosphorylated tauand $\mathrm{A} \beta$-positive pathologies were graded semiquantitatively as given below.

1. Semi-quantitative $0-3$ scale $(0-$ none, +- low, ++- moderate, and +++- high $)$ for tau-positive neurons (neurons demonstrating tangle and pretangle pathology), neuritic plaques (NPs), and neuropil threads (NTs)

2. Semi-quantitative $0-3$ scale ( 0 - none, +- sparse, ++- moderate, and +++- frequent) for A $\beta$-positive senile plaques (SPs - dystrophic neurites and an amyloid core) and diffuse plaques (DPs).

The diagnostic criteria for Alzheimer's disease (AD) neuropathologic change was based on National Institute on Aging - Alzheimer's Association guidelines (NIA-AA) (Montine et al., 2012) - a practical approach which included:

- Consortium to Establish a Registry for AD (CERAD) protocol for NP scoring (Mirra et al., 1991)

- Braak and Braak staging scheme for neurofibrillary tangle (NFT) degeneration (Braak and Braak, 1991; Braak et al., 2006) which was adapted to four stages that improve inter-rater reliability (stage 0, stage I or II, stage III or IV, and stage V or VI) (Nagy et al., 1998)

- A modified version of Thal phases for $A \beta$ plaque accumulation (Thal et al., 2002) which was adapted to four-point scale (phase 0 , phase 1 or 2 , phase 3 , and phase 4 or 5 ).

$\mathrm{AD}$ neuropathologic change was ranked by three parameters: $\mathrm{A} \beta$ plaque phase, Braak and Braak NFT stage, and CEARD NP score to obtain ABC scores and then transformed into four levels: not, low, intermediate, or high (Montine et al., 2012). Actual burden of AD-related pathologies (NFTs and SPs) were counted in specific brain regions such as hippocampus, parahippocampus, superior frontal gyrus, and midbrain based on the methods described by Purohit et al. For this purpose, a medium high power $(\times 20)$ objective lens producing a visual field of $0.785 \mathrm{~mm}^{2}$ (field diameter $=2.0 \mathrm{~mm}$ ) was used. Lesions were counted in medium high $(\times 200$, Olympus U-CTR30-2 Trinocular objective tubes and $\times 10$ eye piece) power fields and then converted into average per $\times 200$ as follows: For superior frontal gyrus, areas with high NFTs/SPs were selected and visual counts were carried out in five nonoverlapping fields. For other regions, areas with high NFTs/SPs were identified in each subfield and then visual counts 
were carried out in nonoverlapping fields (wherever possible five nonoverlapping fields were selected).

Neuropathological criteria for Lewy body diseases (LBDs) including PD and dementia with Lewy bodies (DLBs) were based on NIA-AA (Montine et al., 2012) modifications to existing criteria which included Consortium on DLBs 2005 (CDLB05) (McKeith et al., 2005) and Braak PD staging (Braak et al., 2003) system. To detect Lewy bodies, $\alpha$-synuclein immunohistochemistry is recommended as a preferred method; however, in this study, $\mathrm{H}$ and E staining and ubiquitin immunohistochemistry which were recommended in CDLB 1996 criteria (McKeith et al., 1996) were used. Cerebral amyloid angiopathy (CAA) in leptomeningeal and cortical arteries of the specific neuroanatomical regions was graded based on Greenberg and Vonsattel specifications and the average CAA grade was reported for each case. Intracranial atherosclerosis of the CW (IASCW) was graded into four levels: none, mild, moderate, and severe based on the degree of stenosis of the CW component arteries (World Health Organization Technical Report Series, 1958) and the gross visual inspection (macroscopic grading) (Beach et al., 2007). Extent of other cerebrovascular pathologies: microscopic infarcts in deep white matters ( $7 \mu \mathrm{m}$ thick) stained with Luxol fast blue (LFB) and cresyl violet and white matter hyperintensities (WMHs) in the neocortex and hippocampus regions stained with LFB and eosin were assessed semi-quantitatively as absent (none/rare) and present (above levels). Due to the high variability of morphological findings and multifactorial pathogenesis of vascular cognitive impairment/vascular dementia (VaD) (Grinberg and Thal, 2010; Gorelick et al., 2011; Jellinger, 2013) no generally accepted morphologic scheme for quantitating vascular brain injury and no validated neuropathological criteria for VaD have been established to date (Jellinger, 2013; Alafuzoff, 2012). On the whole, the basis of $\mathrm{VaD}$ diagnosis is simply the presence of brain lesions related to vascular pathology and it highly depends on the neuropathologist's judgment.

\subsubsection{Statistical analysis}

Results were analyzed using statistical software SPSS for windows version 16.0, SPSS Inc., Chicago, USA. Mann-Whitney U-test was used to find the differences in AD-related neuropathological scores in different brain regions among injury deaths caused by traffic accidents and suicide and natural deaths.

\subsection{Results}

This sample consisted of 18 deceased brains aged between 60 and 87 years. The mean age between traffic accidents (78.7 years [3.1]) and natural (78.5 years [3.2]) deaths; suicide (71.6 years [3.4]) and natural deaths (71.8 years [3.2]); and traffic accidents (78.7 years [3.1]) and suicide (71.6 years [3.4]) was not significantly different $(P>0.05$, Mann-Whitney U-test). Sample summary on AD, LBD, and CAA neuropathological stages is given in Table 1. 


\begin{tabular}{|c|c|c|c|c|c|c|}
\hline Sample size & $\begin{array}{c}\text { Braak and } \\
\text { Braak NFT } \\
\text { stage }\end{array}$ & $\begin{array}{l}\text { CERAD NP } \\
\text { score }\end{array}$ & $\begin{array}{l}\text { Thal } A \beta \\
\text { phase }\end{array}$ & NIA-AA (criteria) & CAA grade & LBD stage \\
\hline \multirow{3}{*}{$\begin{array}{c}\text { Traffic } \\
\text { accidents } \\
(4 \text { cases })\end{array}$} & None $0 \%$ & $\begin{array}{c}\text { None } 75.0 \% \\
(3 / 4)\end{array}$ & $\begin{array}{c}\text { None } 50.0 \% \\
(2 / 4)\end{array}$ & Not $75.0 \%(3 / 4)$ & $\begin{array}{l}\text { None } 50.0 \% \\
(2 / 4)\end{array}$ & $\begin{array}{c}\text { None } 100.0 \% \\
(4 / 4)\end{array}$ \\
\hline & $\begin{array}{c}\text { Stage I-II } \\
50.0 \%(2 / 4) \\
\end{array}$ & $\begin{array}{c}\text { Stage B } \\
25.0 \%(1 / 4)\end{array}$ & $\begin{array}{c}\text { Phase } 1-2 \\
50.0 \%(2 / 4)\end{array}$ & Low $25 \%(1 / 4)$ & $\begin{array}{c}\text { Grade 1 } \\
25.0 \%(1 / 4)\end{array}$ & \\
\hline & $\begin{array}{l}\text { stage III-IV } \\
50.0 \%(2 / 4)\end{array}$ & & & $\begin{array}{c}\text { Intermediate/high } \\
25.0 \%(1 / 4)\end{array}$ & $\begin{array}{c}\text { Grade } 2 \\
25.0 \%(1 / 4)\end{array}$ & \\
\hline \multirow[t]{3}{*}{$\begin{array}{l}\text { Suicide } \\
(5 \text { cases })\end{array}$} & None $0 \%$ & $\begin{array}{c}\text { None } 80.0 \% \\
(4 / 5)\end{array}$ & $\begin{array}{c}\text { None } 80.0 \% \\
(4 / 5)\end{array}$ & Not $100.0 \%(5 / 5)$ & $\begin{array}{c}\text { None } 80.0 \% \\
(4 / 5)\end{array}$ & $\begin{array}{c}\text { None } 80.0 \% \\
(4 / 5)\end{array}$ \\
\hline & $\begin{array}{c}\text { Stage I-II } \\
60.0 \%(3 / 5)\end{array}$ & $\begin{array}{c}\text { Stage B } \\
20.0 \%(1 / 5)\end{array}$ & $\begin{array}{c}\text { Phase } 1-2 \\
20.0 \%(1 / 5)\end{array}$ & Low $20 \%(1 / 5)$ & $\begin{array}{c}\text { Grade 1 } \\
20.0 \%(1 / 5)\end{array}$ & $\begin{array}{c}\text { Brain stem- } \\
\text { predominant- } \\
20.0 \%(1 / 5)\end{array}$ \\
\hline & $\begin{array}{l}\text { stage III-IV } \\
40.0 \%(2 / 5)\end{array}$ & & & & & \\
\hline \multirow{3}{*}{$\begin{array}{c}\text { Natural } \\
\text { deaths (9 } \\
\text { cases) }\end{array}$} & $\begin{array}{c}\text { None } 11.1 \% \\
(1 / 9)\end{array}$ & $\begin{array}{c}\text { None } \\
100.0 \%(9 / 9)\end{array}$ & $\begin{array}{c}\text { None } \\
77.78 \%(7 / 9)\end{array}$ & Not $100.0 \%(9 / 9)$ & $\begin{array}{c}\text { None } \\
88.89 \%(8 / 9)\end{array}$ & $\begin{array}{c}\text { None } 100.0 \% \\
(9 / 9)\end{array}$ \\
\hline & $\begin{array}{c}\text { stage I-II } \\
55.56 \%(5 / 9)\end{array}$ & & $\begin{array}{c}\text { Phase } 1-2 \\
22.2 \%(2 / 9)\end{array}$ & Low $22.2 \%(2 / 9)$ & $\begin{array}{c}\text { Grade } 1 \\
11.1 \%(1 / 9)\end{array}$ & \\
\hline & $\begin{array}{l}\text { Stage III-IV } \\
33.3 \%(3 / 9)\end{array}$ & & & & & \\
\hline
\end{tabular}

Table 1. Sample summary on Alzheimer's disease, cerebral amyloid angiopathy, and Lewy body disease neuropathological stages

CAA - Cerebral amyloid angiopathy; LBD - Lewy body disease; CERAD NP - Consortium to establish a registry for Alzheimer's disease protocol for neuritic plaque; A $\beta$ - Amyloid; NIA-AA - National Institute on Aging - Alzheimer's association; NFT - Neurofibrillary tangles; NP - Neuritic plaques

Among these samples, AD neuropathologic change for intermediate level considered as greater likelihood for dementia or cognitive impairment was found only in one out of four traffic accidents and for low level considered as inadequate evident was found in one out of four traffic accidents, one out of five suicides, and two out of nine natural deaths. Figure 1 illustrates the percentage of cases identified with AD-related and cerebrovascular pathologies among injury and natural deaths. AD-related pathologies; Braak NFT stage, Thal A $\beta$ phase, and CERAD NP score were comparatively higher in traffic accidents compared to suicide or natural deaths. CAA and WMHs, which are most frequent coexisting cerebral small vessel diseases in the AD brains, were also identified prominently in the brains of traffic accidents. In contrast, large vessel pathologies; IASCW and white matter microscopic infarcts were identified prominently in natural deaths. 

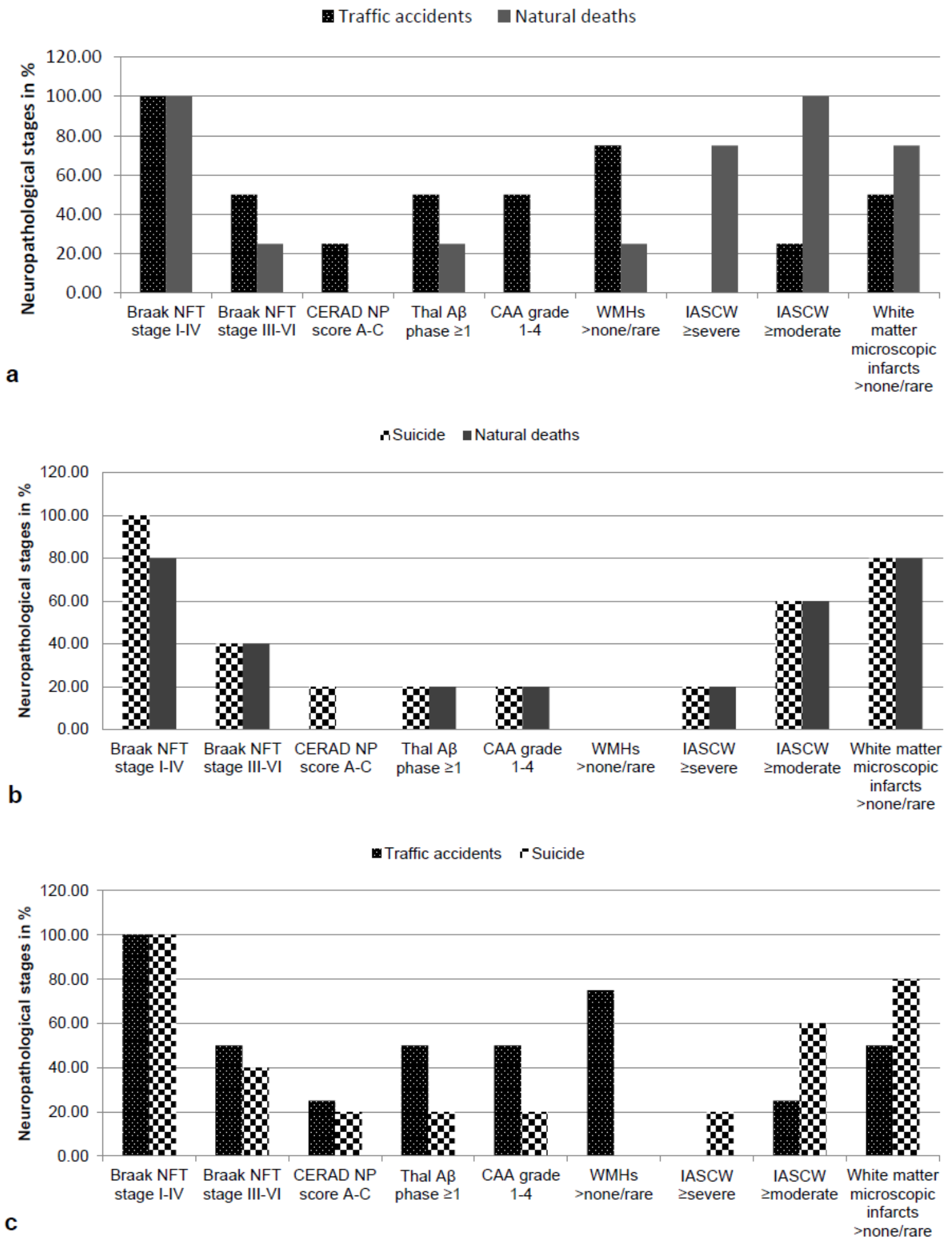

Figure 1. (a-c) Alzheimer and cerebrovascular neuropathological stages among injury deaths caused by traffic accidents and suicide, and natural deaths. NFT - Neurofibrillary tangle; A $\beta$ $\beta$-amyloid; CERAD - Consortium to Establish A Registry for Alzheimer's disease; NP Neuritic plaque; CAA - Cerebral amyloid angiopathy; WMHs - White matter hyperintensities; IASCW - Intracranial atherosclerosis of the circle of Willis 
Association between cause of death and actual burden of AD-related pathologies is presented in Table 2. Mean counts of both NFTs and SPs were comparatively higher in the brains of traffic accidents compared to suicide or natural deaths. In particular, mean NFT counts were significantly higher $(P<0.05)$ in the region of entorhinal cortex. Figure 2 illustrates the hallmark lesions of AD including tau-positive NFTs and NPs, and A $\beta$-positive SPs observed in the brains of injury deaths. One among the 05 suicidal victims who had clinically diagnosed of PD presented brainstem-predominant Lewy bodies (stage 3) at neuropathological diagnosis. 


\begin{tabular}{|c|c|c|c|c|c|c|c|c|c|c|}
\hline Regions & Lesions & $\begin{array}{c}\text { Traffic } \\
\text { Accidents } \\
\left(\text { count } / \mathrm{mm}^{2}\right) \\
\text { mean } \pm \text { S.E. } \\
(\mathrm{n}=04)\end{array}$ & $\begin{array}{c}\text { Natural deaths } \\
\left(\text { count } / \mathrm{mm}^{2}\right) \\
\text { mean } \pm \text { S.E. } \\
(n=04)\end{array}$ & $P$ value & $\begin{array}{c}\text { Suicide } \\
\left(\text { count } / \mathrm{mm}^{2}\right) \\
\text { mean } \pm \text { S.E. } \\
(n=05)\end{array}$ & $\begin{array}{c}\text { Natural deaths } \\
\left(\text { count } / \mathrm{mm}^{2}\right) \\
\text { mean } \pm \text { S.E. } \\
(n=05)\end{array}$ & $\begin{array}{c}P \\
\text { value }\end{array}$ & $\begin{array}{c}\text { Traffic } \\
\text { accidents } \\
\left(\text { count } / \mathrm{mm}^{2}\right) \\
\text { mean } \pm \text { S.E. }\end{array}$ & $\begin{array}{c}\text { Suicide } \\
\left(\text { count } / \mathrm{mm}^{2}\right) \\
\text { mean } \pm \text { S.E. }\end{array}$ & $P$ value \\
\hline Age & - & $78.75 \pm 3.12$ & $78.50 \pm 3.17$ & 0.883 & $71.60 \pm 3.41$ & $71.80 \pm 3.25$ & 0.916 & $78.75 \pm 3.12$ & $71.60 \pm 3.41$ & 0.221 \\
\hline \multirow[t]{2}{*}{ Hippocampus } & NFTs & $57.23 \pm 34.0$ & $23.08 \pm 14.57$ & 0.386 & $29.87 \pm 15.99$ & $18.63 \pm 11.05$ & 0.754 & $57.23 \pm 34.0$ & $29.87 \pm 15.99$ & 0.327 \\
\hline & SPs & $4.12 \pm 2.42$ & $0.00 \pm 0.00$ & 0.131 & $1.33 \pm 1.33$ & $0.00 \pm 0.00$ & 0.317 & $4.12 \pm 2.42$ & $1.33 \pm 1.33$ & 0.244 \\
\hline \multirow[t]{2}{*}{ Entorhinal cortex } & NFTs & $22.56 \pm 6.48$ & $2.54 \pm 1.50$ & $0.021 *$ & $6.11 \pm 3.75$ & $20.65 \pm 9.31$ & 0.754 & $22.56 \pm 6.48$ & $6.11 \pm 3.75$ & $0.050 *$ \\
\hline & SPs & $4.40 \pm 2.88$ & $0.00 \pm 0.00$ & 0.131 & $0.97 \pm 0.97$ & $0.00 \pm 0.00$ & 0.317 & $4.40 \pm 2.88$ & $0.97 \pm 0.97$ & 0.244 \\
\hline \multirow{2}{*}{$\begin{array}{c}\text { Superior frontal } \\
\text { gyrus }\end{array}$} & NFTs & $0.60 \pm 0.45$ & $0.06 \pm 0.06$ & 0.321 & $0.15 \pm 0.10$ & $0.00 \pm 0.00$ & 0.136 & $0.60 \pm 0.45$ & $0.15 \pm 0.10$ & 0.500 \\
\hline & SPs & $2.69 \pm 2.21$ & $0.00 \pm 0.00$ & 0.131 & $1.94 \pm 1.94$ & $0.20 \pm 0.20$ & 0.881 & $2.69 \pm 2.21$ & $1.94 \pm 1.94$ & 0.561 \\
\hline \multirow[t]{2}{*}{ Midbrain } & NFTs & $5.12 \pm 2.22$ & $3.33 \pm 2.28$ & 0.386 & $1.01 \pm 0.51$ & $4.84 \pm 1.95$ & 0.116 & $5.12 \pm 2.22$ & $1.01 \pm 0.51$ & 0.140 \\
\hline & SPs & $0.13 \pm 0.13$ & $0.00 \pm 0.00$ & 0.317 & $0.00 \pm 0.00$ & $0.00 \pm 0.00$ & 1.000 & $0.13 \pm 0.13$ & $0.00 \pm 0.00$ & 0.264 \\
\hline \multirow[t]{2}{*}{ All regions } & NFTs & $85.51 \pm 36.90$ & $29.02 \pm 15.92$ & 0.248 & $37.15 \pm 14.51$ & $44.12 \pm 16.40$ & 0.917 & $85.51 \pm 36.90$ & $37.15 \pm 14.51$ & 0.142 \\
\hline & SPs & $11.34 \pm 6.59$ & $0.00 \pm 0.00$ & 0.131 & $4.23 \pm 4.23$ & $0.20 \pm 0.20$ & 0.881 & $11.34 \pm 6.59$ & $4.23 \pm 4.23$ & 0.383 \\
\hline $\begin{array}{c}\text { Cortical and } \\
\text { leptomeningeal } \\
\text { regions }\end{array}$ & CAA & $2.25 \pm 1.31$ & $0.00 \pm 0.00$ & 0.131 & $0.60 \pm 0.60$ & $1.20 \pm 0.80$ & 0.521 & $2.25 \pm 1.31$ & $0.60 \pm 0.60$ & 0.244 \\
\hline
\end{tabular}

Table 2. Actual burden of Alzheimer related pathologies among injury deaths caused by traffic accidents and suicide, and natural deaths $P$ values are calculated using Mann-Whitney $U$ test and the significant levels are presented at $* P<0.05$

SE, standard error; n, number of cases; NFTs, neurofibrillary tangles; SPs, senile plaques; CAA, cerebral amyloid angiopathy 


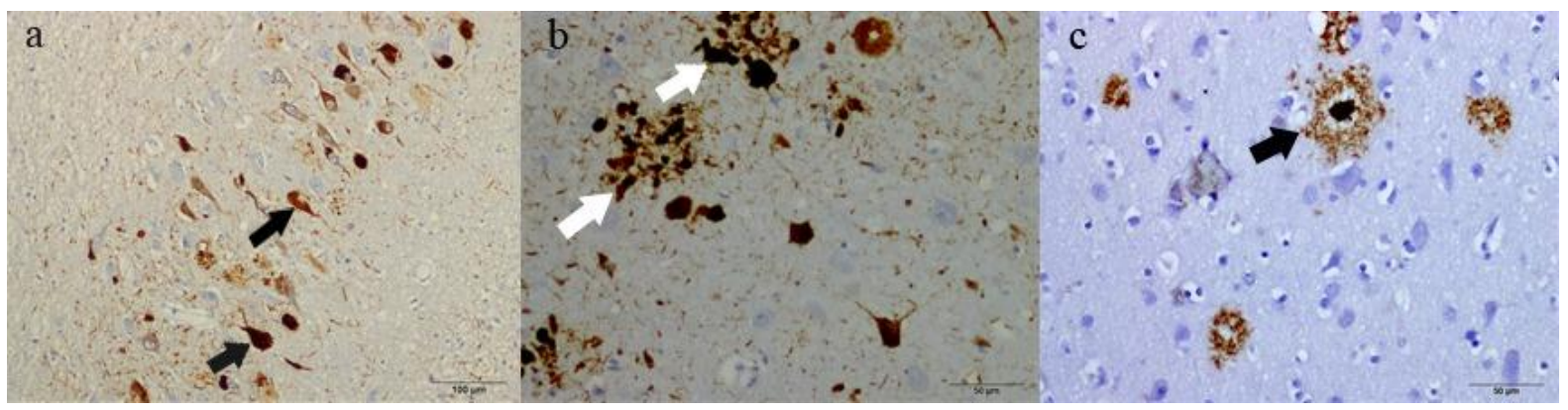

Figure 2. Hall mark lesions of AD. (a) Tau-positive neurofibrillary tangles in hippocampal CA1 region at $\times 10$ (scale bar $100 \mu \mathrm{m}$ ); (b) tau-positive neuritic plaques in hippocampal subiculum region at $\times 20$ (scale bar $50 \mu \mathrm{m}$ ); (c) $\mathrm{A} \beta$-positive senile plaques in the region of middle temporal cortex at $\times 20$ (scale bar $50 \mu \mathrm{m})$

\subsection{Discussion}

Our study demonstrates a trend in elderly brain neuropathology where AD-related pathologies are predominant in injury deaths caused by traffic accidents, whereas large vessel pathologies; IASCW and microscopic infarcts are predominant in natural deaths and also in suicide. There is a significant overrepresentation of NFTs identified in the region of entorhinal cortex, the first area of the brain to be affected in AD (van Hoesen et al., 1991). Therefore, our results suggest that early AD-related neuropathological changes may contribute sufficiently to elderly injury deaths caused by traffic accidents by affecting their cognitive status. For this screening, we have used the recent NIA-AA guidelines - a practical approach (Montine et al., 2012) to assess the neuropathological changes related to $\mathrm{AD}$ and LBDs. NIA-AA recommends immunohistochemistry as the most preferred methodology to screen AD-related pathologies and it was followed in this study ( $\beta$-amyloid for $A \beta$ plaques, phosphorylated tau for Braak and Braak NFT stages, and phosphorylated tau/ubiquitin for CERAD NP score). Further, we have obtained the relative prevalence of comorbid pathologies including CAA, LBDs, IASCW, white matter microscopic infarcts, and WMHs between injury and natural deaths. Thus, apart from AD-related pathologies, other causes of dementia which remain as possible etiological factors in elderly person's injury deaths could be reliably assessed. Moreover, we have employed a vigorous study method to count NFTs and SPs in specific brain regions (hippocampus, entorhinal cortex, superior frontal gyrus, and midbrain); thus, true extent of ADrelated pathologies was identified in respect of cause of death.

While this is the first autopsy verification study investigating dementia-related pathologies as etiological factors in injury deaths, we acknowledge that there are limitations such as sample size, incomplete clinical history of the recruited samples lacking objective psychometry and dementia scores, ubiquitin immunohistochemistry for labeling Lewy bodies instead of $\alpha$ synuclein, semi-quantitative assessments of certain comorbid pathologies lacking exact quantifications, and nonavailability of some brain regions as specified under minimum tissue requirements by the NIA-AA guidelines. In addition to above restrains, our study was based on cases from suicide and fatal traffic accidents, whereas other causes of injury deaths such as falls and drowning which may result from cognitive impairments also need to be included in future concerns.

Suicide in elderly individuals presents unique challenges to clinicians because older people are less likely to report depressive symptoms (Purandare et al., 2009). While high rates of 
psychiatric symptoms during the course of illness have been reported, (Aalten, 2005) the risk of suicide in people with dementia is generally considered to be low (Lim et al., Conwell et al., 2002). The contribution of dementia-related pathologies as the cause of suicide in a geriatric population remains questionable. Low risk of suicide in dementia cases has been partly attributed to the higher levels of personal supervision provided in such cases and the difficulties the person with cognitive impairments might have in planning and carrying out suicidal acts. Neuropathological confirmation of AD-related changes in elderly subjects who committed suicide has been limited to few case reports (Rohde, et al., 1995; Lesco, 1989), a single pilot case-control study (Rubio et al., 2001), and a large-scale study (Peisah et al., 2007). Rubio et al demonstrated that people with moderate-to-severe AD pathology were over-represented among those who committed suicide, suggesting that presence of Alzheimer pathology may increase the risk of suicide. However, a large-scale study by Peisah et al demonstrated that Alzheimer pathology was not over-represented in elderly suicide victims. The above studies were limited by the availability of tissue sections, to hippocampal and neocortical examination. Thus, only prevalence of AD-related changes could be reliably assessed. In the absence of ADrelated pathology, other causes of dementia such as LBDs or cerebrovascular diseases remain possible risk factors for the etiology in elderly persons' suicidal behavior.

On the other hand, cognitive decline due to aging has received much attention as a possible risk factor for fatal traffic accidents in elderly populations. As dementia becomes a risk factor in traffic accidents, it is reasonable to expect increased dementia-related neuropathologies in the brains of accident victims. However, neuropathological confirmation of AD-related changes in such cases has also been limited with few numbers of studies. The study of Viitanen et al in the aged motor vehicle drivers highlighted that incipient AD may contribute to fatal crashes of aged drivers. Therefore, the forensic autopsy of these victims should include neuropathological examination. Another similar study done by Gorrie et al suggested that increased mild neuritic changes, even sparse NPs in the brains of older drivers may be a factor for their cognitive impairments and needs to be replicated elsewhere to clearly establish the association between early AD pathology and crash involvement. Gorrie et al also carried out a study in older pedestrians and suggested that AD-related pathologies, especially NFTs, are more frequent in fatally injured elders and suggested that cognitive impairment associated with $\mathrm{AD}$; even the earliest stages of $\mathrm{AD}$ may be a risk factor for fatal traffic accidents in older pedestrians. In view of above studies, we found that none of the literature cumulatively reported the contribution of dementia, clinically and/or neuropathologically, to the injury deaths in elderly people. Further, none of the above studies assessed the actual burden/true extent of ADrelated pathologies among fatal traffic accidents, suicide, and natural deaths. Therefore, despite small sample size, our study would yield a precise estimate of contribution of AD-related pathologies as an etiological factor in injury deaths caused by traffic accidents in elderly people.

There are limited numbers of studies on pathology of AD from India and other low- and middleincome countries (LMICs) (Purohit et al., 2011; Wijesinghe et al., 2016; Wijesinghe et al., 2016; Yasha et al., 1997; Satishchandra et al., 1997; Barodawala and Ghadi et al., 1992; Shankar et al., 1988; Somasundaram, 1974; Dani et al., 1997; Ogeng'o et al., 1996; Osuntokun et al., 1995; 1994) where the proportion of people affected with dementia is anticipated to rise from 58\% in 2010 to 63\% in 2030 and $71 \%$ in 2050 (Alzheimer's Disease International, 2010). Within South Asia, Sri Lanka shows the fastest aging; $13 \%$ of population was aged over 60 years in 2011 whereas it was $\leq 8 \%$ in rest of the South Asia (World Health Organization, 2013). Prevalence of dementia in Sri Lanka based on clinical diagnosis is higher by comparing similar 
studies of other South Asians reported so far; Sri Lanka - 3.98\% (de Silva et al., 2003), India 2.7\% (Kalaria et al., 2008), and Bangladesh - 3.6\% (Palmer et al., 2014). In Sri Lanka, injury deaths are the second major cause of mortality; 233/100,000 populations in 2008, whereas in other South Asian countries, it is comparatively low (Afghanistan -149; Bangladesh - 91; Bhutan - 105; India - 99; Maldives - 53; Nepal - 58; Pakistan - 92/100,000 population in 2008) (World Health Organization, 2013). Among the causes of injury deaths, suicide rate is in peak (34.6 per 100,000 population in 2015) and comparatively higher than in other South Asian populations (Nepal - 7.2; India - 16.0; Bhutan - 12.1; Pakistan - 2.5; Bangladesh - 6.0; Maldives - 11.0; Afghanistan 7.1 per 100,000 population) (World Health Organization, 2015). Road traffic deaths (road traffic accidents [RTAs]) have also been steadily raising in Sri Lanka and considered as the third leading cause of injury deaths after suicide and collective violence (warrelated deaths) and the annual death rate of RTAs is approximately $12.1 / 100,000$ population (Department of Census and Statistics, Government of Sri Lanka, 2008). Although death counts due to RTAs are high between the ages of 20 and 55 years, which is likely a result of population age structure, the death rates continue to increase with age and are highest in elderly people (Department of Census and Statistics, Government of Sri Lanka, 2008). These are serious public health issues in Sri Lanka as well as in other LMICs; however, it has not been received priority by the government healthcare sectors and it has not been studied extensively by the healthcare professionals. Taken together, our findings suggest that forensic autopsy should include neuropathological examination to the brains of elderly injury deaths caused by fatal accidents aged $\geq 60$ years. Further, it is important for primary carers and healthcare professionals to have an awareness of a possible link between cognitive impairment or early stages AD and cause of death in the elderly. This provides an opportunity to reduce the risk of injury deaths in this age group.

\subsection{References}

Aalten P, de Vugt ME, Jaspers N, Jolles J, Verhey FR. The course of neuropsychiatric symptoms in dementia. Part I: Findings from the two-year longitudinal Maasbed study. Int J Geriatr Psychiatry 2005;20:523-30.

Alafuzoff I, Gelpi E, Al-Sarraj S, Arzberger T, Attems J, Bodi I, et al. The need to unify neuropathological assessments of vascular alterations in the ageing brain: Multicentre survey by the BrainNet Europe consortium. Exp Gerontol 2012;47:825-33.

Alzheimer Disease International. World Alzheimer Report 2010: The Global Economic Impact of Dementia. London: Alzheimer Disease International; 2010.

Barodawala SA, Ghadi PS. A progress report on the prevalence of Alzheimer's lesions in Bombay hospital population. Curr Sci 1992;63:449-55.

Beach TG, Wilson JR, Sue LI, Newell A, Poston M, Cisneros R, et al. Circle of Willis atherosclerosis: Association with Alzheimer's disease, neuritic plaques and neurofibrillary tangles. Acta Neuropathol 2007;113:13-21.

Braak H, Alafuzoff I, Arzberger T, Kretzschmar H, Del Tredici K. Staging of Alzheimer disease-associated neurofibrillary pathology using paraffin sections and immunocytochemistry. Acta Neuropathol 2006;112:389-404. 
Braak H, Braak E. Neuropathological stageing of Alzheimer-related changes. Acta Neuropathol 1991;82:239-59.

Braak H, Del Tredici K, Rub U, de Vos RA, Jansen Steur EN, Braak E. Staging of brain pathology related to sporadic Parkinson's disease. Neurobiol Aging 2003;24:197-211.

Classification of atherosclerotic lesions; a report of a study group. World Health Organ Tech Rep Ser 1958;57:1-20.

Conwell Y, Duberstein PR, Caine ED. Risk factors for suicide in later life. Biol Psychiatry 2002;52:193-204.

Dani SU, Pittella JE, Boehme A, Hori A, Schneider B. Progressive formation of neuritic plaques and neurofibrillary tangles is exponentially related to age and neuronal size. A morphometric study of three geographically distinct series of aging people. Dement Geriatr Cogn Disord 1997;8:217-27.

de Silva HA, Gunatilake SB, Smith AD. Prevalence of dementia in a semi-urban population in Sri Lanka: Report from a regional survey. Int J Geriatr Psychiatry 2003;18:711-5.

Eilertsen HH, Lilleng PK, Mæhle BO, Morild I. Unnatural death in the elderly: A forensic study from Western Norway. Forensic Sci Med Pathol 2007;3:23-31.

Gorelick PB, Scuteri A, Black SE, Decarli C, Greenberg SM, Iadecola C, et al. Vascular contributions to cognitive impairment and dementia: A statement for healthcare professionals from the American Heart Association/American Stroke Association. Stroke 2011;42:2672-713.

Gorrie CA, Rodriguez M, Sachdev P, Duflou J, Waite PM. Increased neurofibrillary tangles in the brains of older pedestrians killed in traffic accidents. Dement Geriatr Cogn Disord 2006;22:20-6.

Gorrie CA, Rodriguez M, Sachdev P, Duflou J, Waite PM. Mild neuritic changes are increased in the brains of fatally injured older motor vehicle drivers. Accid Anal Prev 2007;39:1114-20.

Government of Sri Lanka: Statistical Abstract 2008: Transport and Communication. Department of Census and Statistics, Sri Lanka; 2008.

Greenberg SM, Vonsattel JP. Diagnosis of cerebral amyloid angiopathy. Sensitivity and specificity of cortical biopsy. Stroke 1997;28:1418-22.

Grinberg LT, Thal DR. Vascular pathology in the aged human brain. Acta Neuropathol 2010;119:277-90.

Jellinger KA. Challenges in the neuropathological diagnosis of dementias. Int J Neuropathol $2013 ; 1: 8-52$.

Kalaria RN, Maestre GE, Arizaga R, Friedland RP, Galasko D, Hall K, et al. Alzheimer's disease and vascular dementia in developing countries: Prevalence, management, and risk factors. Lancet Neurol 2008;7:812-26. 
Kumar S, Verma AK. A study of elderly unnatural deaths in medico-legal autopsies at Lucknow locality. Med Sci Law 2014;54:127-31.

Lesco PA. Murder-suicide in Alzheimer's disease. J Am Geriatr Soc 1989;37:167-8.

Lim WS, Rubin EH, Coats M, Morris JC. Early-stage Alzheimer disease represents increased suicidal risk in relation to later stages. Alzheimer Dis Assoc Disord 2005;19:214-9.

McKeith IG, Dickson DW, Lowe J, Emre M, O'Brien JT, Feldman H, et al. Consortium on DLB. Diagnosis and management of dementia with Lewy bodies: Third report of the DLB Consortium. Neurology 2005;65:1863-72.

McKeith IG, Galasko D, Kosaka K, Perry EK, Dickson DW, Hansen LA, et al. Consensus guidelines for the clinical and pathologic diagnosis of dementia with Lewy bodies (DLB): Report of the consortium on DLB international workshop. Neurology 1996;47:1113-24.

Mirra SS, Heyman A, McKeel D, Sumi SM, Crain BJ, Brownlee LM, et al. The consortium to establish a registry for Alzheimer's disease (CERAD). Part II. Standardization of the neuropathologic assessment of Alzheimer's disease. Neurology 1991;41:479-86.

Montine TJ, Phelps CH, Beach TG, Bigio EH, Cairns NJ, Dickson DW, et al. National Institute on Aging-Alzheimer's Association guidelines for the neuropathological assessment of Alzheimer's disease: Practical approach. Acta Neuropathol 2012;123:1-11.

Nagy Z, Yilmazer-Hanke DM, Braak H, Braak E, Schultz C, Hanke J, et al. Assessment of the pathological stages of Alzheimer's disease in thin paraffin sections: A comparative study. Dement Geriatr Cogn Disord 1998;9:140-4.

Ogeng'o JA, Cohen DL, Sayi JG, Matuja WB, Chande HM, Kitinya JN, et al. Cerebral amyloid beta protein deposits and other Alzheimer lesions in non-demented elderly East Africans. Brain Pathol 1996;6:101-7.

Osuntokun BO, Ogunniyi A, Akang EE, Aghadiuno PU, Ilori A, Bamgboye EA, et al. Beta A4-amyloid in the brains of non-demented Nigerian Africans. Lancet 1994;343:56.

Osuntokun BO, Ogunniyi A, Junaid TA, Lekwauwa UG. Autopsy survey for Alzheimer's disease in Nigerian Africans: A preliminary report. Afr J Med Med Sci 1995;24:75-9.

Palmer K, Kabir ZN, Ahmed T, Hamadani JD, Cornelius C, Kivipelto M, et al. Prevalence of dementia and factors associated with dementia in rural Bangladesh: Data from a crosssectional, population-based study. Int Psychogeriatr 2014;26:1905-15.

Peisah C, Snowdon J, Gorrie C, Kril J, Rodriguez M. Investigation of Alzheimer's diseaserelated pathology in community dwelling older subjects who committed suicide. J Affect Disord 2007;99:127-32.

Purandare N, Voshaar RC, Rodway C, Bickley H, Burns A, Kapur N, et al. Suicide in dementia: 9-year national clinical survey in England and Wales. Br J Psychiatry 2009;194:175-80. 
Purohit DP, Batheia NO, Sano M, Jashnani KD, Kalaria RN, Karunamurthy A, et al. Profile of Alzheimer's disease-related pathology in an aging urban population sample in India. $\mathbf{J}$ Alzheimers Dis 2011;24:187-96.

Rohde K, Peskind ER, Raskind MA. Suicide in two patients with Alzheimer's disease. J Am Geriatr Soc 1995;43:187-9.

Rubio A, Vestner AL, Stewart JM, Forbes NT, Conwell Y, Cox C, et al. Suicide and Alzheimer's pathology in the elderly: A case-control study. Biol Psychiatry 2001;49:137-45.

Satishchandra P, Yasha TC, Shankar L, Santosh V, Das S, Swamy HS, et al. Familial Alzheimer disease: First report from India. Alzheimer Dis Assoc Disord 1997;11:107-9.

Shankar SK, Chandra PS, Rao TS. Alzheimer's disease - Histological, ultrastructural, and immunochemical study of an autopsy proven case. Indian J Psychiatry 1988;30:291-8.

Somasundaram O. Alzheimer's disease. J Indian Med Assoc 1974;63:66-8.

Thal DR, Rüb U, Orantes M, Braak H. Phases of A beta-deposition in the human brain and its relevance for the development of AD. Neurology 2002;58:1791-800.

van Hoesen GW, Hyman BT, Damasio AR. Entorhinal cortex pathology in Alzheimer's disease. Hippocampus 1991;1:1-8.

Viitanen M, Johansson K, Bogdanovic N, Berkowicz A, Druid H, Eriksson A, et al. Alzheimer changes are common in aged drivers killed in single car crashes and at intersections. Forensic Sci Int 1998;96:115-27.

Wijesinghe P, Shankar SK, Yasha TC, Gorrie CA, Amaratunga D, Hulathduwa SR, et al. Cytoskeletal pathologies of age related diseases between elderly Sri Lankan and Indian brain samples. Curr Alzheimer Res 2016;13:268-80.

Wijesinghe P, Shankar SK, Yasha TC, Gorrie CA, Amaratunga D, Hulathduwa SR, et al. Vascular contributions in Alzheimer related neuropathological changes: First autopsy evidence from a South Asian ageing population. J Alzheimers Dis 2016;54:1607-18.

World Health Organization. Suicide Rates, age standardized - Data by country. Geneva: World Health Organization Press; 2015. [Retrieved on 2017 April 13]. https://en.wikipedia.org/wiki/List_of_countries_by_suicide_rate\#cite_note-5

World Health Organization. World Health Statistics 2013. Geneva: World Health Organization Press; 2013.

Yasha TC, Shankar L, Santosh V, Das S, Shankar SK. Histopathological \& immunohistochemical evaluation of ageing changes in normal human brain. Indian J Med Res 1997;105:141-50. 


\section{CHAPTER 5}

Circle of Willis abnormalities and their clinical importance in ageing brains: A cadaveric anatomical and pathological study

Wijesinghe P, Steinbusch HWM, Shankar SK, Yasha TC, De Silva KRD

Journal of Chemical Neuroanatomy, 2020;106;101772

doi.org/10.1016/j.jchemneu.2020.101772 


\begin{abstract}
The circle of Willis (CW) located at the base of the brain forms an important collateral network to maintain adequate cerebral perfusion, especially in clinical situations requiring compensatory changes in blood flow. Morphopathological changes in the $\mathrm{CW}$ may relate to the severity of the symptoms of certain neurodegenerative and cerebrovascular disorders. The purpose of this study was to investigate the $\mathrm{CW}$ abnormalities and their clinical importance in ageing brains. The $\mathrm{CW}$ was examined macroscopically in 73 formalin-fixed samples to determine the degree of stenosis of each $\mathrm{CW}$ component, atherosclerosis of the $\mathrm{CW}$, hypoplasia (threshold diameter < 1mm), anatomical variations and aneurysms. Age-related neurodegenerative and cerebrovascular pathologies were screened using immunohistopathological techniques on specific neuroanatomical regions based on standard guidelines. The majority of the elderly brains - 93\% (68/73) presented at least a single hypoplastic CW component at death. Anatomical variations were mostly identified in communicating arteries, followed by proximal posterior and anterior cerebral arteries. Arterial bifurcations were found to be the predominant sites for cerebral aneurysms. More than $90 \%$ of the elderly brains presented $\mathrm{CW}$ atherosclerosis at death. $\mathrm{CW}$ abnormalities did not show any strong associations with neurodegenerative pathologies except for an "at risk" significant association observed between Braak's neurofibrillary tangle (NFT) stages 1-VI and CW atherosclerosis grades $\geq$ mild $(\mathrm{p}=0.05)$. However, a significant association was observed between microscopic infarcts in deep white matter and hypoplasia in communicating arteries with Fisher's exact test $(\mathrm{p}<0.05)$. Overall, $\mathrm{CW}$ abnormalities were predominant in the ageing brains, however their relationships to the occurrence and severity of the symptoms of neurodegenerative pathologies were found to be low.
\end{abstract}

Keywords: ageing brains; circle of Willis atherosclerosis; anatomical variations; neurodegenerative pathologies; microscopic infarcts; vascular genetic risk factors

\title{
5.1 Introduction
}

The circle of Willis $(\mathrm{CW})$ located at the base of the brain forms an important collateral network to maintain adequate cerebral perfusion, especially in clinical situations requiring compensatory changes in blood flow. A typical CW is bilaterally symmetrical and a complete ring of arteries (Hoksbergen et al., 2003). There may be variations in this typical configuration. The CW components generally vary in caliber; often they are hypoplastic, duplicated or even absent (Hoksbergen et al., 2003). It has been reported that in more than $50 \%$ of the healthy brains (Alpers et al., 1959; Lippert and Pabst, 1985; Macchi et al., 2005) and in more than 80\% of the dysfunctional brains (Riggs and Rupp, 1963), the CW contains at least one component that is absent or underdeveloped. Anatomical variations are probably genetically determined, develop in early embryonic stages and persist in post-natal life (Iqbal, 2013). Topological variations may affect the ability to maintain cerebral perfusion, which may increase the risk of stroke and transient ischemic attack in patients with atherosclerosis (Henderson et al., 2000). Typically, older patients who have a limited ability to compensate for acute changes in blood flow are at greater risk for developing an acute ischemia (stroke) or chronic hypoperfusion. Intracranial atherosclerosis increases the risk of stroke, and stroke is one of the main risks for vascular dementia (VaD) (Sacco et al. 1998). The significance of these problems should not be underestimated since stroke ranks second among the leading causes of death and third among the leading causes of disability in elderly populations (Feigin et al., 2017). 
It is well known that subjects with cardiovascular risk factors and a history of stroke have increased risk of both VaD and Alzheimer's disease (AD) (Hofman et al., 1997; Breteler, 2000; Snowdon et al., 1997). Vascular genetic risk factors include apolipoprotein E (ApoE), (Schachter et al., 1994; Corder et al., 1993; Mahley, 1998) angiotensin converting enzyme (ACE) (Catto et al., 1996; Cambien et al., 1992), methylenetetrahydrofolate reductase (MTHFR) (Frosst et al., 1995) and Factor V Leiden (FVL) (Bertina et al., 1994). Chapman et al (1998) determined the ApoE, ACE, MTHFR and FVL polymorphisms in AD and VaD patients and reported that except for the association between ApoE $\varepsilon 4$ allele and AD, genetic risk factors for vascular diseases were not associated with $\mathrm{VaD}$. Our previous work on elderly Sri Lankan brains demonstrated that these were more susceptible to age-related cytoskeletal pathologies compared with those of other South Asian elderly populations and these variations might be related to their genetic, dietary and environmental factors (Wijesinghe et al., 2016a). Here, the minimum recommended brain regions for $\mathrm{AD}$ and Lewy body disease (LBD) neuropathologic change were sampled and evaluated to identify typical appearance in the elderly samples (Montine et al. 2012). We also demonstrated in elderly Sri Lankan brains that AD-related neuropathological stages were significantly associated with risk factors including increasing age, illiteracy and $A p o E$ polymorphism. In addition, we have shown significant associations with coexisting cerebral small artery pathologies such as white matter hyperintensities and cerebral amyloid angiopathy (CAA) (Wijesinghe et al., 2016b).

The present study examined abnormalities of the CW in ageing brains to assess the clinical importance of these anatomical factors in age-related neurodegenerative and cerebrovascular pathologies, and to determine the associations between genetic risk factors and $\mathrm{CW}$ pathologies.

\subsection{Materials and methods}

The circle of Willis from 73 elderly decedents (male: female $=50: 23$; age range 51-89 years; mean age \pm standard deviation $(\mathrm{SD})=67.7$ years \pm 9.96 ; median age 69.0 years; mean post mortem interval $17.3 \mathrm{~h} \pm 14.2 \mathrm{SD}$ ) was collected in the Department of Judicial Medical Office, Colombo South Teaching Hospital following approval by the Institutional Scientific Ethics Committee to carry out the study and informed consent from kin. An ante-mortem questionnaire was administrated retrospectively to obtain decedent's demographics, medical history and health habits from kin. All data were held confidential and all investigators were blinded to case history. Assessment of CW abnormalities and genotyping were carried out at the Genetic Diagnostic Research Laboratory, University of Sri Jayewardenepura, Nugegoda, Sri Lanka. Immunohistopathological staining and neuropathological diagnosis were carried out at the Department of Neuropathology, National Institute of Mental Health and Neurosciences (NIMHANS), Bangalore, India.

\subsubsection{Assessments of ageing $\mathrm{CW}$ samples}

CW samples preserved in 10\% neutral formalin (Catalog no. HT501128, Sigma-Aldrich) were used to study anatomical variations (Ozaki et al., 1977), aneurysms, degree of stenosis, diameter and length of the each CW component such as vertebral artery (VA), basilar artery (BA), P1 segment of the posterior cerebral artery (PCAP1 or proximal PCA), posterior communicating artery (PcomA), internal carotid artery (ICA), middle cerebral artery (MCA), A1 segment of the anterior cerebral artery (ACAA1 or proximal ACA) and anterior communicating artery (AcomA). A portable measuring microscope (Maxta Measuring 
Systems, Graticules Ltd, England) and a measuring scale were used to measure each CW component half circumference and length, respectively.

A portable microscope containing a graticule was placed perpendicular to each $\mathrm{CW}$ component and the flattened component half circumference was measured twice by the first author and the average score was reported. Segments in which half circumference was measured were taken from the following corresponding regions: right and left ICA close to their distal ends, right and left proximal part of ACA and PCA, right and left PcomA and VA at their middle point, and AcomA and BA at their middle point as described in our previous studies (De Silva et al., 2011; 2009). For the segments with severe and occluded stenosis grades, component artery circumference was measured after opening and removing the atherosclerotic plaques. The component artery diameter was calculated from the measured half circumference to identify the relative normality of a typical CW [diameter $(d)=$ circumference (c) $/ \pi, d=c / 2 \pi$ ]. As described in our previous studies (De Silva et al., 2011; 2009), the CW was defined as "typical CW" only if all of the following criteria were met.

1) all the components (ICA, ACAA1, AcomA, PcomA and PCAP1) were present;

2) origin of the components forming the $\mathrm{CW}$ was from its normal source with no extra vessels and

3) the external diameter of a component was not hypoplastic (>1mm).

There is continuing discussion on threshold diameter value for hypoplasia. Krabbe-Hartkamp et al (1998) study on European population recommended a threshold value of $0.8 \mathrm{~mm}$ to define hypoplasia. A recent study of an Asian population by Li and colleagues (Li et al., 2011) has recommended a threshold value of $1 \mathrm{~mm}$. Based on our previous studies (De silva et al., 2011; 2009) and Li et al's (2011) recommendation, we used a threshold value of $1 \mathrm{~mm}$ to determine the hypoplasia in CW components.

The degree of stenosis of the each CW component was measured macroscopically and graded semi quantitatively as none or mild, moderate (more than half the diameter preserved), severe (less than half the diameter preserved) and occlusion [(World Health Organization (WHO), 1958]. Except for small caliber arteries (e.g., communicating arteries), each CW component was opened using an angled scissor to determine whether more than half the lumen was preserved or less the half the lumen was preserved or fully occluded; and to identify the nature of atherosclerotic plaques whether they were diffuse (plaques that spread out over a wide area) or discrete / localized (individually detached or distinct plaques). The degree of stenosis in small caliber arteries was determined visually by the presence of atheromatous plaque and its appearance: diffuse or discrete. Finally, CW atherosclerosis was graded semi quantitatively as none, mild, moderate and severe based on the degree of stenosis of all CW components (WHO, 1958) and cross-checked by gross visual inspection as indicated by Beach et al (2007).

\subsubsection{Screening of neurodegenerative pathologies using histopathological / immunohistochemical techniques}

For this purpose, brain samples from 50 out of 73 elderly subjects at the age of 60 years or above $(72 \cdot 1$ years $\pm 7 \cdot 8$; male: female $=29: 21)$ were used. Elderly subjects who were identified with comparatively insufficient data (unknown history of health habits, family history, education level, etc.), and aged below 60 years were excluded. All the recruited cases had incomplete clinical histories, except three cases which had been clinically diagnosed with Parkinson's disease (PD). Specific neuroanatomical regions sampled for neuropathological diagnosis were dissected from both hemispheres including hippocampus along with parahippocampal gyrus, superior frontal gyrus, middle temporal gyrus, superior parietal lobule and midbrain at superior colliculus level. After routine histological evaluation [Haematoxylin 
and Eosin $(\mathrm{H} \& \mathrm{E})$ staining], brain sections $(4 \mu \mathrm{m}$ thick) were immunostained by standard immunoperoxidase technique following antigen retrieval by heat and $\mathrm{DAB} / \mathrm{H}_{2} \mathrm{O}_{2}$ as the chromogen to visualize the immunolabelling (Dako Real ${ }^{\mathrm{TM}}$ Envision $^{\mathrm{TM}}$ Detection System, Peroxidase/DAB ${ }^{+}$, Rabbit/Mouse). For this screening, three antibodies namely (i) $\beta$ amyloid 1:200 dilution (Novacastra ${ }^{\mathrm{TM}}$ mouse monoclonal antibody, LEICA Biosystems Newcastle Ltd, UK), (ii) ubiquitin - 1:150 dilution (Novacastra ${ }^{\mathrm{TM}}$ mouse monoclonal antibody, LEICA Biosystems Newcastle Ltd, UK), and (iii) phosphorylated tau - PHF-1 monoclonal antibody (1:50 dilution, gifted by Dr. Inge Grundke-Iqbal, discoverer of the abnormal hyperphosphorylation of tau in $\mathrm{AD}$ ) were used. Positive controls were clinically and neuropathologically confirmed brain samples for AD, LBDs, CAA and other tauopathies obtained from Human Brain Bank, NIMHANS, India. Negative controls were carried out without primary antibodies.

The diagnostic criteria for $\mathrm{AD}$ and $\mathrm{LBDs}$ neuropathologic change were based on National Institute on Aging-Alzheimer's Association guidelines - a practical approach (NIA-AA) (Montine et al., 2012). The extent of neurodegenerative pathologies was determined by the first author under the direct guidance of two neuropathologists SKS and YTC. Final decisions were made jointly. Actual burden of AD-related neuropathological markers [neurofibrillary tangles (NFTs) and senile plaques (SPs)] were counted in specific brain regions such as hippocampus and parahippocampus, superior frontal gyrus and midbrain based on the methods described by Purohit and colleagues (2011). Working sheets used for semi quantitative grading and counting are attached as a supplementary file. A medium high power $(20 \mathrm{X})$ objective lens producing a visual field $0.785 \mathrm{~mm}^{2}$ (field diameter $=2.0 \mathrm{~mm}$ ) was used for counting. Lesions were counted in medium high (200 X magnification, Olympus U-CTR30-2 Trinocular objective tubes and $10 \mathrm{X}$ eye piece) power fields and then converted into average per $200 \mathrm{X}$. Areas with high number of SPs / NFTs were selected and the visual counts were carried out in five nonoverlapping fields and the average was presented. CAA in leptomeningeal and cortical arteries of the specific neuroanatomical regions were graded semi quantitatively (grade $0,1,2,3$ and 4) based on Greenberg and Vonsattel (1997) specifications and the average CAA grade was reported for each case.

The extent of microscopic infarcts in deep white matter was determined in all 73 elderly brain samples. Deep white matter sections ( $7 \mu \mathrm{m}$ thick) sampled from the "body" of corpus callosum, the major inter-hemispheric white matter tract, were stained using Luxol Fast Blue (LFB) and Cresyl violet, and graded semi quantitatively as none to mild and moderate to severe. Both right and left hemispheric sections were examined in five non-over lapping $40 \mathrm{X}$ (scale bar $=$ $200 \mu \mathrm{m}$ ) magnification fields, and the highest grade at least in one field (see Fig. 3E-G) was reported for each case.

\subsubsection{Genotyping}

Cadaveric blood specimens collected at post-mortem from 69 out of 73 elderly subjects were used for this purpose. Briefly, samples were minced thoroughly, washed in $1 \mathrm{ml}$ of saline $(9 \mathrm{~g} / \mathrm{L}$ $\mathrm{NaCl})$ and subjected to a series of centrifugations and digestions of nucleated leukocytes with lysis buffers. Genomic DNA was extracted using phenol/ chiasm method and used for subsequent genotyping. Polymorphisms in genes encoding ApoE, ACE, MTHFR (alanine 223 valine: MTHFR C677T), and FVL (arginine 506 glutamine: FVL G1691A) were detected using polymerase chain reaction (PCR) based restriction fragment length polymorphism (RFLP). 


\subsubsection{Statistical analysis}

For the analysis, statistical software SPSS for windows version 16.0, SPSS Inc., Chicago, USA was used. The non-parametric Mann-Whitney $U$ test was used to identify the differences in each CW component stenosis index, diameter and length between sex and hemispheres. To determine significant differences among age groups, non-parametric Kruskal-Wallis test was used. Binary logistic regression was used to determine the risk factors for $\mathrm{CW}$ atherosclerosis including age, sex, genetic risk factors (ApoE, ACE, MTHFR and $F V L$ ), health habits (smoking and alcohol use) and the past medical history (diabetes, high blood pressure, ischemic heart disease and high cholesterol). Fisher's exact test ( 2 X 2 table) was used to determine the degree of association between genetic polymorphisms and age groups, hypoplastic CW components and microscopic infarct pathology in deep white matter, and between AD, PD and CAA neuropathological stages and CW atherosclerosis grades. For this analysis, neuropathological stages were dichotomized based on the number of cases that presented the pathology and by the severity or topographical progression (involvement of different brain regions) as described below. Level of significance was set at $p<0.05$ for all the statistical tests.

I. CERAD (Consortium to Establish a Registry for Alzheimer's disease) neuritic plaques (NPs) scores were divided into none vs. CERAD scores A to $\mathrm{C}$ (presence of tau positive NPs) as few numbers of cases presented NPs $(6 / 50)$,

II. Thal Abeta $(\mathrm{A} \beta)$ phases were divided into none vs. phases $\geq 1(12 / 50)$, and phases $<2$ $(4 / 50)$ vs. phases $\geq 2(8 / 50)$ as few numbers of cases presented $A \beta$ plaques and the neocortical $A \beta$ plaques are considered as the best correlate for cognitive impairment in $A D$, III. Braak staging was divided into none vs. stages I-VI (42/50, presence of tau positive neurofibrillary pathology), stages 0-II (24/50) vs. stages III-VI (18/50, moderate to severe), and stages 0-III (35/50) vs. stages IV-VI (7/50, moderately high to severe) as neurofibrillary pathology was detected more frequently than tau and $\mathrm{A} \beta$ positive plaques and based on its topographical progression.

IV. CAA was divided into none vs. grades 1-4 (10/50) and

V. Lewy body pathologies were divided into none vs. stages I-IV (5/50) as few numbers of cases presented Lewy bodies.

\subsection{Results}

5.3.1 CW component artery length and diameter, relationship between diameter and degree of stenosis, and the lateral effects

CW components lengths and diameters were summarized in Table 1. CW component mean length and diameter were not significantly different between right and left hemispheres and among them, PcomA was hypoplastic in the left. Among the age groups, diameter varied significantly in left VA $(\mathrm{p}=0.002)$, BA $(\mathrm{p}=0.036)$, and in the left PCAP1 ( $=0.037)$. MannWhitney $U$ test revealed that between sexes diameter varied significantly in PCAP1 $(\mathrm{p}=0.029)$ and in AcomA ( $\mathrm{p}=0.042)$. 


\begin{tabular}{lllllll}
\hline $\begin{array}{l}\text { CW } \\
\text { component } \\
\text { artery }\end{array}$ & \multicolumn{2}{l}{ Length $(\mathbf{c m})$} & & & \multicolumn{3}{l}{ External Diameter $(\mathbf{m m})$} \\
\cline { 2 - 7 } & mean \pm S.E. & minimum & maximum & mean \pm S.E. & minimum & maximum \\
\hline VA(R) & $1.75 \pm 0.113$ & 0.50 & 3.80 & $2.11 \pm 0.084$ & 1.11 & 4.45 \\
VA(L) & $1.73 \pm 0.109$ & 0.60 & 3.20 & $2.26 \pm 0.065$ & 0.00 & 3.18 \\
BA & $3.06 \pm 0.055$ & 1.50 & 4.50 & $2.72 \pm 0.064$ & 1.34 & 4.45 \\
PCAP1(R) & $0.68 \pm 0.027$ & 0.30 & 1.50 & $1.61 \pm 0.05$ & 0.76 & 2.55 \\
PCAP1(L) & $0.65 \pm 0.030$ & 0.00 & 1.50 & $1.64 \pm 0.05$ & 0.00 & 2.23 \\
PcomA(R) & $1.53 \pm 0.049$ & 1.00 & 3.00 & $1.00 \pm 0.059$ & 0.32 & 2.42 \\
PcomA(L) & $1.56 \pm 0.056$ & 0.80 & 3.40 & $0.88 \pm 0.048$ & 0.34 & 1.91 \\
ICA(R) & $0.81 \pm 0.031$ & 0.10 & 1.30 & $3.00 \pm 0.065$ & 1.59 & 4.45 \\
ICA(L) & $0.73 \pm 0.029$ & 0.00 & 1.20 & $3.00 \pm 0.066$ & 1.62 & 4.45 \\
MCA(R) & $1.35 \pm 0.057$ & 0.30 & 2.20 & $2.27 \pm 0.038$ & 1.59 & 2.92 \\
MCA(L) & $1.25 \pm 0.053$ & 0.50 & 2.40 & $2.26 \pm 0.039$ & 1.59 & 3.18 \\
ACAA1(R) & $1.58 \pm 0.032$ & 1.00 & 2.60 & $1.59 \pm 0.043$ & 0.38 & 2.23 \\
ACAA1(L) & $1.52 \pm 0.029$ & 1.00 & 2.10 & $1.57 \pm 0.041$ & 0.60 & 2.55 \\
AcomA & $0.27 \pm 0.017$ & 0.05 & 0.60 & $1.14 \pm 0.07$ & 0.19 & 3.18 \\
\hline
\end{tabular}

Table 1. Circle of Willis components length and external diameter Measurements were taken on formalin preserved CW samples representing an elderly Sri Lankan population $(\geq 50$ years)

The relationship between each CW component degree of stenosis and diameter is presented in Fig. 1 where the larger arteries were more atherosclerotic and vice versa. Atherosclerotic plaques in the majority of the larger arteries were diffuse and in the smaller caliber arteries they were localized or discrete (Table 2).

The nature of atherosclerotic plaques was determined macroscopically. Only CW components that presented moderate and severe stenosis grades were used for this purpose. Moderate to severe stenosis grades were predominantly found in BA $-73.2 \%$, followed by ICA $-72.1 \%$. 


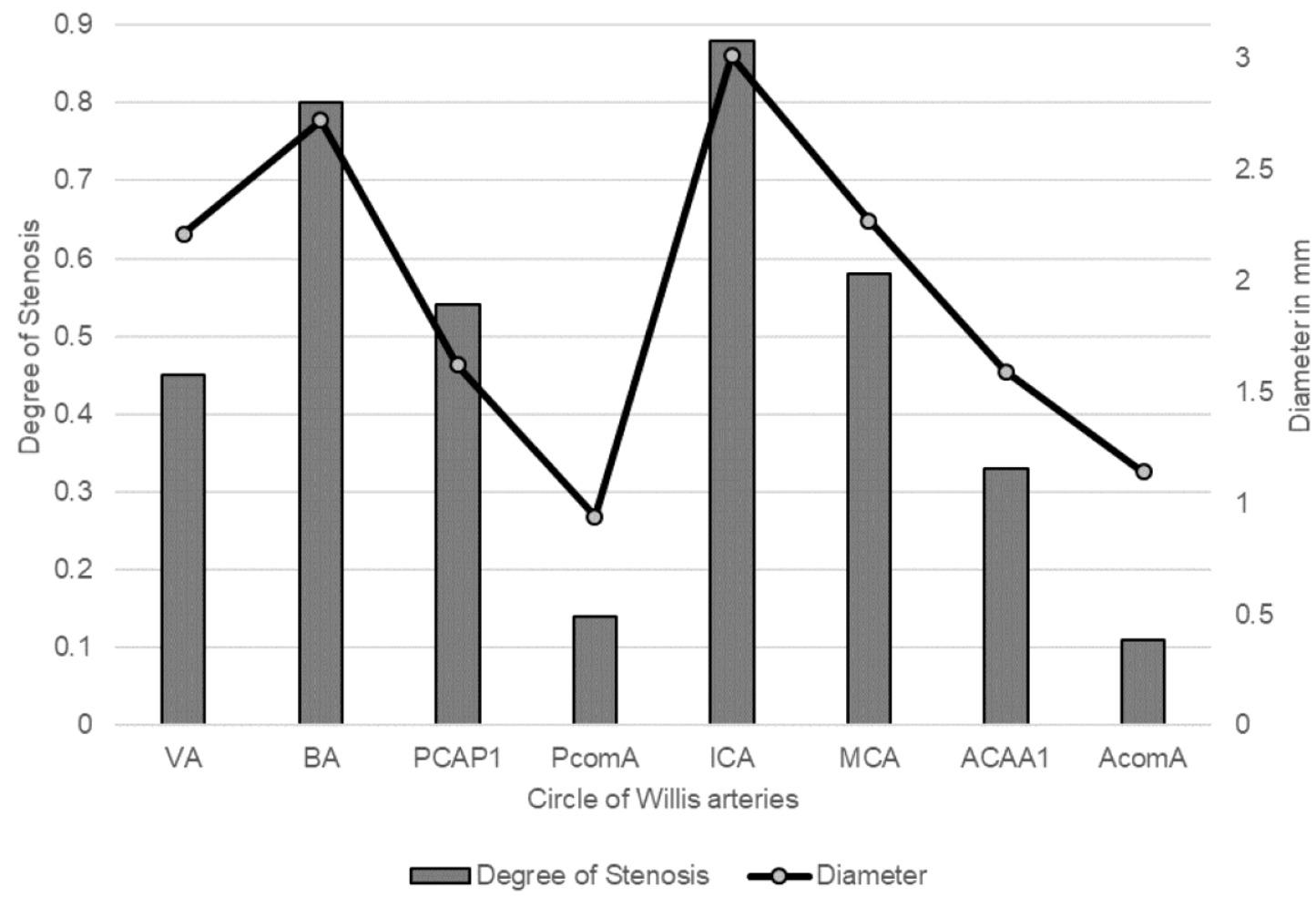

Fig. 1. The relationship between CW components' average stenosis grades and average diameters

CW components' average stenosis grades and diameters are illustrated using a histogram and line graph, respectively. Degree of stenosis was graded semi quantitatively as none (0), mild (1), moderate (2), severe (3) and occlusion (4) (WHO, 1958).

\begin{tabular}{llllll}
\hline $\begin{array}{l}\text { CW } \\
\text { component } \\
\text { artery }\end{array}$ & \multicolumn{2}{l}{ Degree of Stenosis $(\%$ of cases) } & \multicolumn{2}{l}{$\begin{array}{l}\text { Nature of atherosclerotic } \\
\text { plaques } \begin{array}{l}\text { \% of cases) } \\
\text { discrete }\end{array}\end{array}$} \\
& none/mild & moderate & severe & diffuse & \\
\hline VA & 47.7 & 49.5 & 2.8 & 33.0 & 18.9 \\
BA & 26.8 & 66.2 & 7.0 & 47.1 & 26.1 \\
PCAP1 & 51.1 & 43.2 & 5.7 & 29.7 & 19.2 \\
PcomA & 87.1 & 11.4 & 1.5 & 6.5 & 6.5 \\
ICA & 27.8 & 54.3 & 17.8 & 55.4 & 16.7 \\
MCA & 47.1 & 45.7 & 7.1 & 36.9 & 15.9 \\
ACAA1 & 67.1 & 32.1 & 0.7 & 15.7 & 17.1 \\
AcomA & 80.0 & 17.1 & 2.8 & 5.7 & 14.2 \\
\hline
\end{tabular}

Table 2. The degree of stenosis and the nature of atherosclerotic plaques $\mathrm{CW}$ components that presented none to mild stenosis grades are not included in determining the nature of atherosclerotic plaques in each case. 
There were no statistically significant differences between left and right hemispheric CW components in respect of degree of stenosis, diameter and length based on the non-parametric Mann-Whitney $U$ test.

\subsubsection{Anatomical variations}

One hundred and nineteen $\mathrm{CW}$ components showed anatomical variations including asymmetry VA - 3; non-fused and fenestrated BA - 3; absence of proximal PCA - 2; primitive PCA - 1; asymmetry proximal PCA - 8; string like PcomA - 35; asymmetry PcomA - 18; early duplication of MCA - 1; asymmetry proximal ACA - 8; median distal ACA - 3; median proximal ACA - 2; duplication of proximal ACA - 1; duplication of distal ACA - 2; X shaped (one/two point fusion) ACA - 20; and fenestration of the AcomA including Y shaped - 4, V shaped - 1, N shaped - 1, H shaped - 3 and double - 3. Some of the anatomical variations are illustrated in Fig. 2 with black solid arrows and lower-case letters. Asymmetric CW components are indicated by "a" and "b" in a 62-year-old male, and by "g" in an 89-year-old female samples; symmetric string like $\mathrm{CW}$ components are indicated by " $\mathrm{f}$ " and duplication of MCA by "e" in a 62-year-old female sample, and fenestrations in AcomA are indicated by "c", "d" and " $h$ " in above samples, respectively. Adult and fetal or embryonic configurations of the posterior bifurcation of the PcomA are indicated in panel "A". Diameter of the proximal PCA was larger than PcomA in adult configuration, and diameter of the PcomA was larger than proximal PCA in fetal configuration (Van Overbeeke et al., 1991).

\subsubsection{Hypoplasticity}

Sixty-eight out of $73 \mathrm{CW}$ samples (93\%) presented at least a single hypoplastic CW component at death. Of the 133 hypoplastic CW components, $74 \%$ (99/133) was identified posteriorly and $26 \%$ (34/133) was found anteriorly. PcomA was hypoplastic bilaterally in 35 cases (26\%) and unilaterally in 18 cases (14\%), 7 on the right and 11on the left side of the CW. The P1 of the PCA was hypoplastic bilaterally in 1 case (1\%) and unilaterally in 9 cases (7\%), 5 on the right and 4 on the left. The AcomA was hypoplastic in 27 cases $(20 \%)$. The A1 of the ACA was hypoplastic unilaterally in 7 cases $(5 \%), 4$ on the right and 3 on the left.

\subsubsection{Cerebral aneurysms}

Cerebral aneurysms (11/73) identified in these elderly CW samples were as follows: fusiform in vertebrobasilar system - 2 and at the bifurcation of ICA-MCA - 2 and their average diameters were $4.45 \mathrm{~mm}$ and $4.0 \mathrm{~mm}$, respectively. A saccular form was identified at the fusion of ACA 2; AcomA - 1; and at the bifurcation of ACA-AcomA - 1; BA-PCA - 1; ICA-MCA - 1 and ICA-PcomA - 1. Some of the cerebral aneurysms identified in these CW samples are illustrated in Fig. 2 with white solid arrows and lower-case letters. Saccular forms are indicated by "j" at the bifurcation of ICA-PcomA in an 89-year-old female and by " $k$ " at the bifurcation of ICAMCA in a 79-year-old female samples. Fusiform is indicated by "l" at the bifurcation of ICAMCA in a 79-year-old female sample. 


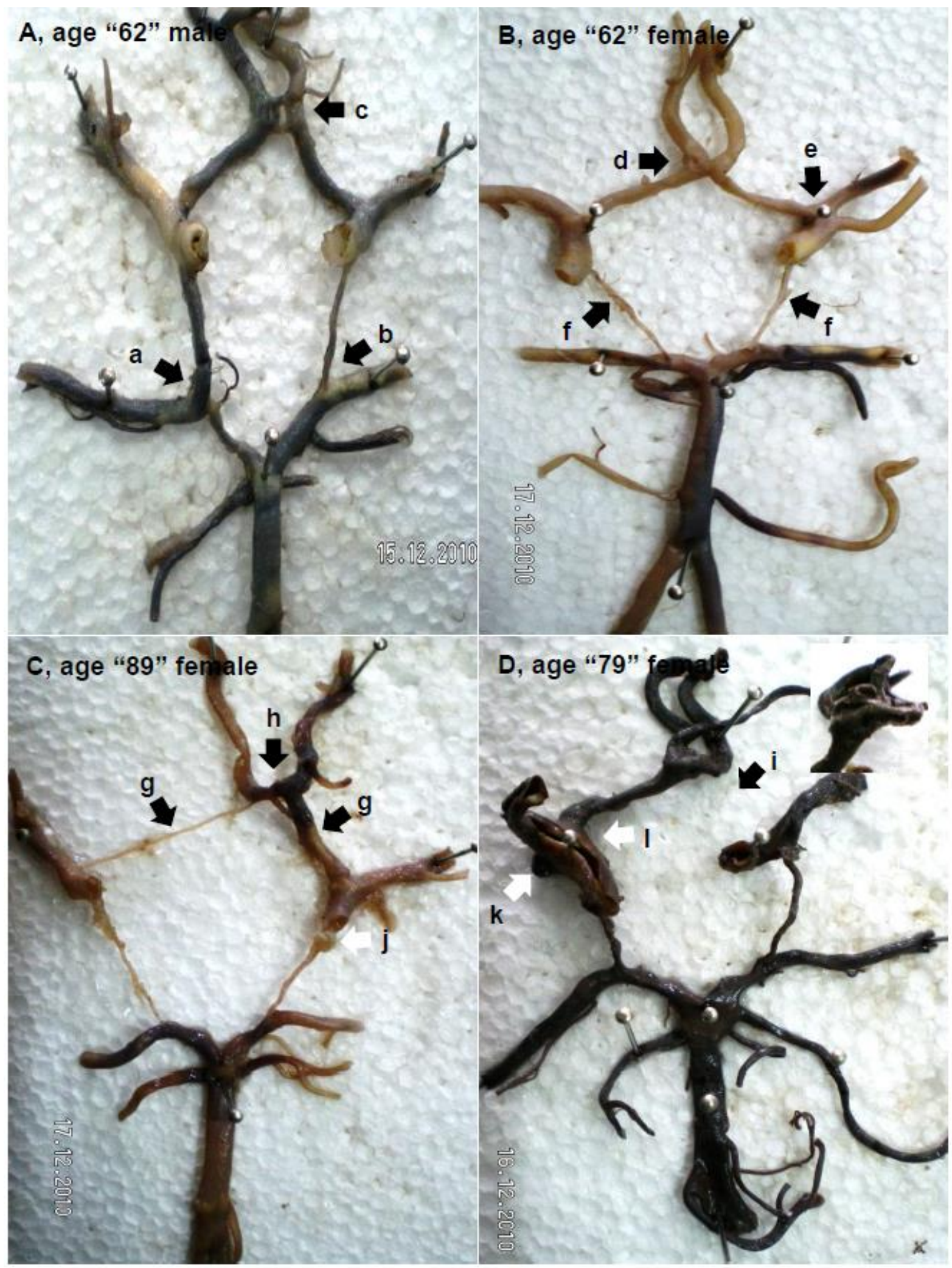

Fig. 2: Age-related circle of Willis abnormalities

Anatomical variations and aneurysms are indicated by black and white solid arrows, respectively. CW samples were from (A) 62-year-old male, (B) 62-year-old female, (C) 89year-old female and (D) 79-year-old female brains: (a) fetal / embryonic configuration where PcomA diameter is $1.62 \mathrm{~mm}$ and proximal PCA diameter is $0.86 \mathrm{~mm}$; (b) adult configuration 
where proximal PCA diameter is $2.23 \mathrm{~mm}$ and PcomA diameter is $0.76 \mathrm{~mm}$; (c) H shaped AcomA, (d) X shaped ACA, (e) early duplication of MCA, (f) symmetric string like PcomA, (g) asymmetry proximal ACA, (h) duplication of distal ACA; (i) absence of proximal ACA; (j) saccular form at the bifurcation of ICA-PcomA, $(\mathrm{k})$ saccular form at the bifurcation of ICAMCA, and (l) fusiform at the bifurcation of ICA-MCA.

\subsubsection{Vascular genetic risk factors and $\mathrm{CW}$ atherosclerosis}

Allelic frequencies of the genes encoding for ApoE, ACE, MTHFR and $F V L$ are summarized (Table 3). ApoE $\varepsilon 4$ allele frequency was high in young elderly decedents (56\%, age range - 50 to 69 years) compared to old elderly decedents (44\%, age range - 70 years and above) but the association (ApoE $\varepsilon 4$ allele and age at death) was not statistically significant $(\mathrm{p}=0.789$, Fisher's exact test). In contrast, frequency of $A C E D D$ genotypes was high in old elderly decedents $(68 \%)$ and the association ( $A C E D D$ genotype and age at death) was statistically significant $(\mathrm{p}=0.037)$.

At the age of 50 and above, prevalence of $\mathrm{CW}$ atherosclerosis was as follows: none $10 \%(7 / 73)$, mild $37 \%$ (27/73), moderate $37 \%$ (27/73) and severe $16 \%(12 / 73)$. More than $90 \%$ of the elderly Sri Lankan brains had this pathology at death. The severity of this condition was significantly related to presence of hypertension [odds ratio $(\mathrm{OR})=5 \cdot 68,95 \%$ CI 1.00-32.18, $\mathrm{p}<0.05]$ and ApoE $\varepsilon 3 / \varepsilon 4$ genotype (OR $=4.48,95 \%$ CI 1.09-18.44, p = 0.038). But, the presence (mild/ moderate/ severe) of atherosclerosis [90\% (66/73)] was related to age $(\mathrm{OR}=$ $1 \cdot 18 ; 95 \%$ CI $1.01-1.37 ; \mathrm{p}=0.031)$ and negatively with $A p o E \varepsilon 3 / \varepsilon 2$ genotype $(\mathrm{OR}=0.03 ; 95$ $\%$ CI $0.00-0.77 ; \mathrm{p}=0.028)$. Between posterior and anterior circulation atherosclerosis, age and hypertension were commonly associated $(\mathrm{p}<0.05)$. But, the presence of ApoE $\varepsilon 3 / \varepsilon 4$ genotype was significantly related to posterior circulation atherosclerosis $(\mathrm{OR}=4.01 ; 95 \% \mathrm{CI}$ $1 \cdot 07-15 \cdot 05 ; \mathrm{p}=0.040)$, whereas presence of $A p o E \varepsilon 3 / \varepsilon 2$ genotype was significantly related to anterior circulation atherosclerosis $(\mathrm{OR}=0.08 ; 95 \% \mathrm{CI} 0 \cdot 01-0.95 ; \mathrm{p}=0.045)$.

\begin{tabular}{|c|c|c|c|}
\hline Gene & Genotype & $\begin{array}{l}\text { Number of } \\
\text { individuals }\end{array}$ & $\begin{array}{l}\text { Allelic } \\
\text { frequency }\end{array}$ \\
\hline \multirow[t]{6}{*}{ ApoE } & $\varepsilon 3 / \varepsilon 3$ & 46 & \\
\hline & $\varepsilon 3 / \varepsilon 4$ & 15 & $\varepsilon 3-0.804$ \\
\hline & $\varepsilon 3 / \varepsilon 2$ & 4 & \\
\hline & $\varepsilon 2 / \varepsilon 2$ & 1 & $\varepsilon 4-0.145$ \\
\hline & $\varepsilon 2 / \varepsilon 4$ & 1 & \\
\hline & $\varepsilon 4 / \varepsilon 4$ & 2 & $\varepsilon 2-0.051$ \\
\hline \multirow[t]{3}{*}{$A C E$} & Insertion $(I I)$ & 20 & \\
\hline & Insertion/Deletion $(I D)$ & 27 & $I-0.485$ \\
\hline & Deletion $(D D)$ & 22 & $D-0.514$ \\
\hline \multirow[t]{3}{*}{ MTHFR } & Wild type $(C C)$ & 61 & \\
\hline & Heterozygous $(C T)$ & 7 & $C-0.935$ \\
\hline & Homozygous (TT) & 1 & $T-0.065$ \\
\hline \multirow[t]{3}{*}{$F V L$} & Wild type $(G G)$ & 67 & \\
\hline & Heterozygous $(G A)$ & 2 & $G-0.985$ \\
\hline & Homozygous $(A A)$ & 0 & $A-0.014$ \\
\hline
\end{tabular}

Table 3. Allelic frequency of the vascular genetic risk factors

Allelic frequencies representing an elderly Sri Lankan population are summarized (missing value -4). 


\subsubsection{CW abnormalities and age-related neuropathologies}

As per NIA-AA (Montine et al., 2012) recommendations, in the cases with incomplete clinical history (47/50), AD neuropathologic change for intermediate level was $4 \cdot 2 \%(2 / 47)$ and low level was $19 \cdot 1 \%(9 / 47)$. Parkinsonism associated pathologies were identified in $8.5 \%(4 / 47)$ of the cases: brainstem predominant Lewy bodies (LBs), hallmarks of PD - $6.4 \%(3 / 47)$ and probable progressive supra nuclear palsy (PSP) - 2.1\% (1/47). Within the 3 clinically diagnosed cases, first case presented mixed dementia pathologies including definite PSP, intermediate $\mathrm{AD}$ neuropathologic change and brainstem predominant LBs; second case presented vascular Parkinsonism due to ischemic stroke; and the third case presented idiopathic PD, Braak stage III. Some of the neurodegenerative and cerebrovascular pathologies observed in these ageing brains are illustrated in Fig. 3. Tau and $\beta$-amyloid positive AD-related neuropathological markers are presented in Fig. 3A and B, respectively. Ubiquitin positive LBs identified in midbrain substantia nigra are indicated by white arrows in Fig. 3C. Since, the lack of high specificity / high correlation among the studied cerebrovascular pathologies and the non-availability of validated criteria for neuropathological diagnosis of $\mathrm{VaD}$, we could not identify any cases confined to $\mathrm{VaD}$. Microscopic infarcts in deep white matter were graded semi quantitatively as none to mild (Fig. 3E) and moderate to severe (Fig. 3F and G). The degree of association between AD, PD and CAA neuropathological stages, and atherosclerosis of the CW is presented in Table 4. Variables such as Braak's NFT stages, Thal's A $\beta$ phases, CERAD's NP scores, CAA grades and CW atherosclerosis grades were dichotomized primarily based on the number of cases that have each variable and then by topographical progression or by its severity. Among them, only Braak's NFT stages I-VI and CW atherosclerosis grades $\geq$ mild showed an "at risk" significant association $(p=0.05)$. Fig. 4 shows the actual burden of Alzheimer-related neuropathological markers such as mean NFTs and SPs counts and mean CAA grades in respect of different degree of CW atherosclerosis. Other neurodegenerative related pathologies did not show any associations with $\mathrm{CW}$ atherosclerosis. 


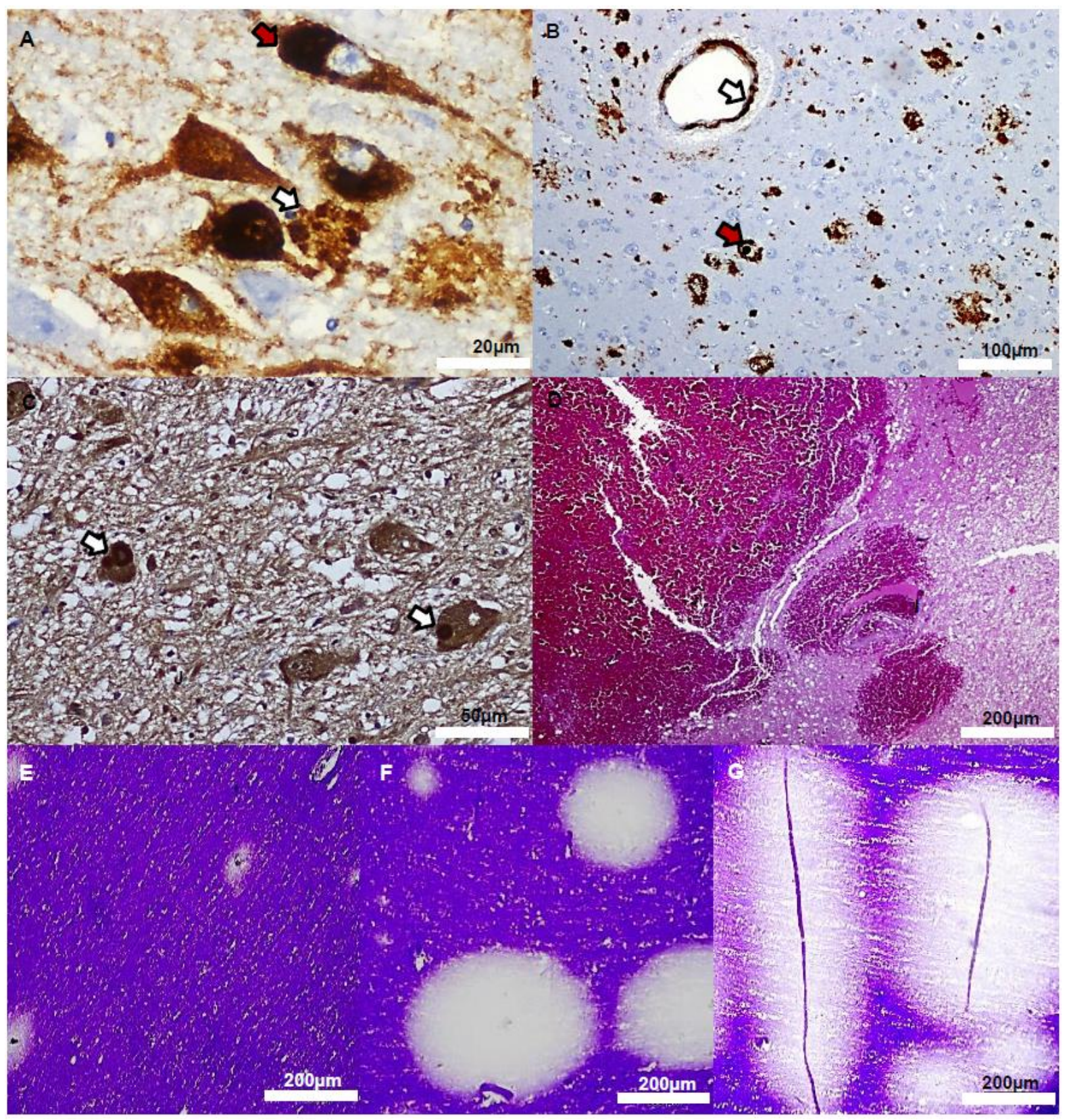

Fig. 3. Immunohistochemical localization of $A D$ - and PD- related neuropathological markers and cerebrovascular pathologies. (A) Tau positive neurofibrillary degenerations including NFTs (red arrow) and NPs (white arrow) in the hippocampus CA1 region (scale bar $=20 \mu \mathrm{m}$ ); (B) $\beta$-amyloid positive pathologies including SPs (red arrow) and CAA in the frontal cortex (scale bar $=100 \mu \mathrm{m}$ ); (C) ubiquitin positive Lewy bodies (white arrows) in the midbrain substantia nigra (scale bar $=50 \mu \mathrm{m}$ ); (D) haemorrhagic lesion (scale bar $=200 \mu \mathrm{m}$ ) with $\mathrm{H}$ and E staining; and (E-G) microscopic infarcts in deep white matter with Luxol fast blue and Cresyl violet staining $(\mathrm{E}-$ mild, $\mathrm{F}$ - moderate and $\mathrm{G}$ - severe, scale bar $=200 \mu \mathrm{m}$ ). 

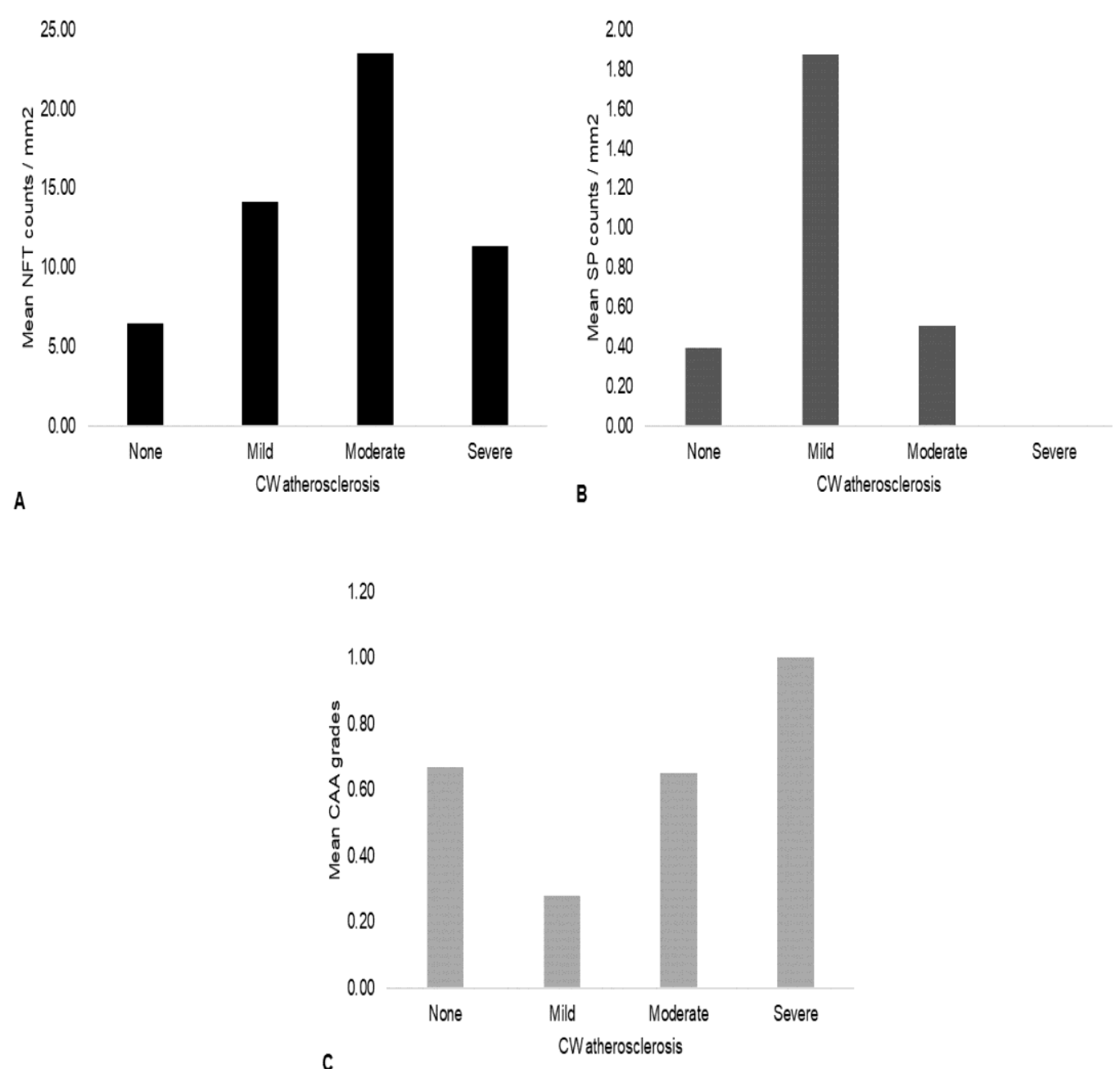

Fig. 4. Relationship between actual burden of AD- related neuropathological markers and CW atherosclerosis grades. (A) Tau positive mean NFTs counts; (B) $\beta$-amyloid positive mean SPs counts, and (C) $\beta$-amyloid positive mean cerebral amyloid angiopathy (CAA) grades.

A total of 49 out of 73 ageing brains showed moderate to severe grades of microscopic infarcts (Fig. 3F and G) in the deep white matter and they were significantly associated with hypoplasia in communicating arteries such as AcomA $(\mathrm{p}<0.05)$ and PcomA $(\mathrm{p}<0.05)$. A history of diabetes was reported in 17 cases; 16 of the 17 cases had a moderate to severe grades of microscopic infarcts in their deep white matter. Diabetes increased the odds for moderate to severe grades of microscopic infarcts by 8.7 times $(\mathrm{OR}=8 \cdot 72 ; 95 \%$ CI $1.03-73 \cdot 75 ; \mathrm{p}=0.047)$. The CW atherosclerosis did not show any association with microscopic infarcts pathology in deep white matter. 


\begin{tabular}{llll}
\hline $\begin{array}{l}\text { AD, PD and CAA } \\
\text { neuropathological stages }\end{array}$ & $\begin{array}{l}\text { CW atherosclerosis } \\
\text { grades }\end{array}$ & $\begin{array}{l}\text { Fisher's exact test } \\
\boldsymbol{P} \text { value }\end{array}$ & $\begin{array}{l}\text { Kendall's tau b } \\
\text { Correlation } \\
\text { coefficient }\end{array}$ \\
\hline (Dichotomized variables) & & $0 \cdot 173$ & $-0 \cdot 252$ \\
\hline Thal A $\beta$ phase 1-5 & $\geq$ severe & $0 \cdot 322$ & $-0 \cdot 195$ \\
Thal A $\beta$ phase $\geq 2$ &, & $0 \cdot 571$ & $-0 \cdot 165$ \\
CERAD NP score A-C &, & $0 \cdot 581$ & $-0 \cdot 180$ \\
Braak NFT stage IV-VI &, & $0 \cdot 693$ & $-0 \cdot 108$ \\
Braak NFT stage III-VI &, & $0 \cdot 581$ & $0 \cdot 180$ \\
Braak NFT stage I -VI &, & $0 \cdot 316$ & $-0 \cdot 178$ \\
Thal A $\beta$ phase 1-5 & $\geq$ moderate & $0 \cdot 060$ & $-0 \cdot 287$ \\
Thal A $\beta$ phase $\geq 2$ &, & $0 \cdot 381$ & $-0 \cdot 180$ \\
CERAD NP score A-C &, & $0 \cdot 683$ & $0 \cdot 118$ \\
Braak NFT stage IV-VI &, & $0 \cdot 377$ & $0 \cdot 147$ \\
Braak NFT stage III-VI &, & $0 \cdot 443$ & $0 \cdot 118$ \\
Braak NFT stage I -VI &, & $0 \cdot 421$ & $-0 \cdot 118$ \\
Thal A $\beta$ phase $\geq 2$ & $\geq$ mild & $0 \cdot 288$ & $0 \cdot 195$ \\
Braak NFT stage III-VI &, & $0 \cdot 050^{\S}$ & $0 \cdot 382$ \\
Braak NFT stage I -VI &, & 0.816 & 0.034 \\
PD stage I-IV & $\geq$ severe & 0.893 & 0.019 \\
, & $\geq$ moderate & 0.551 & 0.086 \\
CAA 1-4 & $\geq$ mild & $0 \cdot 180$ & $-0 \cdot 224$ \\
, & $\geq$ severe & $0 \cdot 482$ & $0 \cdot 132$ \\
\hline
\end{tabular}

Table 4. Degree of association between AD, PD and CAA neuropathological stages and CW atherosclerosis grades.

Significant level is set at $p<0.05$ ( $§$ - "at risk" significant). $P$ values equal to 0 and 1.0 are removed from this table. Fisher's exact test ( 2 X 2 table) and Kendall's tau b correlation coefficient were used as the sample size was small and the variables were categorical. Correlation strength: very weak $0 \cdot 00-0 \cdot 19$, weak $0 \cdot 20-0 \cdot 39$, moderate $0 \cdot 40-0 \cdot 59$, strong $0 \cdot 60-0 \cdot 79$ and very strong $0 \cdot 80-1 \cdot 00$.

\subsection{Discussion}

The results show that in the elderly $\mathrm{CW}$ samples larger arteries are more likely to be atherosclerotic. Previous studies on a large number of sections of cerebral arteries and quantitative assessment of the degree of atherosclerosis showed that there was an almost linear relationship between the degree of atherosclerosis and the radius of the artery (Pasterkamp and Falk, 2000; Reed et al., 1988; Resch et al., 1970). Resch et al (1970) investigated the severity and extent of $\mathrm{CW}$ atherosclerosis in autopsy series of 5031 cases and reported that BA, ICA and MCA were most commonly involved and that the smaller caliber arteries such as PCA, ACA, and the communicating arteries were less commonly involved (Warboys et al., 2011). Similarly, in our study, BA and ICA were primarily involved, followed by MCA and VA and then smaller arteries; PCAP1 and ACAA1. Communicating arteries showed comparatively less involvement and their stenosis indexes were none to mild in $80 \%$ and $87 \%$ of the AcomA and PcomA, respectively. Atherosclerotic lesions develop predominantly at bifurcations, branches and bends because these sites are exposed to low or disturbed blood flow, which exerts low / oscillatory shear stress on the artery wall (Warboys et al., 2011). 
Similarly, arterial bifurcations are sites of maximal hemodynamic stress, where cerebral aneurysms commonly develop (Sakamoto et al., 2006). Atherosclerotic aneurysm is a consequence of cerebral artery wall destruction, rarely leading to subsequent rupture and haemorrhage (Johnson et al., 2005). Cerebral aneurysms traditionally have been thought to be congenital in origin (Bremer, 1943) but there is no evidence of a congenital, developmental, or inherited weakness of the artery wall. Consequently, the most plausible explanation may be that the aneurysms are acquired degenerative lesions (Stehbens, 1989; Hazama and Hoshimoto, 1987; Nakatani et al., 1991). Our findings support this explanation: more than half of the cerebral aneurysms were identified at the bifurcations. In addition, aneurysms in the elderly brains coexisted with anatomical variations or atherosclerosis. Conversely, we did not see any aneurysms without anatomical variations or atherosclerosis in the respective arteries. For example, aneurysms in the vertebrobasilar system coexisted with asymmetric vertebral arteries (2/3). A definite correlation between asymmetric proximal segments of the ACA and aneurysms in the AcomA, and a tendency of correlation in the cases with asymmetric PcomA and aneurysms at the bifurcation of ICA-PcomA was observed in Kayembe et al's study (1984). Some of the aneurysms were observed with a combination of several variations in the component arteries. Therefore, besides doing statistical investigations, it is important to analyse each case in depth to elucidate the pathogenetic role of $\mathrm{CW}$ anatomical variations in the development of particular aneurysms (Kayembe et al., 1984).

Another striking finding of our current study was the distribution of the anatomical variations. It has been reported in earlier studies that roughly $50 \%$ of individuals have a normal or complete configuration of the CW (Vare and Bansal, 1970). Common variations are, in order of frequency, atretic or string-like anterior or posterior communicating arteries, triplication or duplication of arteries, and a fetal origin of one or both posterior cerebral arteries (Alpers et al., 1959; Vander Eecken, 1954). The presence of any of these abnormalities, particularly atretic communicating arteries, can seriously compromise ability to compensate for sudden occlusions. However, in our study, the prevalence of a "typical" CW configuration (De Silva et al., 2011; 2009) was observed only in $6.8 \%$ of the cases. Furthermore, a total of $119 \mathrm{CW}$ components (see section 3.2) showed anatomical variations. In recent studies, the $\mathrm{CW}$ component with most variation was determined to be PcomA and it was $50 \%$ in Gunnal et al's study (2014) and 59.4\% in Yeniceri et al's study (2017). Similarly, in our study, $44.5 \%$ (53/119) of the anatomical variations were identified in PcomA. Our previous study (De Silva et al., 2009) reported that $14.2 \%$ of the 225 Sri Lanka brains examined (age range 18 to 71 years) showed typical CW configurations. Thus, the higher prevalence of atypical $\mathrm{CW}$ identified in this current study could be related to age because we used only elderly brains (age $\geq 50$ years). Atherosclerotic occlusion or narrowing of some arteries in the $\mathrm{CW}$ which occurs during ageing could contribute to these differences. Whereas, studies from India reported to have higher number of typical CW at autopsy; $26.8 \%$ (in 175 brains) in Maharashtra (Vare and Bansal, 1970), $53.2 \%$ (in 357 brains) in South India (Reddy et al., 1972), and $45.2 \%$ (in 1000 brains, age $\geq 1$ year) in Northwest India (Kapoor et al., 2008), and $52.3 \%$ in U.S. (Alpers et al., 1959). The differences observed in above population-based studies might be attributed to their age, genetic predispositions, and / or environmental variations.

Hypoplasia, one of the most common anatomical variations in the CW components, show ranges from $0.7 \%$ (Fawcett and Balchford, 1905) to 80.6 \% (Riggs and Rupp, 1963) based on anatomical studies. There is continuing argument in literature about the threshold diameter for a vessel to be considered hypoplastic. Krabbe-Hartkamp et al (1998) recommended a threshold value of $0.8 \mathrm{~mm}$ for hypoplasia, although there are studies that have recommended a threshold 
value of $1 \mathrm{~mm}$ (Li et al., 2011; Nolte, 2002). In this study, $93.1 \%(68 / 73)$ of the elderly CW samples presented at least a single hypoplastic component at death and the majority $(\sim 75 \%)$ was identified in the posterior CW. The prevalence of the "typical circle" of the normal textbook polygon ranges from $4.6 \%$ (Fisher, 1965) to $72.2 \%$ (Fawcett and Blachford, 1905). A possible reason for the wide range may be the diversity in nomenclature and the criteria used to define hypoplastic arteries. There is little unanimity in nomenclature and quantitative measurements on $\mathrm{CW}$ components diameters. The $\mathrm{CW}$ components diameters have not been measured in several studies and relied up on rough estimations in determining the anomalies of the CW rather than actual measurements (De Silva et al., 2009).

The exact causes and risk factors of atherosclerosis are unknown; however, certain conditions, traits, or habits may raise the chance of developing atherosclerosis (Rafieian-Kopaei et al., 2014). Most risk factors including high cholesterol and low density lipoprotein (LDL), low level of high density lipoprotein (HDL) in the blood, hypertension, tobacco smoke, diabetes mellitus, obesity and inactive lifestyle can be controlled and the atherosclerosis can be delayed or prevented (Weber and Noles, 2011; Ross, 1993). Age and high blood pressure are the two most well-known risk factors for cerebral atherosclerosis (Reed et al., 1988; Sorlie et al., 1981). Diabetes mellitus has been shown to be a predisposing factor for stroke. There is evidence that high blood glucose level confers poor prognosis on those who suffer a stroke (Burton, 1951) and that it doubles the risk of atherothrombotic brain infarcts (Wolf et al., 1981). In our study, 17 of the 55 decedents were reported to have a known history of diabetes; however, it was not associated with any grades of $\mathrm{CW}$ atherosclerosis.

ApoE $\varepsilon 4$ allele is another well-known risk factor in the pathogenesis of atherosclerosis (Corder et al., 1993; Roher et al., 2003a, 2003b). ApoE $\varepsilon 4$ allele has been associated repeatedly with a moderately increased risk of both cardiovascular disease and $\mathrm{AD}$, whereas ApoE $\varepsilon 2$ allele is protective (Panza et al., 2004; Bathum et al., 2006). Here, we found that between posterior and anterior circulation, ApoE $\varepsilon 3 / \varepsilon 4$ and $\varepsilon 3 / \varepsilon 2$ genotypes might be associated with opposing effects. This provides some insight for the differences in prevalence of posterior and anterior circulation atherosclerotic stroke which have been discussed in population-based studies (Lee et al., 2006). A population with predominant posterior circulation atherosclerotic stroke might be a result of increased frequency of $A p o E \varepsilon 3 / \varepsilon 4$ genotypes. Similarly, a population with fewer anterior circulation atherosclerotic strokes might reflect more frequent $A p o E \varepsilon 3 / \varepsilon 2$ genotypes among them. Other vascular genetic risk factors such as polymorphisms in ACE, MTHFR and $F V L$ did not show any associations with any of the $\mathrm{CW}$ abnormalities. Interestingly, the frequency of the $A C E D D$ genotype was significantly higher in old elderly decedents $(68 \%)$ compared to young elderly decedents (32\%). ACE D allele has been reported to be more frequent in centenarians and in nonagenarians (Schachter et al., 1994; Galinsky et al., 1997; Seripa et al., 2006) compared to younger ethnically matched referents. However, controversies still exist with respect to ethnically similar as well as in other population-based studies (Blanche et al., 2001; Yang et al., 2009; Forero et al., 2006).

Intracranial atherosclerosis of the $\mathrm{CW}$ has been discussed in the etiology of sporadic $\mathrm{AD}$ via mechanical obstruction and reduction in cerebral arterial inflow; caused by atherosclerotic lesions (Roher et al., 2003). To address the validity of above association, Beach et al (2007) further used a large autopsy series and found that $\mathrm{CW}$ atherosclerosis was more severe in subjects with $\mathrm{AD}$ and $\mathrm{VaD}$ than in controls, while it was similar between controls and in subjects with non-AD dementias. Further, increasing atherosclerotic grade increased the odds ratios for both increased NP density and higher Braak NFT stage. In contrast, in our study, CW 
atherosclerosis did not show any significant association with AD-related neuropathological stages or with LBD-related stages except, an "at risk" significant association was observed between Braak's NFT stages I-VI and CW atherosclerosis $\geq$ mild. It is also arguable that the association noted between Braak NFT stages and CW atherosclerosis of our cohort may be attributed to the effect of age and not due to a direct relationship because other grades of Braak's NFT stages or CW atherosclerosis did not show any significant associations. We have summarized the discrepancies identified between Beach et al's (2007) study and this study (Table 5).

\begin{tabular}{|c|c|}
\hline Beach et al., 2007 & This study \\
\hline $\begin{array}{l}\text { A large number of clinicopathologically } \\
\text { confirmed AD }(n=215), \text { VaD }(n=30), \text { non- } \\
\text { AD dementias }(n=60) \text { and control }(n=92) \\
\text { samples were used to determine the } \\
\text { associations with CW scores }\end{array}$ & $\begin{array}{l}50 \text { ageing brains including } 47 \text { cases with } \\
\text { incomplete clinical histories and } 3 \text { cases, } \\
\text { clinically diagnosed of PD were used to } \\
\text { determine the association with CW scores }\end{array}$ \\
\hline $\begin{array}{l}\text { Neuropathological diagnosis of AD was } \\
\text { based on NIA-Reagan Institute criteria } \\
\text { (Hyman and Trojanowski, 1997) which } \\
\text { included CERAD criteria (Mirra et al., } \\
\text { 1991) and Braak stages (Braak and Braak, } \\
\text { 1991) }\end{array}$ & $\begin{array}{l}\text { Neuropathological diagnosis of AD was } \\
\text { based on NIA-AA 2012 revised criteria } \\
\text { (Montine et al., 2012) which included } \\
\text { CERAD criteria (Mirra et al., 1991), Braak } \\
\text { and Braak staging scheme for } \\
\text { neurofibrillary degeneration (Braak and } \\
\text { Braak, 1991, Braak et al., 2006a; Nagy et } \\
\text { al., 1998) and a modified version of Thal } \\
\text { A } \beta \text { phase (Thal et al., 2002) }\end{array}$ \\
\hline $\begin{array}{l}\text { Neuropathological criteria for LBDs were } \\
\text { based on Consortium on Dementia with } \\
\text { Lewy Bodies } 1996 \text { (CDLB96) (McKeith } \\
\text { et al., 1996). }\end{array}$ & $\begin{array}{l}\text { Neuropathological criteria for LBDs } \\
\text { including PD and dementia with Lewy } \\
\text { bodies (DLB) were based on NIA-AA } \\
\text { modifications to existing criteria which } \\
\text { included CDLB05 (McKeith et al., 2005) } \\
\text { and Braak's PD staging (2003), and also } \\
\text { based on the reconsidered staging } \\
\text { procedure for the inclusion body } \\
\text { pathology associated with sporadic PD } \\
\text { (Braak et al., 2006b) }\end{array}$ \\
\hline $\begin{array}{l}\text { CW atherosclerosis was graded by gross } \\
\text { visual inspection and validated by } \\
\text { comparison with their previous study } \\
\text { (Roher et al., 2003a). }\end{array}$ & $\begin{array}{l}\text { CW atherosclerosis was graded based on } \\
\text { degree of stenosis of CW components } \\
\text { (WHO, 1958) and cross-checked by gross } \\
\text { visual inspection as recommended by Beach } \\
\text { et al., 2007. }\end{array}$ \\
\hline $\begin{array}{l}\text { Neuropathological diagnosis of VaD was } \\
\text { based on a protocol outlined by NINDS- } \\
\text { AIREN committee (Roman et al., 1993) }\end{array}$ & $\begin{array}{l}\text { Due to the non-availability of validated } \\
\text { criteria for neuropathological diagnosis of } \\
\text { VaD, we did not follow any criteria to } \\
\text { diagnose } \mathrm{VaD}\end{array}$ \\
\hline $\begin{array}{l}\text { Brain tissues were used for } A p o E \\
\text { genotyping }\end{array}$ & $\begin{array}{l}\text { Cadaver blood samples were used for } \\
\text { vascular genetic risk factors: } A p o E, A C E \text {, } \\
M T H F R \text { and } F V L \text { genotyping }\end{array}$ \\
\hline $\begin{array}{l}\text { Possession of } A p o E \varepsilon 4 \text { allele did not affect } \\
\mathrm{CW} \text { atherosclerotic grades }\end{array}$ & $\begin{array}{l}\text { The presence of ApoE } \varepsilon 4 / \varepsilon 3 \text { genotypes } \\
\text { significantly increased the odds for severe } \\
\mathrm{CW} \text { atherosclerosis grades whereas, the }\end{array}$ \\
\hline
\end{tabular}




\begin{tabular}{|l|l|}
\hline & $\begin{array}{l}\text { presence of ApoE } \varepsilon 3 / \varepsilon 2 \text { genotypes } \\
\text { significantly decreased the odds for CW } \\
\text { atherosclerosis mild and above. } \\
\text { Polymorphisms in } A C E, M T H F R \text { and } F V L \\
\text { genes did not associate with CW } \\
\text { atherosclerotic grades }\end{array}$ \\
\hline $\begin{array}{l}\text { Increasing CW atherosclerotic grades } \\
\text { increased the odds for the diagnosis of AD } \\
\text { and VaD and also increased the odds for } \\
\text { both increased NP density and higher Braak } \\
\text { NFT stage }\end{array}$ & $\begin{array}{l}\text { Increased CW atherosclerotic grade } \\
\text { (moderate or moderate to severe or severe) } \\
\text { did not associate with AD or PD related } \\
\text { neuropathological changes and mean NFT } \\
\text { or SP counts }\end{array}$ \\
\hline
\end{tabular}

Table 5: Discrepancies observed between Beach et al's (2007) and present (Wijesinghe et al) studies in determining the role of $\mathrm{CW}$ atherosclerosis in dementia-related neuropathologies are summarized

On the other hand, Luoto et al (2009) study comprised a consecutive series of 285 autopsy specimens representing a general population aged 50 years and over suggested that $\mathrm{CW}$ atherosclerosis is not in direct association with $A \beta$ load in frontal cortex or NFTs numbers in hippocampus - hallmarks of AD neuropathology. Recently, Bangen et al (2015) found that the presence of cerebrovascular changes (CVC) including cerebral arteriosclerosis, CW atherosclerosis, lacunes and microscopic infarcts were associated with lower Braak stage, yet there were no differences in severity of cognitive impairment between the AD+CVC and ADCVC groups. The fact that the AD+CVC groups showed the same degree of overall cognitive impairment as the AD-CVC group, despite having a significantly lower burden of NFT pathology, suggests that vascular pathology has an additive effect on cognitive impairment, even in patients with autopsy-confirmed AD and relatively mild CVC. These observations confirm the inconsistent relationship that still exists between intracranial $\mathrm{CW}$ atherosclerosis and $\mathrm{AD}$.

On the other hand, Garde et al's (2000) longitudinal study in healthy octogenarians revealed that arteriolosclerosis contributes only a small part of age-related cognitive decline, highlighting the need to identify other contributors to cognitive impairment. Brain arterial diameters are radiological biomarkers of cerebrovascular health and they are intimately related to the functionality of the brain parenchyma they perfuse (Gutierrez et al., 2018). White matter lesions (WML) are regarded as a cerebral small artery disease, and the diameters of these arteries are often smaller than $0.1 \mathrm{~mm}$ (He et al., 2016). The pathological feature of WML manifests diffuse white matter demyelination, mainly around the lateral ventricles deep white matter, corona radiata area, usually with silent lacunar infarctions in basal ganglia, thalamus and subcortical white matter region (He et al., 2016). The etiology of WML is unclear. It may be due to chronic hypoperfusion of white matter and blood-brain barrier damage causing chronic leakage of plasma into white matter (Pantoni, 2010). However other studies report nonischemic causes for WML (Pantoni and Garcia, 1997; Fazekas et al., 1993). Associations, between white matter diseases and incomplete $\mathrm{CW}$ or absent $\mathrm{CW}$ arteries have been demonstrated in magnetic resonance imaging (MRI) studies (Ryan et L., 2015). He et al's (2016) study reported that incomplete CW and cerebral artery stenosis may impair selfregulation of cerebral blood flow and hemodynamic stability, but there is insufficient evidence to suggest that incomplete $\mathrm{CW}$ and cerebral artery stenosis are associated with white matter lesion. In our studyt hypoplasia in communicating arteries showed significant associations with 
microscopic infarct pathology in deep white matter obtained from corpus callosum. The corpus callosum serves to unite the 2 hemispheres anatomically and functionally, and its atrophy may be associated with cognitive and motor deficits. Pathologies of the corpus callosum result in defects in interhemispheric coordination and the infarcts in these regions are generally a part of large artery ischemia (Chrysikopoulos et al., 1997). However, further work is required to identify the role of hypoplasia in $\mathrm{CW}$ arteries in age-related neurodegenerative and cerebrovascular pathologies.

Finally, there are some limitations in our study. Incomplete clinical histories of the recruited subjects as well as a lack of objective psychometry and dementia scores, ubiquitin immunohistochemistry for labelling LBs instead of $\alpha$-synuclein and the non-availability of some brain regions as specified under minimum tissue requirements by NIA-AA guidelines (Montine et al., 2012) are considered as important limiting factors of this study. This is a retrospective study. The case history was obtained through kin who were familiar with intellectual and functional status of the subjects before death. However, uncertainty around cognitive status of the subjects at the time of tissue removal affects the final diagnosis of AD. For the LBDs, although $\mathrm{H}$ and $\mathrm{E}$ staining may be used to detect LBs, greater sensitivity can be achieved with $\alpha$-synuclein immunohistochemistry. It is recommended as preferred method in the NIA-AA guidelines (Montine et al., 2012). In our study, in addition to H\&E staining, ubiquitin immunohistochemistry instead of $\alpha$-synuclein was used. Ubiquitin immunohistochemistry is recommended for LB labelling according to CDLB 1996 guidelines (McKeith et al., 1996). Finally, we collected specific brain regions between May 2009 and March 2010. As a result, some of the brain sections, as specified in the NIA-AA guidelines (Montine et al., 2012) were not available in this study.

\subsection{Conclusion}

CW abnormalities were predominant in the ageing Sri Lankan brains; however, their contribution to the occurrence and severity of the symptoms of neurodegenerative pathologies was relatively low. Reduced CW arterial diameters might have downstream effects in brain function. Identifying the mechanisms and the direction of such interactions may increase the understanding of the vascular contribution to cognitive impairment and dementia. The wide range in the prevalence of atypical configurations and pathologies between Sri Lankan populations and those in other studies indicates that further work is necessary to ascertain the influences of genetic, racial, regional, environmental, hemodynamic factors, or a combination of any of them.

\subsection{References}

Alpers, B., Berry, J., Paddison, R., 1959. Anatomical studies of the circle of Willis in normal brain. AMA. Arch. Neurol. Psychiatry 81, 409-418.

Bangen, K.J., Nation, D.A., Delano-Wood, L., Weissberger, G.H., Hansen, L.A., Galasko, D.R., Salmon, D.P., Bondi, M.W., 2015. Aggregate effects of vascular risk factors on cerebrovascular changes in autopsy-confirmed Alzheimer's disease. Alzheimers Dement. 2011, 394-403. 
Bathum, L., Christiansen, L., Jeune, B., Vaupel, J., McGue, M., Christensen, K., 2006. Apolipoprotein E genotypes: relationship to cognitive functioning, cognitive decline, and survival in nonagenarians. J. Am. Geriatr. Soc. 54, 654-658.

Beach, T.G., Wilson, J.R., Sue, L.I., Newell, A., Poston, M., Cisneros, R., Pandya, Y., Esh, C., Connor, D.J., Sabbagh, M., Walker, D.G., Roher, A.E., 2007. Circle of Willis atherosclerosis: association with Alzheimer's disease, neuritic plaques and neurofibrillary tangles. Acta Neuropathol. 113, 13-21.

Bertina, R.M., Koeleman, B.P., Koster, T., Rosendaal, F.R., Dirven, R.J., de Ronde, H., van der Velden, P.A., Reitsma, P.H., 1994. Mutations in blood coagulation factor V associated with resistance to activated protein C. Nature 369, 64-67.

Blanché, H., Cabanne, L., Sahbatou, M., Thomas, G., 2001. A study of French centenarians: are ACE and APOE associated with longevity? C. R. Acad. Sci. III 324, 129-135.

Braak, H., Alafuzoff, I., Arzberger, T., Kretzschmar, H., Del Tredici, K., 2006a. Staging of Alzheimer disease - associated neurofibrillary pathology using paraffin sections and immunocytochemistry. Acta Neuropathol. 112, 389-404.

Braak, H., Bohl, J.R., Muller, C.M., Rub, U., de Vos, R.A., Del Tredici, K., 2006b. Stanley Fahn Lecture 2005: The staging procedure for the inclusion body pathology associated with sporadic Parkinson's disease re- considered. Mov. Disord. 21, 2042-2051.

Braak, H., Braak, E., 1991. Neuropathological staging of Alzheimer-related changes. Acta Neuropathol (Berl). 82, 239-259.

Braak, H., Del Tredici, K., Rub, U., de Vos, R.A., Jansen Steur, E.N., Braak, E., 2003. Staging of brain pathology related to sporadic Parkinson's disease. Neurobiol. Aging 24, 197211.

Bremer, J.L., 1943. Congenital aneurysms of the cerebral arteries. Arch. Pathol. 35, 819-831. Breteler, M.M., 2000. Vascular risk factors for Alzheimer's disease: an epidemiologic perspective. Neurobiol. Aging 21, 153-160.

Burton, A.C., 1951. On the physical equilibrium of small blood arteries. Amer. J. Physiol. 164, 319-322.

Cambien, F., Poirier, O., Lecerf, L., Evans, A., Cambou, J.P., Arveiler, D., Luc, G., Bard, J.M., Bara, L., Ricard, S., et al., 1992. Deletion polymorphism in the gene for angiotensin-converting enzyme is a potent risk factor for myocardial infarction. Nature 359, 641-644.

Catto, A., Carter, A.M., Barrett, J.H., Stickland, M., Bamford, J., Davies, J.A., Grant, P.J., 1996. Angiotensin-converting enzyme insertion/deletion polymorphism and cerebrovascular disease. Stroke 27, 435-440.

Chapman, J., Wang, N., Treves, T.A., Korczyn, A.D., Bornstein, N.M., 1998. ACE, MTHFR, factor V Leiden, and APOE polymorphisms in patients with vascular and Alzheimer's dementia. Stroke 29, 1401-1404. 
Chrysikopoulos, H., Andreou, J., Roussakis, A., Pappas, J., 1997. Infarction of the corpus callosum: Computed tomography and magnetic resonance imaging. Eur. J. Radiol. 25, 2-8.

Classification of atherosclerotic lesions; a report of a study group., 1958. World Health Organ. Tech. Rep. Ser. 57, 1-20.

Corder, E.H., Saunders, A.M., Strittmatter, W.J., Schmechel, D.E., Gaskell, P.C., Small, G.W., Roses, A.D., Haines, J.L., Pericak-Vance, M.A., 1993. Gene dose of apolipoprotein E type 4 allele and the risk of Alzheimer's disease in late onset families. Science 261, 921-923.

De Silva, K.R., Silva, R., Gunasekera, W.S., Jayesekera, R.W., 2009. Prevalence of typical circle of Willis and the variation in the anterior communicating artery: A study of a Sri Lankan population. Ann. Indian Acad. Neurol. 12, 157-161.

De Silva, K.R., Silva, R., Amaratunga, D., Gunasekera, W.S., Jayesekera, R.W., 2011. Types of the cerebral arterial circle (circle of Willis) in a Sri Lankan Population. BMC. Neurol. 11, 2-8.

Fawcett, E., Blachford, J.V., 1905. The circle of Willis. An examination of 700 specimens. J. Anat. Physiol. 40, 2-70.

Fazekas, F., Kleinert, R., Offenbacher, H., Schmidt, R., Kleinert, G., Payer, F., Radner, H., Lechner, H., 1993. Pathologic correlates of incidental MRI white matter signal hyperintensities. Neurology 43, 1683-1689.

Feigin, V.L., Norrving, B., Mensah, G.A., 2017. Global burden of stroke. Circ. Res. 120, 439448.

Fisher, C.M., 1965. The circle of Willis: Anatomical variations. Vasc. Dis. 2, 99-105.

Forero, D.A., Pinzon, J., Arboleda, G.H., Yunis, J.J., Alvarez, C., Catano, N., Arboleda, H., 2006. Analysis of common polymorphisms in angiotensin-converting enzyme and apolipoprotein E genes and human longevity in Colombia. Arch. Med. Res. 37, 890-894.

Frosst, P., Blom, H.J., Milos, R., Goyette, P., Sheppard, C.A., Matthews, R.G., Boers, G.J., den Heijer, M., Kluijtmans, L.A., van den Heuvel, L.P., et al., 1995. A candidate genetic risk factor for vascular disease: a common mutation in methylenetetrahydrofolate reductase. Nat. Genet. $10,111-113$.

Galinsky, D., Tysoe, C., Brayne, C.E,, Easton, D.F., Huppert, F.A., Dening, T.R., Paykel, E.S., Rubinsztein, D.C., 1997. Analysis of the apo E/apo C-I, angiotensin converting enzyme and methylenetetrahydrofolate reductase genes as candidates affecting human longevity. Atherosclerosis 129, 177-183.

Garde, E., Mortensen, E.L., Krabbe, K., Rostrup, E., Larsson, H.B., 2000. Relation between age-related decline in intelligence and cerebral white-matter hyperintensities in healthy octogenarians: a longitudinal study. Lancet 356, 628-634. 
Greenberg, S.M., Vonsattel, J.P., 1997. Diagnosis of cerebral amyloid angiopathy: Sensitivity and specificity of cortical biopsy. Stroke 28, 1418-1422.

Gunnal, S.A., Farooqui, M.S., Walbale, R.N., 2014. Anatomical variations of the circulus arteriosus in cadaveric human brains. Neurol. Res. Int. 2014, 687281.

Gutierrez, J., Kulick, E., Park Moon. Y., Dong C, Cheung, K., Ahmet, B., Stern, Y., Alperin, N., Rundek, T., Sacco, R.L., Wright, C.B., Elkind, M.S.V., 2018. Brain arterial diameters and cognitive performance: the Northern Manhattan Study. J. Int. Neuropsychol. Soc. 24, 335-346.

Hazama, F., Hoshimoto, N., 1987. An animal model of cerebral aneurysms. Neuropathol. Appl. Neurobiol. 13, 77-90.

He, Y., Li, Y., Jiang, H., Teng, F., Nie, Z., 2016. Is incomplete circle of Willis associated with white matter lesion? Int. J. Clin. Exp. Med. 9, 11657-11662.

Henderson, K., Eliasziw, M., Fox, A.J., Rothwell, P.M., Barnett, J.M., 2000. Collateral ability of the circle of Willis in patients with unilateral carotid artery occlusion. Border zone infarcts and clinical symptoms. Stroke 31, 128-132.

Hofman, A., Ott, A., Breteler, M.M., Bots, M.L., Slooter, A.J., van Harskamp, F., van Duijn, C.N., van Broeckhoven, C., Grobbee, D.E., 1997. Atherosclerosis, apolipoprotein E, and prevalence of dementia and Alzheimer's disease in the Rotterdam Study. Lancet 349, 151-154.

Hoksbergen, A.W., Fulesdi, B., Legemate, A.D., Csiba, I., 2003. Collateral configuration of the circle of Willis: Transcranial colour-coded duplex ultrasonography and comparison with post-mortem anatomy. Stroke 31, 1346-1351.

Hyman, B.T., Trojanowski, J.Q., 1997. Consensus recommendations for the postmortem diagnosis of Alzheimer disease from the National Institute on Aging and the Reagan Institute Working Group on diagnostic criteria for the neuropathological assessment of Alzheimer disease. J Neuropathol Exp Neurol 56,1095-1097.

Iqbal, S., 2013. A comprehensive study of the anatomical variations of the circle of willis in adult human brains. J. Clin. Diagn. Res. 7, 2423-2427.

Johnson, M.W., Hammond, R.R., Vinters, H.V., 2005. Fusiform, infectious and other aneurysmal lesions. In: Kalimo, H. (Ed.), Cerebrovascular diseases. ISN Neuropath Press, Basel, pp. 112-118.

Kapoor, K., Singh, B., Dewan, L.I., 2008. Variations in the configuration of the circle of Willis. Anat. Sci. Int. 83, 96-106.

Kayembe, K.N., Sasahara, M., Hazama, F., 1984. Cerebral aneurysms and variations in the circle of Willis. Stroke 15, 846-850.

Krabbe-Hartkamp, M.J., van der Grond, J., de Leeuw, F.E., de Groot, J.C., Algra, A., Hillen, B., Breteler, M.M., Mali, W.P., 1998. Circle of Willis: morphologic variation on threedimensional time-of-flight MR angiograms. Radiology 207, 103-111. 
Lee, J.H., Han, S.J., Yun, Y.H., Choi, H.C., Jung, S., Cho, S.J., Yu, K.H., Lee, S.M., Hwang, S.H., Song, H.K., Kwon, K.H., Lee, B.C., 2006. Posterior circulation ischemic stroke in Korean population. Eur. J. Neurol. 13, 742-748.

Li, Q., Li, J., Lv, F., Li, K., Luo, T., Xie, P., 2011. A multidetector CT angiography study of variations in the circle of Willis in a chinese population. J. Clin. Neurosci. 18, 379-383.

Lippert, H., Pabst, R., 1985. In: Bergmann, J.F. (Ed.), requencyArterial Variations in Man: Classification and Frequency. Verlag, Munich.

Luoto, T.M., Haikonen, S., Haapasalo, H., Goebeler, S., Huhtala, H., Erkinjuntti, T., Karhunen, P.J., 2009. Large artery cerebral atherosclerosis is not in direct association with neuropathological lesions of Alzheimer's disease. Eur. Neurol. 62, 93-98.

Macchi, C., Pratesi, C., Conti, A.A., Gensini, G.F., 2005. The circle of Willis in healthy older persons. J. Cardiovasc. Surg. (Toronto) 43, 887-890.

Mahley, R.W., 1988. Apolipoprotein E: cholesterol transport protein with expanding role in cell biology. Science 240, 622-630.

McKeith, I.G., Dickson, D.W., Lowe, J., Emre, M., O’Brien, J.T., Feldman, H., Cummings, J., Duda, J.E., Lippa, C., Perry, E.K., Aarsland, D., Arai, H., Ballard, C.G., Boeve, B., Burn, D.J., Costa, D., Del Ser, T., Dubois, B., Galasko, D., Gauthier, S., Goetz, C.G., GomezTortosa, E., Halliday, G., Hansen, L.A., Hardy, J., Iwatsubo, T., Kalaria, R.N., Kaufer, D., Kenny, R.A., Korczyn, A., Kosaka, K., Lee, V.M., Lees, A., Litvan, I., Londos, E., Lopez, O.L., Minoshima, S., Mizuno, Y., Molina, J.A., Mukaetova-Ladinska, E.B., Pasquier, F., Perry, R.H., Schulz, J.B., Trojanowski, J.Q., Yamada, M., 2005. Diagnosis and management of dementia with Lewy bodies: third report of the DLB Consortium. Neurology $65,1863-1872$.

McKeith, I.G., Galasko, D., Kosaka, K., Perry, E.K., Dickson, D.W., Hansen, L.A., Salmon, D.P., Lowe, J., Mirra, S.S., Byrne, E.J., Lennox, G., Quinn, N.P., Edwardson, J.A., Ince, P.G., Bergeron, C., Burns, A., Miller, B.L., Lovestone, S., Collerton, D., Jansen, E.N., Ballard, C., de Vos, R.A., Wilcock, G.K., Jellinger, K.A. and Perry, R.H., 1996. Consensus guidelines for the clinical and pathologic diagnosis of dementia with Lewy bodies (DLB): report of the consortium on DLB international workshop. Neurology 47, 1113-1124.

Mirra, S.S., Heyman, A., McKeel, D., Sumi, S.M., Crain, B.J., Brownlee, L.M., Vogel, F.S., Hughes, J.P., van Belle, G., Berg, L., 1991. The consortium to establish a registry for Alzheimer's Disease (CERAD). Part II. Standardization of the neuropathologic assessment of Alzheimer's disease. Neurology 41, 479-486.

Montine, T.J., Phelps, C.H., Beach, T.G., Bigio, E.H., Cairns, N.J., Dickson, D.W., Duyckaerts, C., Frosch, M.P., Masliah, E., Mirra, S.S., Nelson, P.T., Schneider, J.A., Thal, D.R., Trojanowski, J.Q., Vinters, H.V. and Hyman, B.T., 2012. National Institute on AgingAlzheimer's Association guidelines for the neuropathological assessment of Alzheimer's disease: practical approach. Acta Neuropathol. 123, 1-11. 
Nagy, Z., Yilmazer-Hanke, D.M., Braak, H., Braak, E., Schultz, C., Hanke, J., 1998. Assessment of the pathological stages of Alzheimer's disease in thin paraffin sections: a comparative study. Dement. Geriatr. Cogn. Disord. 9, 140-144.

Nakatani, H., Hashimoto, N., Kang, Y., Yamazoe, N., Kikuchi, H., Yamaguchi, S., Niimi, H., 1991. Cerebral blood flow patterns at major artery bifurcations and aneurysms in rats. J. Neruosurg. 74, 258-262.

Nolte, J., 2002. The Human Brain. An introduction to its functional anatomy. $5^{\text {th }}$ edition. Mosby, St. Louis, 2002.

Ozaki, T., Handa, H., Tomimoto, K., Hazama, F., 1977. Anatomical variations of the arterial system of the base of the brain. Niho. Geka. Hokan. 46, 3-17.

Pantoni, L., Garcia, J.H., 1997. Pathogenesis of leukoaraiosis: a review. Stroke, 28, 652-659.

Pantoni, L., 2010. Cerebral small artery disease: from pathogenesis and clinical characteristics to therapeutic challenge. Lancet Neurol. 9, 689-701.

Panza, F., D’Introno, A., Colacicco, A.M., Capurso, S., Kehoe, P.G., Capurso, A., Solfrizzi, V., 2004. Vascular genetic factors and human longevity. Mech. Ageing. Dev. 125, 169-178.

Pasterkamp, G., Falk, E., 2000. Atherosclerotic plaque rupture: An overview. J. Clin. Basic. Cardiol. 3, 81-85.

Purohit, D.P., Batheia, N.O., Sano, M., Jashnani, K.D., Kalaria, R.N., Karunamurthy, A., Kaur, S., Shenoy, A.S., Van Dvk, K., Schmeidler, J., Perl, D.P., 2011. Profile of Alzheimer's disease-related pathology in an aging urban population sample in India. J Alzheimers Dis. 24, 187-196.

Rafieian-Kopaei, M., Setoki, M., Doudi, M., Baradaran, A., Nasri, H., 2014. Athersclerosis: Process, Indicators, Risk Factors and New Hopes. Int. J. Prev. Med. 5, 927-946.

Reddy, D.R., Prabhakar, V., Rao, B.D., 1972. Anatomical study of circle of Willis. Neurol. India 20, 8-12.

Reed DM, Resch JA, Hayashi T, MacLean C, Yano K. A Prospective Study of Cerebral Artery Atherosclerosis. Stroke. 1988;19:820-825.

Resch, J.A., Loewenson, R.B., Baker, A.B., 1970. Physical factors in the pathogenesis of cerebral atherosclerosis. Stroke 1, 77-85.

Riggs, H., Rupp, C., 1963. Variations in form of circle of Willis. The relation of the variations to collateral circulation: Anatomic analysis. Arch. Neurol. 8, 8-14.

Roher, A.E., Esh, C., Kokjohn, T.A., Kalback, W., Luehrs, D.C., Seward, J.D., Sue, L.I., Beach, T.G., 2003a. Circle of Willis atherosclerosis is a risk factor for sporadic Alzheimer's disease. Arterioscler. Thromb. Vasc. Biol. 23, 2055-2062. 
Roher, A.E., Kuo, Y.M., Esh, C., Knebel, C., Weiss, N., Kalback, W., Luehrs, D.C., Childress, J.L., Beach, T.G., Weller, R.O., Kokjohn, T.A., 2003b. Cortical and leptomeningeal cerebrovascular amyloid and white matter pathology in Alzheimer's disease. Mol. Med. 9, 112-122.

Roman, G.C., Tatemichi, T.K., Erkinjuntti, T., Cummings, J.L., Masdeu, J.C., Garcia, J.H., Amaducci, L., Orgogozo, J.M., Brun, A., Hofman, A., 1993. Vascular dementia: diagnostic criteria for research studies. Report of the NINDS-AIREN International Workshop.

Neurology 43, 250-260.

Ross R., 1993. The pathogenesis of atherosclerosis: A perspective for the 1990s. Nature 362, 801-809.

Ryan, D.J., Byme, S., Dunne, R., Harmon, M., Harbison, J., 2015. White matter disease and an incomplete circle of Willis. Int. J. Stroke 10, 547-552.

Sacco, R.L., Boden-Albala, B., Gan, R., Chen, X., Kargman, D.E., Shea, S., Paik, M.C., Hauser, W.A., 1998. Stroke incidence among white, black and Hispanic residents of an urban community: The Northern Manhattan Stroke Study. Am. J. Epidemiol. 147, 259-268.

Sakamoto, S., Ohba, S., Shibukawa, M., Kiura, Y., Okazaki, T., Arita, K., Kurisu, K., 2006. Characteristics of aneurysms of the internal carotid artery bifurcations. Acta Neurochir (Wien). 148, 139-143.

Schachter, F., Faure-Delanef, L., Guenot, F., Rouger, H., Froguel, P., Lesueur-Ginot, L., Cohen, D., 1994. Genetic associations with human longevity at the APOE and ACE loci. Nat. Genet. 6, 29-32.

Seripa, D., Franceschi, M., Matera, M.G., Panza, F., Kehoe, P.G., Gravina, C., Orsitto, G., Solfrizzi, V., Di Minno, G., Dallapiccola, B., Pilotto, A., 2006. Sex differences in the association of apolipoprotein $\mathrm{E}$ and angiotensin-converting enzyme gene polymorphisms with healthy aging and longevity: a population-based study from Southern Italy. J. Gerontol. A. Biol. Sci. Med. Sci. 61, 918-923.

Snowdon, D.A., Greiner, L.H., Mortimer, J.A., Riley, K.P., Greiner, P.A., Markesbery, W.R., 1997. Brain infarction and the clinical expression of Alzheimer disease. The Nun Study. JAMA. 277, 813-817.

Sorlie, P.D., Garcia-Palmieri, M.R., Catillo-Staab, M.I., Costas, R. Jr., Oalmann, M.C., Havlik, R., 1981. The relation of antemortem factors to atherosclerosis at autopsy. The Puerto Rico Heart Health Program. Am. J. Pathol. 103, 345-352.

Stehbens, W.E., 1989. Etiology of intracranial berry aneurysms. J. Neurosurg. 70, 823-831. Thal, D.R., Rub, U., Orantes, M., Braak, H. 2002. Phase of A beta-deposition in the human brain and its relevance for the development of AD. Neurology 58, 1791-1800.

Vander Eecken, H.M., 1954. Morphological significance of leptomeningeal anastomoses confined to the territory of cerebral arteries. Acta Neurol. Psychiatr. Belg. 54, 525-532. 
Van Overbeeke, J.J., Hillen, B., Tulleken, C.A., 1991. A comparative study of the circle of Willis in fetal and adult life. The configuration of the posterior bifurcation of the posterior communicating artery. J. Anat. 176, 45-54.

Vare, A.M., Bansal, P.C., 1970. Arterial pattern at the base of the human brain. J. Anat. Soc. India. 19, 71-79.

Warboys, C.M, Amini, N., de Luca, A., Evans, P.C., 2011. The role of blood flow in determining the sites of atherosclerotic plaques. F1000 Med. Reports. 3, 5.

Weber, C., Noels, H., 2011. Atherosclerosis: Current pathogenesis and therapeutic options. Nat. Med. 17, 1410-1422.

Wijesinghe, P., Shankar, S.K., Chickabasaviah Y.T., Gorrie, C., Amaratunga, D., Hulathduwa, S., Kumara, K.S., Samarasinghe, K., Suh, Y.H., Steinbusch, H.W., De Silva., 2016a. Cytoskeletal Pathologies of Age-related Diseases between Elderly Sri Lankan (Colombo) and Indian (Bangalore) Brain Samples. Curr. Alzheimer Res. 13, 268-280.

Wijesinghe, P., Shankar, S.K., Yasha, T.C., Gorrie, C., Amaratunga, D., Hulathduwa, S., Kumara, K.S., Samarasinghe, K., Suh, Y.H., Steinbusch, H.W., De Silva., 2016b. Vascular contributions in Alzheimer related neuropathological changes: First autopsy evidence from a South Asian ageing population. J. Alzheimers Dis. 54, 1607-1618.

Wolf, P.A., Kannel, W.B., Sorlie, P., McNamara, P., 1981. Asymptomatic carotid bruit and risk of stroke. The Framingham study. JAMA. 245, 1142-1145.

Yang, J.K., Gong, Y.Y., Xie, L., Lian, S.G., Yang, J., Xu, L.Y., Gao, S.J., Zhang, Y.P., 2009. Lack of genetic association between the angiotensin-converting enzyme gene insertion/ deletion polymorphism and longevity in a Han Chinese population. J. Renin. Syst. 10, 115118.

Yeniceri, I.O., Cullu, N., Deveer, M., Yeniceri, E.N., 2017. Circle of Willis variations and artery diameter measurements in the Turkish population. Folia Morphol (Warsz). 76, 420-425. 


\section{CHAPTER 6}




\subsection{General Discussion}

Population aging is having a profound impact on the emergence of the dementia epidemic. Recent reviews estimate that globally nearly 9.9 million people develop dementia each year; this figure translates into one new cases every three seconds. About $60 \%$ of people with dementia currently live in low- and middle-income countries and most new cases (71\%) are expected to occur in those countries (Prince et al., 2015). The estimated worldwide annual cost for the society of dementia was US $\$ 818$ billion in 2015, an increase of $35 \%$ since 2010 , and the $86 \%$ of the total cost, incurred in high income countries and the rest in low- and middleincome countries (Wimo et al., 2017). This highlights the enormous impact that the dementia has on socioeconomic conditions.

This study is aimed to provide the actual burden of dementia-related neuropathological changes in the brains of elderly sample populations representing South Asia, a region which contribute about one fourth of the world population. In addition, we attempted to explore AD-related neuropathological changes with respect to vascular and genetic risk factors and comorbid cerebrovascular pathologies.

Age-related cytoskeletal pathologies in South Asian elderly populations: Is there any difference between the two closely related elderly populations?

Our first objective is focused on this question. We screened 79 brains with incomplete clinical histories and their mean age at death (Colombo- 72.0 years and Bangalore- 65.2 years) was almost equivalent to their standard population life expectancy (Sri Lankans- 75 years and Indians- 65 years) (World Health Statistics, WHO, 2013). 87\% (41/47) of the Colombo and $62.5 \%$ (20/32) of the Bangalore samples had tau positive cytoskeletal alterations at death suggesting that age difference could possibly be a one of the reasons for this difference. However, neuropathologic change for AD (NIA-AA, 2012) is comparable between Colombo (4.25\%) and Bangalore (3.12\%) elderly samples. Pathologies associated with Parkinsonism (PD and PSP), cerebrovascular changes (spongiform changes and dilated perivascular spaces) and granular cell loss in DG region were more frequently observed in Colombo samples, suggesting that in addition to age difference, genetic, dietary, and/or environmental exposures might contribute to these differences.

In Asia, regardless of small differences in age among population compared, systematic analyses of the clinical studies (Kalaria et al., 2008; Catindig et al., 2012) clearly indicate a higher prevalence $\mathrm{AD}$ over $\mathrm{VaD}$. This trend has been discussed reversely in earlier Asian studies and it might be attributed to the changes in demographic profiles, urbanization, environmental exposures, ethnicity, and the advances in the use of neuroimaging techniques (Catindig et al., 2012). In contrast, our neuropathological findings in elderly Sri Lankan brains indicate a higher prevalence of pathologies associated with Parkinsonism followed by AD. Even though cognitive impairment is not an essential feature of PD that might be a reason to escape from the clinical screenings, it has become increasingly recognized that patients with PD can have decline in cognitive functions and develop dementia up to 80\% (Aarsland et al., 2003).

Through this study, we demonstrate that neuropathologic change for AD seems to be high in both elderly sample populations (India and Sri Lanka) compared to clinical prevalence that reported earlier. These discrepancies affect the true extent of dementia burden and in turn affects the societal costs. In fact, conducting a clinico-pathological correlative study in elderly Sri Lankans or in elderly Indians could provide better indications of the true extent of dementia burden, help plan for future health care needs and offer neurobiological perspectives that underlie lifestyle and environmental risk / protective factors for AD affecting these cultures. 
Can ageing brains' neuropathologies be used to discover the vascular contributions in the etiology of sporadic AD?

The contribution of vascular risk factors and cerebrovascular pathologies in the etiology of sporadic $\mathrm{AD}$ remain controversial. Our second objective is to unravel this issue based on ageing brains' neuropathologies. We found that increasing age, ApoE $\varepsilon 4$ allele, methylene tetrahydrofolate reductase (MTHFR) $T$ allele and illiteracy were significantly associated with AD-related tau and/or A $\beta$ positive pathologies. Similarly, cerebral small vessel pathologies: white matter hyperintensities (WMHs) and cerebral amyloid angiopathy (CAA) were significantly coexisted with $\mathrm{AD}$-related tau and/or $\mathrm{A} \beta$ positive pathologies compared to large vessel pathology - CW atherosclerosis.

ApoE $\& 4$ allelic frequency is an important genetic risk factor for explaining the ethnic differences (Venketasubramanian et al., 2010). The $\varepsilon 4$ allele of $A p o E$ has been found to be the most consistent risk factor for late-onset $A D$ possibly via $A \beta$ protein accumulation (Verghese et al., 2011; Morris et al., 2010; Kok et al., 2009). However, associations reported between ApoE $\varepsilon 4$ allele and NFTs pathologies are inconsistent (Morris et al., 2010; Kok et al., 2009). Our findings in elderly Sri Lankans suggest that age-based risk of NFTs, ApoE $\varepsilon 4$ allele-based risk of $A \beta$ plaques and the survival probabilities of $A p o E \varepsilon 4$ allele carriers could possibly be a one of the reasons for the discordance observed between NFT and A $\beta$ plaque stages in AD neuropathological diagnosis. As like Geddes et al. (1997) and Kazee and Johnson (1998), we therefore support the inapplicability of National Institute on Aging and Reagan Institute (NIA$\mathrm{RI})$ criteria in $\mathrm{AD}$ research settings.

Increased plasma homocysteine level is a strong, independent risk factor for the development of dementia and AD (Seshadri et al., 2002). In recent studies, plasma total homocysteine has been emerged as a major vascular risk factor (O'Brien and Markus, 2014). MTHFR is the central enzyme involved in homocysteine metabolism. We found a significant association between MTHFR C677T polymorphism and sporadic CAA pathology in elderly Sri Lankans. However, it remains unclear as there is no such evidence in the literature. Further, polymorphisms in angiotensin converting enzyme (ACE) gene did not show any statistical significance with AD-related neuropathologies. However, $A C E D D$ genotypes were found significantly higher in old elderly decedents (68\%, age range 70 to 89 years) compared to young elderly decedents (32\%, age range 50 to 69 years). ACE D allele has been reported to be more frequent in centenarians and in nonagenarians (Schachter et al., 1994; Galinsky et al., 1997; Seripa et al., 2006) compared to younger ethnically matched referents.

Besides, the association between education and reduced risk of dementia in population-based studies is explained via two hypotheses: "brain reserve" and "brain battering" (Fratiglioni and Wang, 2007; Del Ser et al., 1999). Brain reserve hypothesis emphasizes the protective effect of education via enhancement of cognitive assets above the threshold for dementia, possibly by increasing synaptic density or efficiency or by acquired skills whereas; brain battering hypothesis indicates that individuals with greater educational attainment and associated higher socio-economic status would be exposed to fewer toxins, enjoy a healthier life style and have greater access to quality health care, all of which would tend to spare their brains from lesions contributing to dementing illnesses. De Silva et al's (2003) study in elderly Sri Lankans mentioned that illiteracy was strongly associated with clinical dementia in addition to greater age and female gender. However, there has been no autopsy evidence that investigated the relationship between education and AD in South Asians. Existing autopsy evidence which reports the relationship between education and AD neuropathologies are inconsistent (Del Ser et al., 1999; Munoz et al., 2000). In this study, we saw strong associations between illiteracy and both increased risk of Braak's NFT stages and reduced risk of microscopic infarcts. Increased risk of Braak's NFT stages in illiterates i.e. reduced risk of Braak's NFT stages in 
literates are in line with "brain reserve hypothesis" whereas reduced risk of microscopic infarcts in illiterates might be attributed to their low level of exposure to cerebrovascular risk factors such as smoking, hypertension, diabetes and obesity (Ferri et al., 2005; Llibre et al., 2008).

Other than the above factors, significant associations were obtained between history of hypertension and atherosclerosis of the $\mathrm{CW}$, and between history of diabetes and microscopic infarcts pathology in elderly Sri Lankan brains. However, these metabolic risk factors did not show any significant associations with AD-related neuropathological changes. As like Arvanitakis et al. (2006) and Chui et al. (2012) studies, we suggest that metabolic risk factors could contribute to dementia via vascular degenerations rather than AD. Similarly, smoking and alcohol consumption did not show any statistical significance with any of the age-related neuropathological changes. As far as smoking or alcohol consumption is concerned, it could be that there is a small effect which cannot be detected with statistical significance without a large sample size. It could also have attributed to cultural factors that may attenuate overall effects seen with smoking or alcohol consumption as Sri Lankan females are generally straight edge.

Coexisting cerebrovascular pathologies are growing interest in the burden of sporadic AD. However, neuropathological studies which rely on intracranial atherosclerosis of the CW as a major cause for cerebral hypoperfusion have been found to be inconsistent (Luoto et al., 2009; Dolan et al., 2010; Bangen et al., 2015). In some studies, the relationship between white matter disease (MRI based) and AD-related neuropathologies (Braak score, CERAD score and a composite AD pathology score) are strongly proven. And, this could explain in part the relationship between white matter disease and cognition (Moghekar et al., 2012; Prins and Scheltens, 2015). The relationship between white matter disease and cognition has been also acclaimed to coexisting atherosclerosis (Roher et al., 2011; Roher et al., 2003; Beach et al., 2007); however, it is not essential in all neuropathological studies (Moghekar et al., 2012). In our study, a higher degree of association was found between cerebral small vessel diseasesWMHs and AD-related neuropathological scores: Braak's NFT stages, Thal's A $\beta$ phases and CERAD's neuritic plaque (NP) scores; and CAA and Thal's A $\beta$ phases and CERAD's NP scores, while, atherosclerosis of the $\mathrm{CW}$ did not show any significant $(\mathrm{p}<0.05)$ associations with AD-related neuropathological scores. Further, we obtained a strong association between WMHs and CAA as like reported literatures (Hancu et al., 2009; Gurol et al., 2013; Gouw et al., 2011) that suggests WMHs as a feature of sporadic CAA. As per Luoto et al. (2009), it is also arguable that an at risk $(\mathrm{p}=0.05)$ significant association observed between Braak's NFT stages (I-VI) and CW atherosclerosis (mild to severe) could be attributed to the effect of age and not due to a pathologically direct relationship as other grades of Braak's NFT stages or $\mathrm{CW}$ atherosclerosis were not associated. Therefore, these findings confirm the contribution of cerebral small vessel diseases and question the true effect of intracranial atherosclerosis of the $\mathrm{CW}$ in the etiology of sporadic AD.

Taken together, ageing brains' neuropathologies clearly identify the vascular and genetic risk factors, and the coexisting cerebrovascular pathologies that could possibly lead to sporadic AD, and these findings are mostly in line with the previous literature.

Is there an overrepresentation of AD-related neuropathologies in the brains of elders who succumbed to injury deaths?

Cognitive impairment affects elders' quality of life substantially. In this objective, we compared the elderly brains' neuropathology based on their cause of death. Our comparison demonstrates a trend in elderly brains' neuropathology where AD-related neuropathological changes were predominant in injury deaths caused by traffic accidents, whereas 
cerebrovascular pathologies: intracranial atherosclerosis of the $\mathrm{CW}$ and microscopic infarcts were prominently detected in natural deaths and suicides. A significant overrepresentation of NFTs was identified in the region of entorhinal cortex of the victims of fatal traffic accidents, the first area of the brain to be affected in AD. Hippocampus is a structure that appears to be an early target of neurodegenerative processes and whose involvement is key to the memory impairments seen in age-related cognitive disorders (van Hoesen et al., 1991).

In addition, we examined the relative prevalence of comorbid pathologies such as CAA, CW atherosclerosis, white matter pathologies and Lewy body diseases between injury and natural deaths. Thus, other causes of dementia that possibly contribute to elderly injury deaths could be reliably assessed, however those pathologies did not show any statistical significance between injury and natural deaths. Since this study was based on cases from suicide and fatal traffic accidents, other causes of injury deaths such as falls and drowning which may result from cognitive impairments also need to be included in future concerns.

What are the CW abnormalities commonly observed in the ageing brains and their possible contibutions in the etiology of sporadic AD and other dementias?

For this specific objective, we assessed 73 elderly CW samples macroscopically and microscopically, and determined the clinical importance of these anatomical factors with respect to neuropathological findings. We found that most of the elderly Sri Lankan brains aged 50 years and above contained atypical CW (68 out of 73, approximately 93\%) at death and PcomA was recognized as the CW component artery with most anatomical variations (Gunnal et al, 2014; Yeniceri et al, 2017). In our previous study (De Silva et al., 2011), 85.8\% Sri Lankan brains between the ages of 18 and 71 years were found with atypical CW at death. These observations are comparatively higher than the studies reported in other populations: $53.2 \%$ (in 357 brains) in South India (Reddy et al., 1972), $45.2 \%$ (in 1000 brains, age $\geq 1$ year) in Northwest India (Kapoor et al., 2008), and 52.3 \% in U.S. (Alpers et al., 1959). The differences observed in these population-based studies might be attributed to their age, genetic predispositions, and / or environmental variations. Further, anatomical defects, particularly atretic communicating arteries, can seriously compromise ability to compensate for sudden occlusions. Similarly, most of the cerebral aneurysms were identified at the arterial bifurcations, raising the possibility that the unique hemodynamic conditions associated with flow dividers predispose the apical vessel wall to aneurysm formation (Meng et al., 2007). In addition, cerebral aneurysms were coexisted with either anatomical variations or atherosclerosis or both. These observations suggest the importance of analysing each CW sample thoroughly to elucidate the pathogenetic role of CW abnormalities in the development of cerebral aneurysms (Kayembe et al., 1984).

Apart from the $\mathrm{CW}$ anatomical defects, increased risk of $\mathrm{CW}$ atherosclerosis was significantly associated with age, history of hypertension and $A p o E \varepsilon 3 / \varepsilon 4$ genotype, whereas ApoE $\varepsilon 3 / \varepsilon 2$ genotype was found vice versa (Roher et al., 2011; Beach et al., 2007). Between posterior and anterior circulation arteries, $A p o E$ genotypes played an important role. Cases with ApoE $\varepsilon 3 / \varepsilon 4$ genotype showed an increased risk of severe atherosclerosis in the posterior circulation whereas cases with $A p o E \varepsilon 3 / \varepsilon 2$ genotype showed reduced risk of atherosclerosis in the anterior circulation. Still now, there is little known about the risk factors associated between posterior and anterior circulation atherosclerosis (Kim et al., 2012; Subramanian et al., 2008; Turan et al., 2010). Posterior circulation stroke is comparatively higher in Asian populations and its etiology and the characteristics are appeared to be different from Caucasians (Lee et al., 2006). Based on the results of this study, we suggest that $A p o E \varepsilon 2$ and $\varepsilon 4$ allelic frequencies and their carriers' survival probabilities could possibly be a one of reasons for the discrepancies observed 
between posterior and anterior circulation atherosclerotic stroke incidence in population-based studies.

Moreover, in this study, we demonstrated a significant relationship between hypoplastic communicating arteries (diameter $<0.1 \mathrm{~mm}$ ) and microscopic infarcts pathology in deep white matter. White matter lesions (WMLs) are regarded as a cerebral small artery disease, and the diameters of these arteries are often smaller than $0.1 \mathrm{~mm}$ (He et al., 2016). The pathological feature of WML manifests diffuse white matter demyelination, mainly around the lateral ventricles deep white matter, corona radiata area, usually with silent lacunar infarctions in basal ganglia, thalamus and subcortical white matter region (He et al., 2016). The etiology of WML is unclear. It may be due to chronic hypoperfusion of white matter and blood-brain barrier damage causing chronic leakage of plasma into white matter (Pantoni, 2010). He et al. (2016) described that incomplete $\mathrm{CW}$ and cerebral artery stenosis may impair self-regulation of cerebral blood flow and hemodynamic stability, but there is insufficient evidence to confirm that incomplete $\mathrm{CW}$ and cerebral artery stenosis are associated with WMLs. Associations, between white matter diseases and incomplete $\mathrm{CW}$ or absent $\mathrm{CW}$ arteries have been reported in magnetic resonance imaging (MRI) studies (Ryan et L., 2015). Our observations are novel in the etiopathogenesis of WMLs. However, additional work is required to identify the actual role and the underlying mechanism of hypoplastic CW components in WMLs.

\section{Study Limitations}

Finally, we acknowledge that there are some limitations in this study. Incomplete clinical history of the recruited subjects as well as a lack of objective psychometry and dementia scores, ubiquitin immunohistochemistry for labelling LBs instead of $\alpha$-synuclein, not performed screening on ageing-related tau astrogliopathy (ARTAG) (Kovas et al., 2016), and the non-availability of some brain regions as specified under minimum tissue requirements by NIA-AA guidelines (Montine et al., 2012) are considered as important limiting factors of this study. This is a retrospective autopsy study. Thus, case history is obtained through kin who were familiar with intellectual and functional status of the subjects before death. However, uncertainty around cognitive status of the subjects at the time of tissue removal affects the final diagnosis of AD. For the LBDs, although $\mathrm{H}$ and $\mathrm{E}$ staining may be used to detect LBs, greater sensitivity can be achieved with $\alpha$-synuclein immunohistochemistry. It is recommended as preferred method in the NIA-AA guidelines (Montine et al., 2012). In our study, in addition to H\&E staining, ubiquitin immunohistochemistry is used to label LBs instead of $\alpha$-synuclein. Ubiquitin immunohistochemistry is recommended for LB labelling according to CDLB 1996 guidelines (McKeith et al., 1996). We did not screen the extent of ARTAG in these elderly brains. Pathological accumulation of abnormally phosphorylated tau protein in astrocytes is a poorly characterized feature of the aging brain (Kovacs et al., 2016). Further, there has been lack of consensus on how best to classify these tau astrogliopathies (Kovacs et al., 2013). These impeded us not to undertake ARTAG screening in these ageing brains. Lastly, we collected specific brain regions between May 2009 and March 2010. As a result, some of the brain sections, as specified in the NIA-AA guidelines (Montine et al., 2012) were not available in this study. Besides, there was a little difference in mean ages between the 2 elderly sample populations. This could be one of the possible reasons for the differences in tau positive cytoskeletal alternations that were prominently identified in elderly Sri Lankan brains. In fact, mean age of the samples reflected their standard population life expectancy, however, should be considered cautiously when interpreting the results. 


\section{Future Perspectives}

We carried out a retrospective autopsy to see the extent of age-related cytoskeletal pathologies, representing two South Asian elderly sample populations. To determine the actual burden of dementia, we recommend carrying out a prospective clinico-pathological study in these populations. Since the dementia epidemic is anticipated to rise in low- and middle-income countries, it is advisable to conduct such longitudinal studies to estimate the actual prevalence of different types of dementia in these populations.

We recognized that ageing brains' neuropathologies representing vulnerable elderly populations could help to explore the potential vascular and genetic risk factors in the aetiology of sporadic AD. Most of our findings are in line with the literatures. Some are novel findings that open new avenues for healthy discussions and advancements. Importantly, we obtained significant associations between ApoE genotypes and AD neuropathological scores (Thal's A $\beta$ phases and Braak's NFT stages, an opposite relationship), and between ApoE genotypes and $\mathrm{CW}$ atherosclerosis (posterior and anterior circulation, an opposite relationship). Therefore, we recommend that $A p o E$ genotyping should be considered as an essential requirement in $\mathrm{AD}$ and stroke research settings and in population-based studies.

Next, a significant association observed between MTHFR C677T polymorphism and sporadic CAA pathology in elderly brains suggests that plasma homocysteine could be a predisposing factor in sporadic CAA. Plasma homocysteine level has been demonstrated to be a major risk factor for AD and dementia (Seshadri et al., 2002). Cerebral amyloid angiopathy (CAA) is increasingly recognized as a major contributor of $\mathrm{AD}$ pathogenesis (Ghiso et at., 2010). Therefore, we hypothesize that plasma homocysteine could contribute to AD pathogenesis possibly via CAA, and recommend large scale genetic and neuropathological studies to explore possible underlying mechanism.

Finally, we observed a significant association between hypoplastic communicating arteries $(<0.1 \mathrm{~mm})$ and microscopic infarcts in deep white matter. It is well known that WMLs are cerebral small artery diseases, and the diameters of these arteries are often smaller than $0.1 \mathrm{~mm}$ (He et al., 2016). This explains that hypoplastic CW components could possibly contribute to WMLs. However, further evidence either pathological or radiological to confirm the associations between hypoplastic $\mathrm{CW}$ components and white matter lesions are warranted.

\subsection{References}

Aarsland D, Andersen K, Larsen JP, Lolk A, Kragh-Sorensen P (2003) Prevalence and characteristics of dementia in Parkinson disease: an 8-year prospective study. Arch Neurol 60, 387-392.

Alpers B, Berry J, Paddison R, (1959) Anatomical studies of the circle of Willis in normal brain. AMA Arch Neurol Psychiatry 81, 409-418.

Arvanitakis Z, Schneider JA, Wilson RS, Li Y, Arnold SE, Wang Z, et al (2006) Diabetes is related to cerebral infarction but not to AD pathology in older persons. Neurology 67, 19601965.

Bangen KJ, Nation DA, Delano-Wood L, Weissberger GH, Hansen LA, Galasko DR, et al (2015) Aggregate effects of vascular risk factors on cerebrovascular changes in autopsyconfirmed Alzheimer's disease. Alzheimers Dement 11, 394-403. 
Beach TG, Wilson JR, Sue LI, Newell A, Poston M, Cisneros R, et al (2007) Circle of Willis atherosclerosis: association with Alzheimer's disease, neuritic plaques and neurofibrillary tangles. Acta Neuropathol 113, 13-21.

Catindig JA, Venketasubramanian N, Ikram MK, Chen C (2012) Epidemiology of dementia in Asia: insights on prevalence trends and novel risk factors. J Neurol Sci 321, 11-16.

Chui HC, Zheng L, Reed BR, Vinters HV, Mack WJ (2012) Vascular risk factors and Alzheimer's disease: are these risk factors for plaques and tangles or for concomitant vascular pathology that increases the likelihood of dementia? An evidence-based review. Alzheimers Res Ther 4, 1.

De Silva HA, Gunathilake SB, Smith AD (2003) Prevalence of dementia in a semi-urban population in Sri Lanka: report from a regional survey. Int J Geriatr Psychiatry 18, 711-715.

De Silva KR, Silva R, Amaratunga D, Gunasekera WS, Jayesekera RW (2011) Types of the cerebral arterial circle (circle of Willis) in a Sri Lankan Population. BMC Neurol 11, 2-8.

Del Ser T, Hachinski V, Merskey H, Munoz DG (1999) An autopsy-verified study of the effect of education on degenerative dementia. Brain 122, 2309-2319.

Dolan D, Troncoso J, Resnick SM, Crain BJ, Zonderman AB, O'Brien RJ (2010) Age, Alzheimer's disease and dementia in the Baltimore Longitudinal Study of Ageing. Brain 133, $2225-2231$.

Ferri CP, Prince M, Brayne C, Brodaty H, Fratiglioni L, Ganguli M, et al (2005) Global prevalence of dementia: a Delphi consensus study. Lancet 366, 2112-2117.

Fratiglioni L, Wang HX (2007) Brain reserve hypothesis in dementia. J Alzheimers Dis 12, 11 22.

Galinsky D, Tysoe C, Brayne CE, Easton DF, Huppert FA, Dening TR, et al (1997) Analysis of the apo E/apo C-I, angiotensin converting enzyme and methylenetetrahydrofolate reductase genes as candidates affecting human longevity. Atherosclerosis 129, 177-183.

Geddes JW, Tekirian TL, Soultanian NS, Ashford JW, Davis DG, Markesbery WR (1997) Comparison of neuropathologic criteria for the diagnosis of Alzheimer's disease. Neurobiol Ageing 18, S99-S105.

Ghiso J, Tomidokoro Y, Revesz T, Frangione B, Rostagno A (2010) Cerebral amyloid angiopathy and Alzheimer's disease. Hirosaki Igaku 61, S111-S124.

Gouw AA, Seewann A, van der Filer WM, Barkhof F, Rozemuller AM, Scheltns P, et al (2011) Heterogeneity of small vessel disease: a systematic review of MRI and histopathological correlations. J Neurol Neurosurg Psychiatry 82, 126-135.

Gunnal SA, Farooqui MS, Walbale RN (2014) Anatomical variations of the circulus arteriosus in cadaveric human brains. Neurol Res Int 2014, 687281. 
Gurol ME, Viswanathan A, Gidicsin C, Hedden T, Martinez-Ramirez S, Dumas A, et al (2013) Cerebral amyloid angiopathy burden associated with leukoaraiosis: a positron emission tomography/ magnetic resonance imaging study. Ann Neurol 73, 529-536.

Hancu A, Rasanu I, Butoi G (2009) White matter changes in cerebrovascular disease: Leukoaraiosis. In Advances in Brain Imaging, Chaudhary V ed. InTech, Europe, pp 249-250.

He Y, Li Y, Jiang H, Teng F, Nie Z (2016) Is incomplete circle of Willis associated with white matter lesion? Int J Clin Exp Med 9, 11657-11662.

Kalaria NR, Maestre GE, Arizaga R, Friedland RP, Galasko D, Hall K, et al (2008)

Alzheimer's disease and vascular dementia in developing countries: prevalence, management, and risk factors. Lancet Neurol 7, 812-826.

Kapoor K, Singh B, Dewan LI (2008) Variations in the configuration of the circle of Willis. Anat Sci Int 83, 96-106.

Kayembe KN, Sasahara M, Hazama F (1984) Cerebral aneurysms and variations in the circle of Willis. Stroke 15, 846-850.

Kazee AM, Johnson EM (1998) Alzheimer's disease pathology in non-demented elderly. $J$ Alzheimers Dis 1, 81-89.

Kim JS, Nah HW, Park SM, Kim SK, Cho KH, Lee J, et al (2012) Risk factors and stroke mechanisms in atherosclerotic stroke: intracranial compared with extracranial and anterior compared with posterior circulation disease. Stroke 43, 3313-3318.

Kok E, Haikonen S, Luoto T, Huhtala H, Goebeler S, Haapasalo H, et al (2009) Apolipoprotein E dependent accumulation of Alzheimer disease-related lesions begins in middle age. Ann Neurol 65, 650-657.

Kovacs GG, Milenkovic I, Wöhrer A, Höftberger R, Gelpi E, Haberler C, et al (2013) NonAlzheimer neurodegenerative pathologies and their combinations are more frequent than commonly believed in the elderly brain: a community-based autopsy series. Acta Neuropathol $126,365-84$.

Kovacs GG, Ferrer I, Grinberg LT, Alafuzoff I, Attems J, Budka H, et al (2016) Aging-related tau astrogliopathy (ARTAG): harmonized evaluation strategy. Acta Neuropathol 131, 87-102.

Lee JH, Han SJ, Yun YH, Choi HC, Jung S, Cho SJ, et al (2006) Posterior circulation ischemic stroke in Korean population. Eur J Neurol 13, 742-748.

Llibre Rodriguez JJ, Ferri CP, Acosta D, Guerra M, Huang Y, Jacob KS, et al (2008) Prevalence of dementia in Latin America, India and China: a population based cross-sectional slurvey. Lancet 372, 464-474.

Luoto TM, Haikonen S, Haapasalo H, Goebeler S, Huhtala H, Erkinjuntti T, et al (2009) Large vessel cerebral atherosclerosis is not in direct association with neuropathological lesions of Alzheimer's disease. Eur Neurol 62, 93-98. 
McKeith IG, Galasko D, Kosaka K, Perry EK, Dickson DW, Hansen LA, et al (1996) Consensus guidelines for the clinical and pathologic diagnosis of dementia with Lewy bodies (DLB): report of the consortium on DLB international workshop. Neurology 47, 1113-24.

Meng H, Wang Z, Hoi Y, Gao L, Metaxa E, Swartz DD, et al (2007) Complex hemodynamics at the apex of an arterial bifurcation induces vascular remodeling resembling cerebral aneurysm initiation. Stroke 38, 1924-1931.

Moghekar A, Kraut M, Elkins W, Troncoso J, Zonderman AB, Resnick SM, et al (2012) Cerebral white matter disease is associated with Alzheimer pathology. Alzheimers Dement 8, S71-S77.

Montine TJ, Phelps CH, Beach TG, Bigio EH, Cairns NJ, Dickson DW, et al (2012) National Institute on Aging; Alzheimer's Association. National Institute on Aging-Alzheimer's Association guidelines for the neuropathologic assessment of Alzheimer's disease: a practical approach. Acta Neuropathol 123, 1-11.

Morris JC, Roe CM, Xiong C, Fagan AM, Goate AM, Holtzman DM, et al (2010) APOE predicts amyloid-beta but not tau Alzheimer pathology in cognitively normal ageing. Ann Neurol 67, 122-131.

Munoz DG, Ganapathy GR, Eliasziw M, Hachinski V (2005) Educational attainment and socioeconomic status of patients with autopsy-confirmed Alzheimer disease. Arch Neurol 57, 85-89.

O’Brien JT, Markus HS (2014) Vascular risk factors and Alzheimer's disease. BMC Med 12, 218.

Pantoni L (2010) Cerebral small artery disease: from pathogenesis and clinical characteristics to therapeutic challenge. Lancet Neurol 9, 689-701.

Prince M, Wimo A, Guerchet M, Ali GC, Wu Y, Prina M (2015) World Alzheimer Report 2015. The global impact of dementia: an analysis of prevalence, incidence, cost and trends. London: Alzheimer's Disease International; 2015.

Prins ND, Scheltens P (2015) White matter hyperintensities, cognitive impairment and dementia: an update. Nat Rev Neurol 11, 157-165.

Purohit DP, Batheia NO, Sano M, Jashnani KD, Kalaria RN, Karunamurthy A, et al (2011) Profile of Alzheimer's disease-related pathology in an aging urban population sample in India. J Alzheimers Dis 24, 187-196.

Reddy DR, Prabhakar V, Rao BD (1972) Anatomical study of circle of Willis. Neurol India 20, 8-12.

Roher AE, Esh C, Kokjohn TA, Kalback W, Luehrs DC, Seward JD, et al (2003) Circle of Willis atherosclerosis is a risk factor for sporadic Alzheimer's disease. Arterioscler Thromb Vasc Biol 23, 2055-2062. 
Roher AE, Tyas SL, Maarouf CL, Daugs ID, Kokjohn TA, Emmerling MR, et al (2011) Intracranial atherosclerosis as a contributing factor to Alzheimer's disease dementia. Alzheimers Dement 7, 436-444.

Ryan DJ, Byme S, Dunne R, Harmon M, Harbison J (2015) White matter disease and an incomplete circle of Willis. Int J Stroke 10, 547-552.

Schachter F, Faure-Delanef L, Guenot F, Rouger H, Froguel P, Lesueur-Ginot L, et al (1994) Genetic associations with human longevity at the APOE and ACE loci. Nat Genet 6, 29-32.

Seripa D, Franceschi M, Matera MG, Panza F, Kehoe PG, Gravina C, et al (2006) Sex differences in the association of apolipoprotein $\mathrm{E}$ and angiotensin-converting enzyme gene polymorphisms with healthy aging and longevity: a population-based study from Southern Italy. J Gerontol A Biol Sci Med Sci 61, 918-923.

Seshadri S, Beiser A, Selhub J, Jacques PF, Rosenberg IH, D'Agostino RB, et al (2002) Plasma homocysteine as a risk factor for dementia and Alzheimer's disease. $N$ Engl J Med 346, 47683.

Subramanian G, Silva J, Silver FL, Fang J, Kapral MK, Oczkowski W, et al (2009) Risk factors for posterior compared to anterior ischemic stroke: an observational study of the Canadian Stroke Network. Neuroepidemiology 33, 12-16.

Turan TN, Makki AA, Tsappidi S, Cotsonis G, Lynn MJ, Cloft HJ, et al (2010) Risk factors associated with severity and location of intracranial arterial stenosis. Stroke 41, 1636-1640.

van Hoesen GW, Hyman BT, Damasio AR (1991) Entorhinal cortex pathology in Alzheimer's disease. Hippocampus 1, 1-8.

Venketasubramanian N, Sahadevan S, Kua EH, Chen CP, Ng TP (2010) Interethnic differences in dementia epidemiology: Global and Asia-Pacific perspectives. Dement Geriatr Cogn Disord 30, 492-498.

Verghese PB, Castellano JM, Holtzman DM (2011) Roles of Apolipoprotein E in Alzheimer's disease and other neurological disorders. Lancet Neurol 10, 241-252.

Wijesinghe P, Shankar SK, Yasha TC, Gorrie CA, Amaratunga D, Hulathduwa SR, et al (2016) Cytoskeletal pathologies of age related diseases between elderly Sri Lankan and Indian brain samples. Curr Alzheimer Res 13, 268-280.

Wimo A, Guerchet M, Ali GC, Wu YT, Prina AM, Winblad B, et al (2017) The worldwide costs of dementia 2015 and comparisons with 2010. Alzheimers Dement 13, 1-7.

World Health Organization. World Health Statistics 2013. Geneva: World Health Organization Press, (2013).

Yeniceri IO, Cullu N, Deveer M, Yeniceri EN (2017) Circle of Willis variations and artery diameter measurements in the Turkish population. Folia Morphol (Warsz) 76, 420-425. 


\subsection{Societal Impact}

Our neuropathological evidence in elderly Sri Lankan brains indicates a higher prevalence of Parkinsonism associated pathologies $(8.51 \%)$ followed by $\mathrm{AD}(4.25 \%)$. It urges the neuroscientific body in Sri Lanka to continue further investigations based on genetic susceptibility, environmental exposures and the dietary patterns which are unique to this region. Vascular burden in brain aging and its coexistence in the manifestation of AD-related neuropathological changes are highly focused in this study. We demonstrated that besides age, education, and genetic factors such as $A p o E \& 4$ alleles and MTHFR $T$ alleles, other vascular risk factors were not associated with AD-related neuropathological changes. Moreover, cerebral small vessel pathologies such as WMHs and CAA were identified as potential coexisting cerebrovascular changes in the etiology of sporadic AD. We further emphasize that consumption of natural products that contains anti-amyloidogenic components and folic acid supplementations could be used as preventative strategies against these pathologies. Large vessel pathology, atherosclerosis of the $\mathrm{CW}$ did not show any significant associations with $\mathrm{AD}$ related neuropathological changes, thus interrogates vascular hypothesis in the etiology of sporadic $\mathrm{AD}$ which was proposed on intracranial atherosclerosis of the $\mathrm{CW}$, a major cause for cerebral hypoperfusion. We suggest that $\mathrm{CW}$ atherosclerosis might contribute to vascular cognitive impairment rather than sporadic AD.

Differences in ApoE allelic frequencies and their carriers' survival probabilities could possibly be the main reasons for the variations observed in sporadic AD prevalence among populationbased studies. Age-based risk of NFTs, ApoE $\varepsilon 4$ allele-based risk of A $\beta$ plaques and the survival probabilities of $A p o E \& 4$ allele carriers may cause discordance between NFT and A $\beta$ plaque stages in $\mathrm{AD}$ neuropathological diagnosis. Our observations support the inapplicability of NIA-RI criteria on AD research settings. Similarly, ApoE $\varepsilon 2$ and $\varepsilon 4$ allelic frequencies and their carriers' survival probabilities could possibly be the main reasons for the discrepancies observed between posterior and anterior circulation atherosclerotic stroke incidence in population-based studies. In our study, subjects with $A p o E \varepsilon 3 / \varepsilon 4$ genotype showed an increased risk of severe atherosclerosis in posterior circulation whereas subjects with ApoE $\varepsilon 3 / \varepsilon 2$ genotype showed reduced risk of atherosclerosis in anterior circulation. We also reported some novel findings such as significant associations obtained between sporadic CAA and MTHFR C677T polymorphism, and between hypoplastic $\mathrm{CW}$ component arteries and microscopic infarcts in deep white matter. However, large-scale neuropathological studies in ageing brains are recommended. We further demonstrated that early AD-related neuropathological changes may contribute sufficiently to elderly injury deaths caused by traffic accidents. This is a serious public health issue in Sri Lanka as well as in other low- and middle-income countries; however, it has not been taken into consideration by the government or healthcare systems. We suggest that forensic autopsy should include neuropathological examination in elderly injury deaths caused by fatal accidents. Further, it is important to have an awareness of a possible link between cognitive impairment or early stages $\mathrm{AD}$ and cause of death in the elderly. This provides an opportunity to reduce the risk of injury deaths in this age group.

There are no cures for dementia caused by progressive neurodegenerations including AD and LBD. A better understanding of dementia causes, as well as their diagnosis and treatment, will make it possible for affected individuals and their caretakers to live and meet their daily challenges mostly. It is an urgent requirement to develop cost effective packages of medical and social care that fulfills affected individuals and their caretakers need throughout the course of illness. Government and health care systems need to be prepared adequately for future and must seek the possible ways to improve their quality of lives. Only by investing now in research and cost-effective approaches to early diagnosis and care can future societal costs be anticipated and managed. 
CHAPTER 7 


\subsection{Acknowledgments}

I would like to express my sincere thanks to Prof. Dr. Harry W.M. Steinbusch, Department of Translational Neuroscience and Prof. Dr. Ranil de Silva, Department of Anatomy who have selected me as an eligible Double Doctoral candidate through signing of memorandum of understanding between Maastricht University, The Netherland and the University of Sri Jayewardenepura, Sri Lanka, and continued their support and courage throughout the study. I would like to extend my sincere gratitude to Emeritus Prof. Dr. S.K. Shankar and Prof. Dr. Yasha. T.C., Department of Neuropathology, National Institute of Mental Health and Neurosciences, Bangalore, India who have accepted me at their institute to get trained and carried out the neuropathological diagnosis of ageing brains under their excellent guidance and support. I sincerely thank Prof. Yoo-Hun Suh, Department of Pharmacology, Seoul National University, South Korea; Dr. Dhammika Amaratunga (Retired), Department of Nonclinical Statistics, Johnson \& Johnson Pharmaceutical Research \& Development, New York, USA; Dr. Catherine Gorrie, University Technology of Sydney, Australia; Judicial Medical Officers Dr. Sanjayah Hulathduwa, Department of Forensic Medicine, the University of Jayewardenepura, and Dr. K. Sunil Kumara, Colombo South Teaching Hospital, Columbo, Sri Lanka and the Pathologist Dr. Kamani Samarasinghe, Department of Pathology, the University of Jayewardenepura for sharing knowledge, and helping me to carry out the research activities at their facilities.

I greatly acknowledge the funding agencies: Sri Lanka Council for Agricultural Research Policy (CARP Project Grant No- 12/684/515), Sri Lanka National Science Foundation (Grant No- RG 2000/M/16), University of Sri Jayewardenepura (Grant No- ASP/06/RE/2010/07; ASP/06/RE/2013/28), University of New South Wales, and the International Brain Research Organization-Asia Pacific Regional Committee (IBRO-APRC) for their financial contribution.

I kindly acknowledge the staff, Department of Neuropathology, National Institute of Mental Health and Neurosciences, Bangalore, India, the staff, Departments of Pathology, Anatomy, Forensic Medicine and Post Graduate Education, the University of Sri Jayewardenepura and the staff, Judicial Medical Office, Colombo South Teaching Hospital, Columbo for their kind assistance thorough out the course. My heartfelt thanks to donors and their families for their substantial contribution in this research.

Last but not least, my mother and family who have given freedom and support to decide my carrier. Lots of thanks to my daughter Pooja who is keeping my life fulfilled. 


\subsection{Appendix I: Abbreviations}

A1ACA, A1 segment of the anterior cerebral artery; ACA, Anterior cerebral artery; ACE, Angiotensin converting enzyme; AcomA, Anterior communicating artery; AD, Alzheimer's disease; APOE, Apolipoprotein E; A $\beta$, Beta amyloid; BA, Basilar artery; CA, Cornu Ammonis; CAA, Cerebral amyloid angiopathy; CI, Confidence interval; CW, Circle of Willis; DAB, 3,3'-Diaminobenzidine; DG, Dentate gyrus; DLB, Dementia with Lewy bodies; DLBD, Diffuse Lewy body disease; DP, Diffuse plaque; FTD, Frontotemporal dementia; FVL, Factor V Leiden; H\&E, Haematoxylin and eosin; $\mathrm{H}_{2} \mathrm{O}_{2}$, Hydrogen peroxide; HIC, High- income country; IASCW, Intracranial atherosclerosis of the circle of Willis; ICA, Internal carotid artery; LB, Lewy bodies; LBDs, Lewy body diseases; LFB, Luxol fast blue; LMICs, Low- and middle- income countries; MCA, Middle cerebral artery; MTHFR, Methylenetetrahydrofolate reductase; NFTs, Neurofibrillary tangles; NIA-AA, National Institute on Aging-Alzheimer's Association; NIA-RI, National Institute on Aging and Reagan Institute; NP, Neuritic plaque; NT, Neuropil thread; OR, Odds ratio; P1PCA, P1 segment of the posterior cerebral artery; PCA, Posterior cerebral artery; PcomA, Posterior communicating artery; PCR, Polymerase chain reaction; PD, Parkinson's disease; PHF, Paired-helical filament; PSP, Progressive supranuclear palsy; RFLP, Restriction fragment length polymorphism; RTAs, Road traffic accidents; S.D., Standard deviation; SEM, Standard error of mean; SP, Senile plaque; VA, Vertebral artery; VaD, Vascular dementia; VCI, Vascular cognitive impairment; WHO, World Health Organization; WMHs, White matter hyperintensities; WMLs, White matter lesions 


\subsection{Appendix II: Publications \& Presentations}

1) Wijesinghe, P., Steinbusch, H., Shankar, S. K., Yasha, T. C., \& De Silva, K. (2020). Circle of Willis abnormalities and their clinical importance in ageing brains: A cadaveric anatomical and pathological study. Journal of chemical neuroanatomy, 106, 101772. Advance online publication. https://doi.org/10.1016/j.jchemneu.2020.101772

2) Wijesinghe, P., Gorrie, C., Shankar, S. K., Chickabasaviah, Y. T., Amaratunga, D., Hulathduwa, S., Kumara, K. S., Samarasinghe, K., Suh, Y. H., Steinbusch, H., \& De Silva, K. (2017). Early stages of Alzheimer's disease are alarming signs in injury deaths caused by traffic accidents in elderly people ( $\geq 60$ years of age): A neuropathological study. Indian journal of psychiatry, 59(4), 471-477.

3) Wijesinghe, P., Shankar, S. K., Yasha, T. C., Gorrie, C., Amaratunga, D., Hulathduwa, S., Kumara, K. S., Samarasinghe, K., Suh, Y. H., Steinbusch, H. W., \& De Silva, K. R. (2016). Vascular Contributions in Alzheimer's Disease-Related Neuropathological Changes: First Autopsy Evidence from a South Asian Aging Population. Journal of Alzheimer's disease: JAD, 54(4), 1607-1618.

4) Wijesinghe, P., Shankar, S. K., Chickabasaviah, Y. T., Gorrie, C., Amaratunga, D., Hulathduwa, S., Kumara, K. S., Samarasinghe, K., Suh, Y. H., Steinbusch, H. W., \& De Silva, K. R. (2016). Cytoskeletal Pathologies of Age-Related Diseases between Elderly Sri Lankan (Colombo) and Indian (Bangalore) Brain Samples. Current Alzheimer research, 13(3), 268-280.

5) Printha, K., Hulathduwa, S. R., Samarasinghe, K., Suh, Y. H., \& De Silva, K. R. (2009). Apoptosis in subicular neurons: A comparison between suicide and Addison's disease. Indian journal of psychiatry, 51(4), 276-279.

\section{Accepted}

1. Wijekoon, N., Gonawala, L., Wijesinghe, P., Steinbusch, H.W.M., Mohan, C., De Silva, K.R.D. Genetic testing and Biobank linking East and West: Experience from a developing country. Lancet Neurology. Correspondence.

\section{International Presentations}

1) De Silva KRD, Wijesinghe $\mathbf{P}$. Culture and lifestyle factors in cognitive screening and neuropathology of ageing: a South Asian experience. Symposium on Brain Ageing and Dementia in developing countries, Safari Park Hotel Conference Center, Nairobi, Kenya, December $5^{\text {th }}$ to $9^{\text {th }}, 2016$ (Podium)

2) Wijesinghe P, Shankar S, Yasha T, Gorrie C, Amaratunga D, Kumara S, Samarasinghe K, Suh Y, Steinbusch HW, De Silva KD. Can South Asian diet lead to healthy brain ageing? $14^{\text {th }}$ Meeting of the Asian-Pacific Society for Neurochemistry, Kuala Lumpur, Malaysia, August $27^{\text {th }}$ to $30^{\text {th }}, 2016$ (Poster)

3) Wijesinghe P, Yasha TC, Shankar SK, Gorrie C, Amaratunga D, Kumara S, Samarasinghe K, Suh Y, De Silva KD. Age-related cytoskeletal pathology in human brain: A comparison between elderly Sri Lankan (Colombo) and Indian (Karnataka) samples. FAONS Symposium 2013 in Association with the $33^{\text {rd }}$ Annual Meeting of the Australian Neuroscience Society (ANS 2013), Melbourne, West Australia, February $3^{\text {rd }}$ to $6^{\text {th }}, 2013$ (Poster)

4) Kentheeswaran P, De Silva R. Prevalence of Methylene Tetra Hydro Folate Reductase (C677T) and Factor V Leiden Mutations in Young Female Sri Lankan Population: A Pilot Study. ISN/APSN/IBRO School $\& 8^{\text {th }}$ Biennial Meeting of the 
Asian Pacific Society for Neurochemistry (APSN), Shanghai, China, June $16^{\text {th }}$ to $26^{\text {th }}$, 2008 (Poster)

\section{Local Presentations}

1. Wijesinghe P, Samarasinghe K, Steinbusch HWM, et al. Abnormalities in the Circle of Willis as observed in ageing Sri Lankan human brains and their clinical implications: A cadaveric study. $19^{\text {th }}$ EURON PhD day, October $25-26^{\text {th }}, 2017$, Abdij Rolduc, Heyendallaan 82, 6464 EP Kerkrade, The Netherlands (Poster)

2. Wijesinghe P, Shankar SK, Yasha TC, et al. Vascular genetic biomarkers associated with Alzheimer's disease related neuropathological changes and longevity: $1^{\text {st }}$ report from a South Asian ageing population. $9^{\text {th }}$ Research Day, School for Mental Health and Neuroscience, November $30^{\text {th }}$ 2016, Maastricht University, Netherlands (Poster)

3. Wijesinghe P, Shankar SK, Yasha TC, et al. Neuropathology of the ageing brains across two genetically affiliated sample populations - India vs. Sri Lanka: Does the vascular risk factors play a role in evolution of Alzheimer related pathologies. Annual Research Day, School for Mental Health and Neuroscience, October $6^{\text {th }} 2015$, Maastricht University, Netherlands, pp 65-66 (Poster) 


\subsection{Appendix III: Biography}

Printha Kentheeswaran was born on $13^{\text {th }}$ March 1979 in Jaffna, northern Sri Lanka. She completed her bachelor's degree in agriculture (specialized in food chemistry) in the university of Jaffna from October 2000 to November 2004. She worked as a demonstrator and assistant lecturer in the Department of Agricultural Chemistry, however due to the continuing civil disturbances, she decided to move to Colombo, Sri Lanka for her higher education. She followed a master's degree in biochemistry, molecular biology \& gene technology in the Department of Biochemistry and Molecular Biology, Faculty of Medicine, University of Colombo from May 2006 to May 2008. For her master's thesis, she worked on a research project "identification of nematode specific fatty acid and retinol binding protein encoding gene far-1 from filarial parasitic nematode Setaria digitate" and obtained partial mRNA sequence (164bp) which gave $\geq 95 \%$ homology with fatty acid retinoid binding protein precursor mRNAs. Immediately after her master's degree, she joined as a research assistant to Prof. Dr. Ranil de Silva in the Genetic Diagnostic \& Research Laboratory and Human Brain Tissue and DNA Repository, Department of Anatomy, Faculty of Medical Sciences, University of Sri Jayewardenepura with a vision to obtain a doctor of philosophy in medical sciences. For this research project, she collected 76 human brain samples at postmortem which formed one of the largest "Human Brain Banks" in South Asia and the only one in Sri Lanka. This dedication recognized her as a successful candidate for International Brain Research Organization-Asia Pacific Regional Committee (IBRO-APRC) Exchange Fellowship in 2010. Through this fellowship, she got trained and carried out neuropathological diagnosis of age-related cytoskeletal pathologies in elderly brains in the Department of Neuropathology, National Institute of Mental Health and Neurosciences, Bangalore, India under the direct guidance of Emeritus Prof. Dr. S.K. Shankar and Prof. Dr. Yasha. T.C. from June 2011 to September 2011. She was also successful in obtaining student travel awards (ISN/APSN/IBRO school, Shanghai, China, 2008; FAONS Symposium, Melbourne, Australia, 2013) to present her research findings at the international conferences. She received a "President Award for Scientific Publications" from the Government of Sri Lanka in November 2018.

She migrated to Canada with her husband (Abhinash Wijesinghe) in November 2011, however she continued her research activities in Sri Lanka and published her findings in peer reviewed journals. She was selected as a double doctoral candidate through signing of memorandum of understanding between Maastricht University, The Netherland and University of Sri Jayewardenepura, Sri Lanka by Prof. Dr. Harry W.M. Steinbusch and Prof. Dr. Ranil de Silva in 2015. Currently, she lives in Vancouver, British Columbia with her family. Since March 2017, she has been working as a research assistant in the Division of Otolaryngology, Department of Surgery, Faculty of Medicine, The University of British Columbia. She is described as a well-trained experimenter, who finds problems that can be tackled with the resources that are available and who makes sure that the problems are original and well worth while doing. 


\subsection{Supplementary file I: Consent Form}

CONSENT FORM

TO COLLECT POSTMORTEM BRAIN SPECIMENS AND CADAVER BLOOD.

Department of Anatomy, Faculty of Medical Sciences, University of Sri

Jayewardenepura

I.

of

give informed consent to collect a small specimens of brain and clotted blood of my

(includes relationship with full name) for the purpose of establishing diagnosis and for the research purposes. I authorize the Department of Anatomy/Human Brain Bank to collect and store the material to the extent permitted and utilize for the above-mentioned purposes. I have read fully, understood and has been explained the procedure in the language I best understand. I have been assured that strict confidentiality will be maintained about the deceased and the specimens retrieved and their findings.

Name of consenting person:

Brain Bank No:

NIC No:

Address:

\section{Witnesses:}

Signature:

Signature:

Date:

Date:

Note: Kindly fill the blanks and strike off the inappropriate segments of the consent form. 


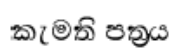

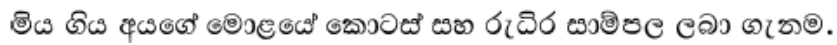

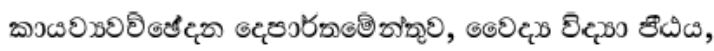

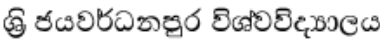

.3) उदृ. है

On (อ) అ๐s

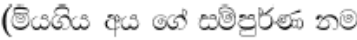

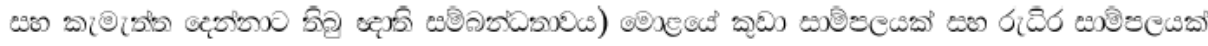

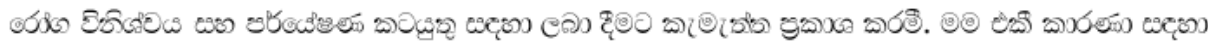

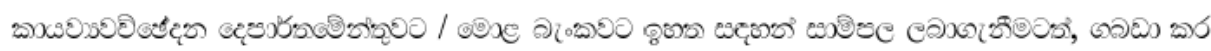

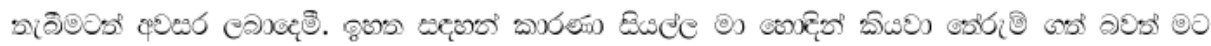

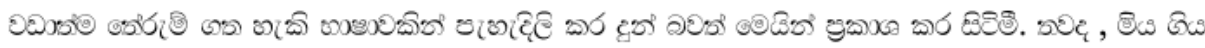

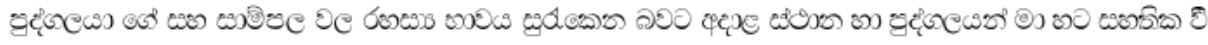
\%(5).

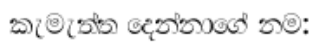

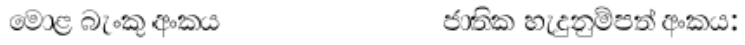

อรికx:

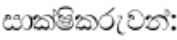

costers:

costers:

दุऽn:

टेकि:

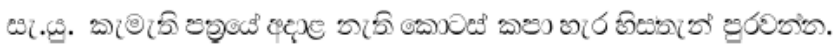




\subsection{Supplementary file II: Antemortem Questionnaire}

\section{Antemortem Questionnaire}

\section{Case Number:}

\section{(Confidential Information)}

Administration of Antemortem Questionnaire through informants who are familiar with intellectual and functional status of the subjects before death.

1) Name

2) Age:

3) Sex:

4) Race:

5) Address:

6) Cause of death and the effect of agonal factors at the time of death:

a) Protracted illness: if yes, put underline to suitable one
1. Multi organ failure
2. Gradual failure of primary organs
3. Coma
4. Respiratory arrest
5. Hypoxia/Ischemia
6. Others (specify)

b) Sudden death: if yes, put underline to suitable one
1. Cardiac arrest
2. Asphyxia
3. Accident
4. Suicide
5. Others (specify)

7) Date and time of death:

8)Postmortem interval:

9) Time difference between postmortem and tissue removal:

10) Details of hospital admission before death:

Ward no:

Date of admission:

11) Hospitalization: Please provide details of any history of being admitted to hospital. Include hospital name, date/year of admission and reason for admission: 
12) History of unconscious experiences: if yes please give the cause and duration:

13) Medication: List the medications including dosage and frequency e.g. daily, twice daily, etc.:.

14) General Medical History: If yes, please give the year first diagnosed.

Diabetes

$\bigcirc Y$

$N \bigcirc$

Ischemic Disease

$\bigcirc$

$N$

High Blood Pressure

$\bigcirc Y$

$N \bigcirc$

High Cholesterol

$\bigcirc Y$

$N \bigcirc$

Movement disorders

$\bigcirc Y$

$N \bigcirc$

Stroke

OY

$N \bigcirc$

Alzheimer's disease

$O Y$

$N \bigcirc$

Parkinson disease

$\bigcirc Y$

$N \bigcirc$

Other dementias

$\bigcirc Y$

$N \bigcirc$

Epilepsy

$\bigcirc Y$

$N \bigcirc$

Any other conditions

$\bigcirc Y$

$N \bigcirc$

15) Lab Investigations: if yes, please give year and details of the test 


\section{6) Activities of daily living:}

i. Able to function independently

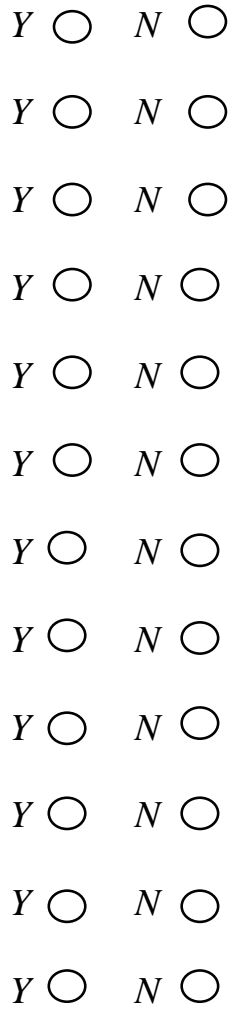

xii. Incontinent of urine or faces

\section{7) Attended to neurologic/psychiatric clinic:}

Y

$N$

If yes, give details:

\section{A month before death, did he/she expressed followings;}

a) Delusions: Did he/she have beliefs that you knew were not true? For example, insisting that people were trying to harm him/her or steal from him/her? Did he/she say that family members were not who they said they were or that the house was not their home?
Not available
No
Yes

b) Hallucinations: Did he/she have hallucinations such as false visions or voices? Did he/she seem to see, hear or experience things that were not present?
Not available
No
Yes 
c) Agitation/Aggression: Did he/she have periods when he/she refused to cooperate or wouldn't let people help him/her? Was he/she hard to handle?
Not available
No
Yes

d) Depression/Dysphoria: Did he/she seem sad or depressed? Did he/she say that he/she felt sad or depressed?
Not available
No
Yes

e) Anxiety: Was he/she very nervous, worried, or frightened for no apparent reason? Did he/she seem very tense or fidgety? Was he/she afraid to be apart from you?
Not available
No
Yes

f) Elation/Euphoria: Did he/she seem too cheerful or too happy for no reason? I don't mean the normal happiness that comes from seeing friends, receiving presents, or spending time with family members. I am asking if he/she had a persistent and abnormally good mood or found humour where others did not.
Not available
No
Yes

g) Apathy/Indifference: Did he/she loose interest in the world around him/her? Had he/she lost interest in doing things or lacked motivation for starting new activities? Was he/she more difficult to engage in conversation or in doing cores? Was he/she apathetic or indifferent?
Not available
No
Yes

h) Disinhibition: Did he/she seem to act impulsively without thinking? Does he/she do or say things that are not usually done or said in public. Did he/she do things that are embarrassing to you or others?
Not available
No
Yes

i) Irritability/Lability: Did he/she get irritated or easily disturbed? Were his/her moods very changeable? Was he/she abnormally impatient?
Not available
No
Yes

j) Aberrant Motor Behaviour: Did he/she pace, do things over and over such as opening closets or drawers, or repeatedly pick at things or wind string or threads? 

Not available
No
Yes

k) Nighttime Behaviour: Did he/she have difficulty sleeping? Was he/she up at night? Did he/she wander at night, get dressed, or disturb your sleep?
Not available
No
Yes

k) Appetite / Eating change: Did he/she have any changes in appetite, weight, or eating habits? Was there any change in type of food he/she preferred? (Count as NA if he/she was incapacitated and had to be fed)
Not available
No
Yes

18) Education:

i) Duration of Education: (Put "X") $\quad \leq 12 \mathrm{yrs} \square \quad \geq 12 \mathrm{yrs}$

ii) Includes,

Primary education

Secondary education

Trade or technical training

University degree/ diploma

Other $\square$ specify

19) Details of the occupation:

20) Frequency of recent consumption of 5 beverages: (Put " $X$ ") 


\begin{tabular}{|c|c|c|c|c|c|c|c|c|c|}
\hline Beverages & $\begin{array}{l}\text { Specify } \\
\text { the brand }\end{array}$ & Never & $\begin{array}{l}<1 \\
\text { cup/wk }\end{array}$ & $\begin{array}{l}1 \\
\text { cup/wk }\end{array}$ & $\begin{array}{l}2-3 \\
\text { cups/wk }\end{array}$ & $\begin{array}{l}4-6 \\
\text { cups/wk }\end{array}$ & $\begin{array}{l}1 \\
\text { cup/d }\end{array}$ & $\begin{array}{l}2-3 \\
\text { cups/d }\end{array}$ & $\begin{array}{l}\geq 4 \\
\text { cups/d }\end{array}$ \\
\hline $\begin{array}{l}\text { Tea with } \\
\text { milk }\end{array}$ & & & & & & & & & \\
\hline $\begin{array}{l}\text { Tea without } \\
\text { milk }\end{array}$ & & & & & & & & & \\
\hline Coffee & & & & & & & & & \\
\hline Cola/Juice & & & & & & & & & \\
\hline $\begin{array}{l}100 \% \text { fresh } \\
\text { vegetable } \\
\text { juice }\end{array}$ & & & & & & & & & \\
\hline $\begin{array}{l}\text { Any other } \\
\text { non } \\
\text { alcoholic } \\
\text { beverages }\end{array}$ & & & & & & & & & \\
\hline
\end{tabular}

(1cup=100ml)

21) Green/yellow vegetable consumption: (Put " $X ")$ 22) Fish consumption: (Put " $X ")$

\begin{tabular}{|l|l|}
\hline$<1$ time/ week & \\
\hline $1-6$ times/week & \\
\hline$\geq 1$ time/day & \\
\hline
\end{tabular}

\begin{tabular}{|l|l|}
\hline$<1$ time/ week & \\
\hline $1-6$ times/week & \\
\hline$\geq 1$ time/day & \\
\hline
\end{tabular}

23) Intake of non dietary antioxidants: (Vitamin E, Vitamin C, etc)
Y $\bigcirc$
$N O$ 
24) Smoking: Quantity of cigarettes/tobacco per day....

Number of years smoking:

Most of adult life

$\bigcirc Y \bigcirc N$

For less than 1 year

$\bigcirc Y \bigcirc N$

For less than 5 years

$\bigcirc Y \bigcirc N$

For less than 10 years

$\bigcirc Y \bigcirc N$

For less than 20 years

$\bigcirc Y \bigcirc N$

Which brand usually?

If he was addicted to smoking/ chain smoker, please fill attached Form I (a).

\section{5) Alcohol intake:}

Amount in glasses: glasses per day glasses per week

\section{Number of years drinking:}

Most of adult life

$\bigcirc Y \bigcirc N$

For less than 1 year $\bigcirc Y \quad \bigcirc_{N} \quad$ For less than 5 years

$\bigcirc Y \bigcirc N$

Which brand usually?

If he was an alcoholic, please fill attached Form I (b).

26) Family History: Any family history of neurological/ psychiatric disorders? If yes please fill the attached Form II

27) Further information (if available):

Person contributing the questionnaire:

Name:

Relationship to donor:

Contact details: Telephone number.

Mob:

Address: 


\section{Form I: Health Habits History:}

\section{Form I (a): Smoking}

1. Had he smoked more than 100 cigarettes or 5 packs of cigarettes in his life?

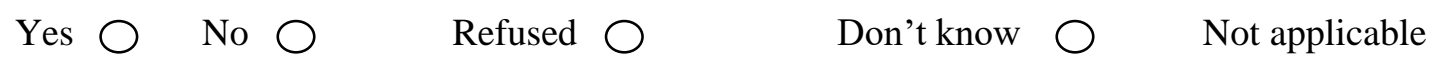

2. What was the average number of cigarettes per day he smoked one month before the death?

Cigarettes per day:

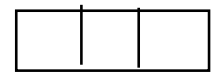

Cigarettes per week:

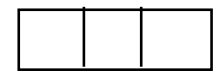

Not applicable $\bigcirc \quad$ Refused $\bigcirc \quad$ Don't know $\bigcirc$

3. If he had stopped smoking completely, how old was he when he stopped?
Age
Refused
Don't know
Not applicable

4. How old was he when he first started to smoke cigarettes?
Age $\square$
Refused
Don't know $\bigcirc$

5. Did he smoke continuously or did he stop and start?

Continuously $\bigcirc$ stop \& start $\bigcirc$ Refused $\bigcirc$ Don't know $\bigcirc \quad$ Not applicable

6. About how many years did he actually smoke?
Years
Refused
Don't know
Not applicable

\section{Form I (b): Alcohol Consumption}

1. Before his death, did he have any kind of alcoholic beverage?
Yes $\bigcirc$ No
Refused
Don't know
Not applicable

2. Did he drink alcoholic beverages at one time and then quit?
Yes
No $\bigcirc$
Refused
Don't know
Not applicable

3. How old was he when he quit drinking alcoholic beverages?
Yes
No
Refused
Don't know
Not applicable

4. What was the reason that he quit drinking at that time?

5. Please give the details of alcohol consumption (if you know) 


\begin{tabular}{|c|c|c|c|c|c|}
\hline Type & Beer & Arrack & Toddy & Casippu & Others \\
\hline $\begin{array}{l}\text { How often } \\
\text { (day/week/month/year) }\end{array}$ & & & & & \\
\hline $\begin{array}{l}\text { How much } \\
\text { (glasses/bottles/cans/coconut } \\
\text { shells) }\end{array}$ & & & & & \\
\hline
\end{tabular}

\section{Form II: FAMILY HISTORY}

Does any of his/her family members have any of the following diseases? Are they from the mothers or fathers side?

\section{Disease}

\section{Present Absent Mothers side Fathers side}

Diabetes

Ischemic Disease

High Blood Pressure

$\bigcirc \quad \bigcirc$

$\bigcirc$

$\bigcirc \bigcirc$

$\bigcirc$

High Cholesterol

$\bigcirc$

$\bigcirc$

O

$\bigcirc$

Movement disorders

Stroke

$\bigcirc$

$\bigcirc$

$\bigcirc$

$\bigcirc$

O

$\bigcirc$

$\bigcirc$

$\bigcirc$

Alzheimer's and other dementias

$\bigcirc$

Epilepsy

$\bigcirc$

O

$\bigcirc$

$\bigcirc$

Psychiatric disorders

0

O

$\bigcirc$

$\bigcirc$

$\bigcirc$<smiles>[CH-]C=C</smiles>

○

$\bigcirc$

Any other conditions 
For his/her blood relatives, what is the present age of his/her mother, father, brother or sister? If they have died, what was their age at death? FOR HALF SIBLINGS, ASK IF THEY ARE ON

MOTHER'S OR FATHER'S SIDE. Of his/her blood relatives, did his/her mother, father, brother, or sister have a neurological disorder? Do you know what type of disease he/she had? Of his/her blood relatives, did his/her mother, father, brother, or sister have any psychiatric problems?

\section{ENTER CODES IN THE FIRST COLUMN OF THE FOLLOWING TABLE USING THE} FOLLOWING KEY.

Sibling Codes

disorders

$1=$ Both Parents

$2=$ Mother's Side

$3=$ Father's Side

4 = Adopted

$7=$ Not Applicable

$8=$ Refused

9= Unknown
Neurological disorder

$0=$ No diseases

$1=$ Alzheimer's disease

$2=$ Vascular diseases

3= Parkinson's disease

4=Other dementia

$5=$ Stroke

6=Movement disorders

7=Not applicable

$8=$ Refused

9=Unknown $\underline{\text { Psychiatric }}$

$0=\mathrm{No}$

$1=$ Yes

7 =Not applicable

$8=$ Refused

9= Unknown 


\begin{tabular}{|c|c|c|c|c|c|c|c|}
\hline Relation & $\begin{array}{l}\text { Sibling } \\
\text { code }\end{array}$ & $\begin{array}{l}\text { Vital } \\
\text { status } \\
\text { 0= Dead } \\
\text { 1= Alive } \\
\text { 9=Unknow }\end{array}$ & $\begin{array}{l}\text { Present } \\
\text { age/ } \\
\text { Age at } \\
\text { death }\end{array}$ & $\begin{array}{l}\text { Neurolog } \\
\text { ical } \\
\text { disease } \\
\text { code }\end{array}$ & $\begin{array}{l}\text { Age at } \\
\text { disease } \\
\text { (earliest) }\end{array}$ & $\begin{array}{l}\text { Psych } \\
\text { iatric } \\
\text { disor } \\
\text { der- } \\
\text { code }\end{array}$ & $\begin{array}{l}\text { Age at } \\
\text { Psychiatri } \\
\text { c disorder } \\
\text { (earliest) }\end{array}$ \\
\hline MOTHER & & & & & & & \\
\hline FATHER & & & & & & & \\
\hline BROTHER & & & & & & & \\
\hline BROTHER & & & & & & & \\
\hline BROTHER & & & & & & & \\
\hline BROTHER & & & & & & & \\
\hline BROTHER & & & & & & & \\
\hline BROTHER & & & & & & & \\
\hline BROTHER & & & & & & & \\
\hline SISTER 1 & & & & & & & \\
\hline SISTER 2 & & & & & & & \\
\hline SISTER 3 & & & & & & & \\
\hline SISTER 4 & & & & & & & \\
\hline SISTER 5 & & & & & & & \\
\hline SISTER 6 & & & & & & & \\
\hline SISTER 7 & & & & & & & \\
\hline
\end{tabular}




\subsection{Supplementary file III: Working Sheet}

7.7.1 Working sheet for semi quantitative grading and counting on hippocampus and parahippocampus

\begin{tabular}{|c|c|c|c|c|c|c|c|c|c|c|c|c|}
\hline \multicolumn{2}{|c|}{ Left Hemisphere } & \multirow[t]{2}{*}{$D G$} & \multirow[t]{2}{*}{$\mathrm{CA4}$} & \multirow[t]{2}{*}{$C A 3$} & \multirow[t]{2}{*}{$C A 2$} & \multirow[t]{2}{*}{ CA1 } & \multirow{2}{*}{$\begin{array}{l}\text { CA1 } \\
/ S u b\end{array}$} & \multirow[t]{2}{*}{$S u b$} & \multicolumn{2}{|c|}{ Ento. cortex } & $\begin{array}{l}\text { Trans } \\
\text { ento } \\
\text { cortex }\end{array}$ & \multirow{2}{*}{$\begin{array}{l}\text { White } \\
\text { matter }\end{array}$} \\
\hline \multirow{5}{*}{$\begin{array}{l}\text { Tau } \\
\text { IHC }\end{array}$} & NFTs - Grade & & & & & & & & & & & \\
\hline & $\begin{array}{l}\text { NFTs - } \\
\text { Density } \\
(\text { Avg/20X) }\end{array}$ & & & & & & & & & & & \\
\hline & NPs-Grade & & & & & & & & & & & \\
\hline & $\begin{array}{l}\text { NPs }- \text { Density } \\
(\operatorname{Avg} / 20 \mathrm{X})\end{array}$ & & & & & & & & & & & \\
\hline & NTs - Density & & & & & & & & & & & \\
\hline \multirow{4}{*}{$\begin{array}{l}\text { Beta } \\
\text { amyloid } \\
\text { IHC }\end{array}$} & SPs - Grade & & & & & & & & & & & \\
\hline & $\begin{array}{l}\text { SPs - Density } \\
(\text { Avg/20X) }\end{array}$ & & & & & & & & & & & \\
\hline & DPs - Grade & & & & & & & & & & & \\
\hline & CAA Grade & & & & & & & & & & & \\
\hline \multirow{2}{*}{\multicolumn{2}{|c|}{ Right Hemisphere }} & \multirow[t]{2}{*}{$D G$} & \multirow[t]{2}{*}{$C A 4$} & \multirow[t]{2}{*}{ CA3 } & \multirow[t]{2}{*}{$C A 2$} & \multirow[t]{2}{*}{ CA1 } & \multirow{2}{*}{$\begin{array}{l}\text { CA1 } \\
/ S u b\end{array}$} & \multirow[t]{2}{*}{ Sub } & \multicolumn{2}{|c|}{ Ento. cortex } & Trans & White \\
\hline & & & & & & & & & $M E C$ & $L E C$ & $\begin{array}{l}\text { ento } \\
\text { cortex }\end{array}$ & matter \\
\hline
\end{tabular}




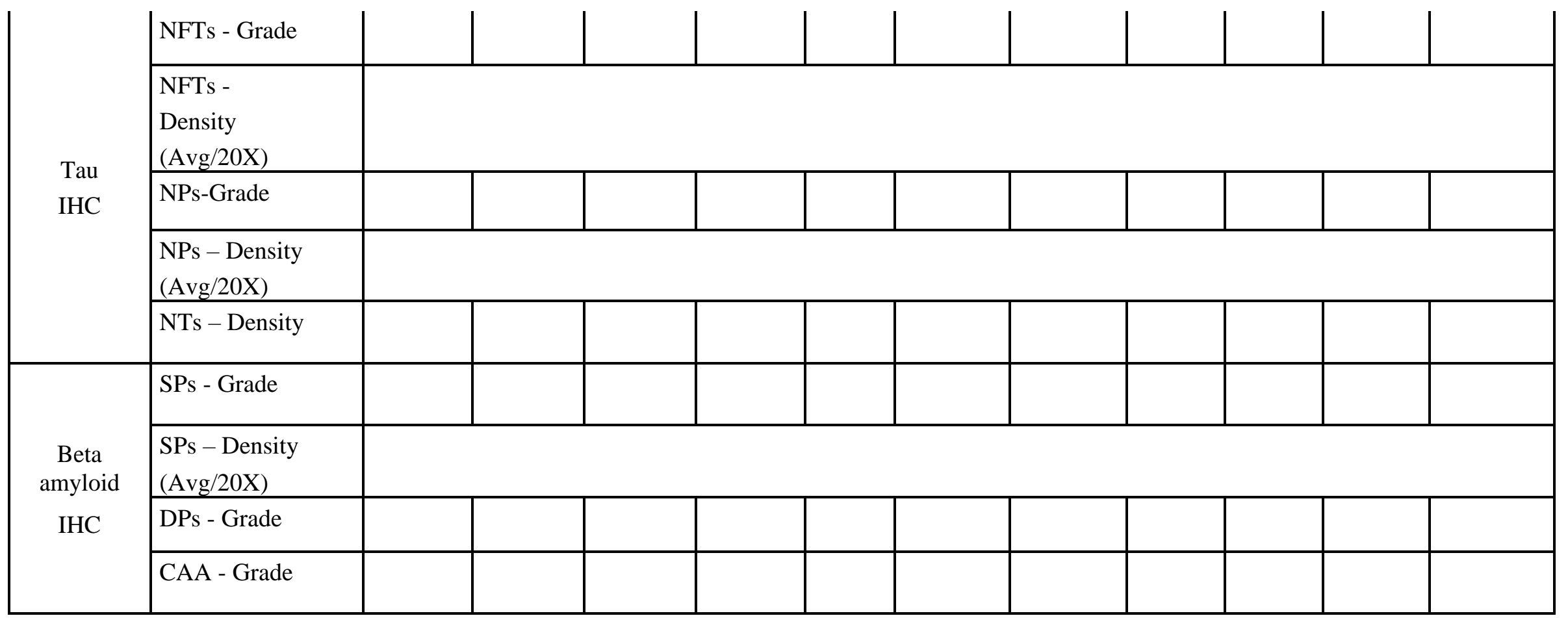

IHC, immunohistochemistry; Avg, average; 20X, objective lens; NFTs, neurofibrillary tangles; NPs, neuriticplaques; NTs, neuropil threads; SPs, senile plaques; DPs, diffuse plaques; CAA, cerebral amyloid angiopathy, DG, dentate gyrus; CA, Cornu Ammonis area 1 to 4; Sub, subiculum; MEC, medial entorhinal cortex; LEC, lateral entorhinal cortex 
7.7.2 Working sheet for semi quantitative grading and counting on superior frontal gyrus

\begin{tabular}{|c|c|c|c|c|c|}
\hline & & \multicolumn{2}{|c|}{ Left Hemisphere } & \multicolumn{2}{|c|}{ Right Hemisphere } \\
\hline & & Cortex & White matter & Cortex & White matter \\
\hline \multirow{5}{*}{$\begin{array}{l}\text { Tau } \\
\text { IHC }\end{array}$} & NFTs -Grade & & & & \\
\hline & $\begin{array}{l}\text { NFTs-Density } \\
(\text { Avg /20X) }\end{array}$ & & & & \\
\hline & NPs- Grade & & & & \\
\hline & $\begin{array}{l}\text { NPs - Density } \\
(\operatorname{Avg} / 20 \mathrm{X})\end{array}$ & & & & \\
\hline & NTs- Grade & & & & \\
\hline \multirow{4}{*}{$\begin{array}{c}\text { Beta amyloid } \\
\text { IHC }\end{array}$} & SPs- Grade & & & & \\
\hline & $\begin{array}{l}\text { SPs- Density } \\
(\text { Avg/20X) }\end{array}$ & & & & \\
\hline & DPs - Grade & & & & \\
\hline & CAA grade & & & & \\
\hline
\end{tabular}

IHC, immunohistochemistry; Avg, average; 20X, objective lens; NFTs, neurofibrillary tangles; NPs, neuritic plaques; NTs, neuropil threads; SPs, senile plaques; DPs, diffuse plaques; CAA, cerebral amyloid angiopathy 
7.7.3 Working sheet for semi quantitative grading and counting on midbrain

\begin{tabular}{|c|c|c|c|c|c|c|c|c|c|c|c|}
\hline & & & & & Mid & in at the & el of supe & colliculus & & & \\
\hline & & $S N$ & $R N$ & $\begin{array}{l}\text { Raphe } \\
\text { nucleus }\end{array}$ & $\begin{array}{l}\text { Dorsal } \\
\text { raphe } \\
\text { nucleus }\end{array}$ & $\begin{array}{l}\text { III } \\
\text { nerve } \\
\text { nucleus }\end{array}$ & $\begin{array}{l}\text { Dorsal } \\
\text { tegmental } \\
\text { nucleus }\end{array}$ & $\begin{array}{l}\text { Peri } \\
\text { aquaductal } \\
\text { gray }\end{array}$ & $\begin{array}{l}\text { V nerve } \\
\text { nucleus }\end{array}$ & $\begin{array}{l}\text { Interpendu } \\
\text { cular } \\
\text { nucleus }\end{array}$ & $\begin{array}{l}\text { Superior } \\
\text { colliculi } \\
\text { region }\end{array}$ \\
\hline & $\begin{array}{l}\text { NFTs - } \\
\text { Grade }\end{array}$ & & & & & & & & & & \\
\hline Tau & $\begin{array}{l}\text { NFTs- } \\
\text { Density } \\
\text { (Avg /20x) }\end{array}$ & & & & & & & & & & \\
\hline IHC & $\begin{array}{l}\text { NPs- } \\
\text { Grade }\end{array}$ & & & & & & & & & & \\
\hline & $\begin{array}{l}\text { NPs - } \\
\text { Density } \\
\text { (Avg/20x) }\end{array}$ & & & & & & & & & & \\
\hline & $\begin{array}{l}\text { NTs- } \\
\text { Grade }\end{array}$ & & & & & & & & & & \\
\hline & $\begin{array}{l}\text { SPs- } \\
\text { Grade }\end{array}$ & & & & & & & & & & \\
\hline $\begin{array}{c}\text { Beta } \\
\text { amyloid } \\
\text { IHC }\end{array}$ & $\begin{array}{l}\text { SPs- } \\
\text { Density } \\
(\text { Avg/20x) }\end{array}$ & & & & & & & & & & \\
\hline & $\begin{array}{l}\text { DPs - } \\
\text { Grade }\end{array}$ & & & & & & & & & & \\
\hline & $\begin{array}{l}\text { CAA } \\
\text { grade }\end{array}$ & & & & & & & & & & \\
\hline
\end{tabular}

IHC, immunohistochemistry; Avg, average; 20X, objective lens; NFTs, neurofibrillary tangles; NPs, neuritic plaques; NTs, neuropil threads; SPs, senile plaques; DPs, diffuse plaques; CAA, cerebral amyloid angiopathy; SN, substantia nigra; RN, red nucleus 
7.8 Supplementary file IV: Observation Sheet

Observation Sheet

Case/Autopsy No:.

Age \& Sex:

Diagnosis: .
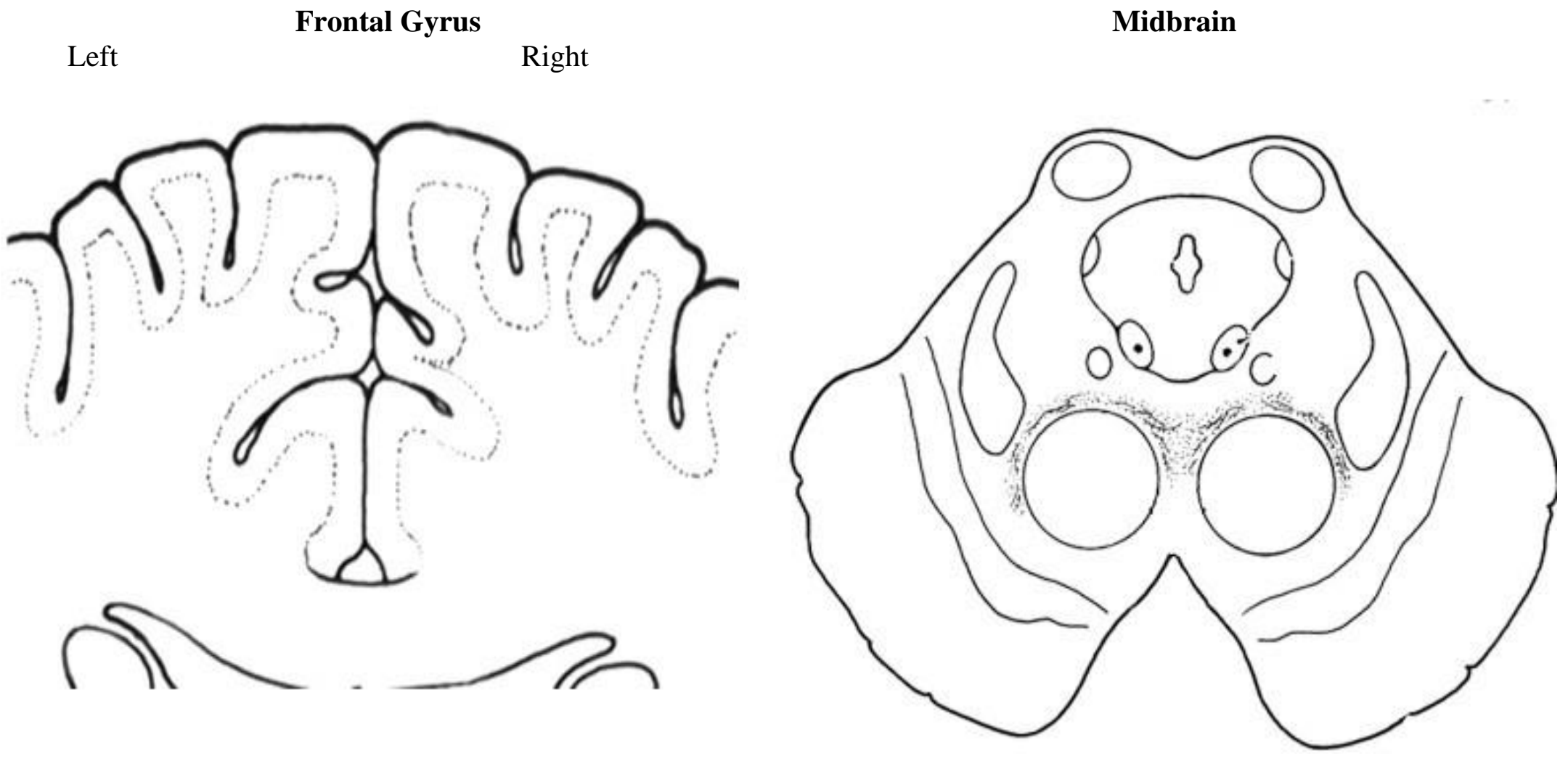


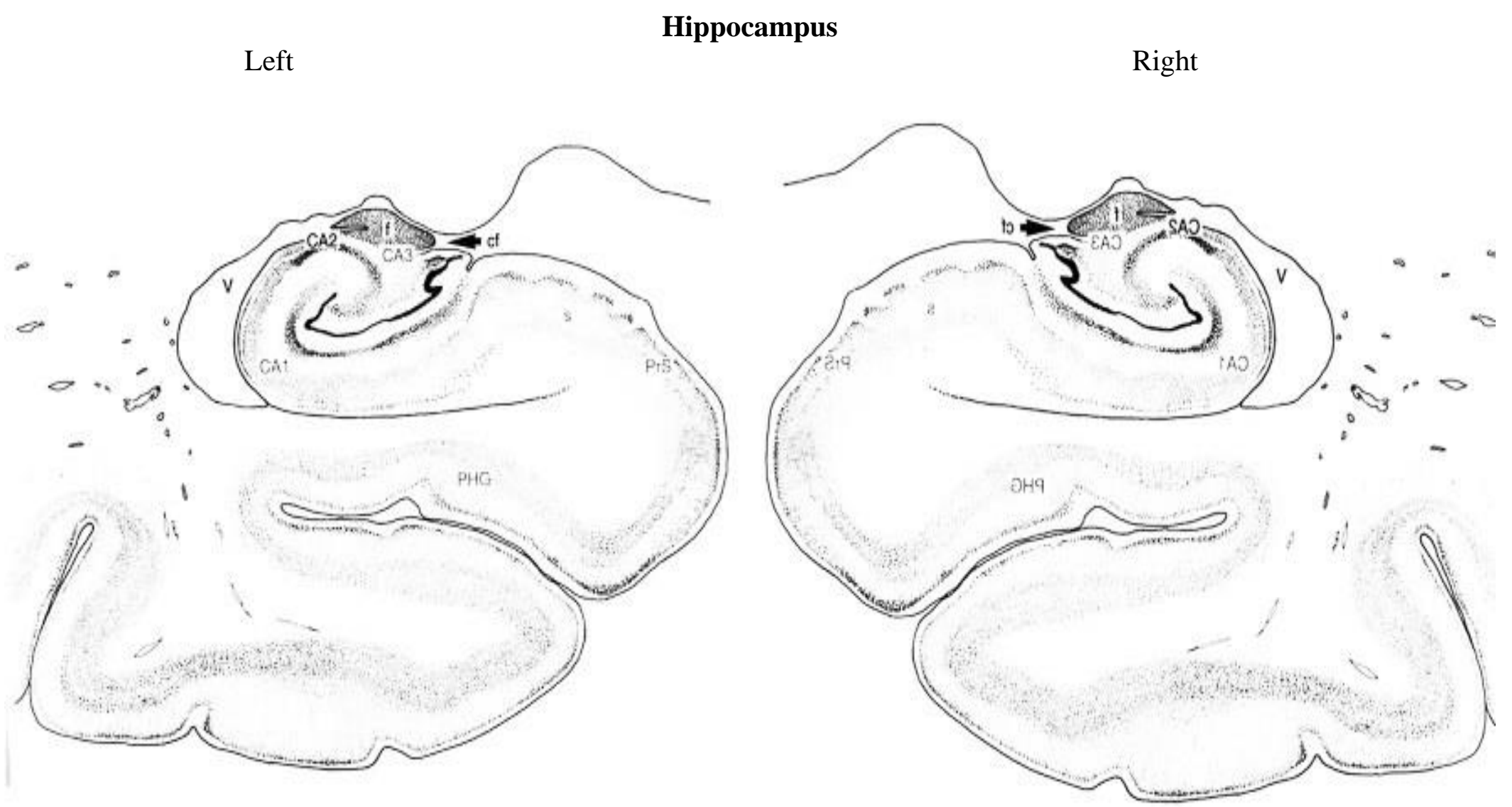

Tau pathologies include neuritic plaques, neurofibrillary tangles and neuropil threads

Beta amyloid pathologies include dystrophic neurites, amyloid core plaques, diffuse plaques and cerebral amyloid angiopathy 